\title{
Losing Hurts: The Happiness
}

Impact of Partisan Electoral

\section{Loss}

\section{Faculty Research Working Paper Series}

\section{Lamar Pierce}

Washington University, St. Louis

\section{Todd Rogers}

Harvard Kennedy School

\section{Jason A. Snyder}

University of California Los Angeles

\section{March 2015 (Revised from October 2014) RWP14-051}

Visit the HKS Faculty Research Working Paper Series at:

https://research.hks.harvard.edu/publications/workingpapers/Index.aspx

The views expressed in the HKS Faculty Research Working Paper Series are those of the author(s) and do not necessarily reflect those of the John F. Kennedy School of Government or of Harvard University. Faculty Research Working Papers have not undergone formal review and approval. Such papers are included in this series to elicit feedback and to encourage debate on important public policy challenges. Copyright belongs to the author(s). Papers may be downloaded for personal use only. 


\title{
Losing Hurts: \\ The Happiness Impact of Partisan Electoral Loss
}

\author{
Lamar Pierce ${ }^{1}$, Todd Rogers ${ }^{2}$, and Jason A. Snyder ${ }^{3 *}$
}

Forthcoming in Journal of Experimental Political Science

\begin{abstract}
Words: 149):
Partisan identity shapes social, mental, economic, and physical life. Using a novel dataset, we study the consequences of partisan identity by examining the immediate impact of electoral loss and victory on happiness and sadness. Employing a quasi-experimental regression discontinuity model we present two primary findings. First, elections strongly affect the immediate happiness/sadness of partisan losers, but minimally impact partisan winners. This effect is consistent with psychological research on the good-bad hedonic asymmetry, but appears to dissipate within a week after the election. Second, the immediate happiness consequences to partisan losers are relatively strong. To illustrate, we show that partisans are affected two times more by their party losing the 2012 U.S. Presidential Election than both respondents with children were to the Newtown shootings and respondents living in Boston were to the Boston Marathon bombings. We discuss implications regarding the centrality of partisan identity to the self and its well-being.
\end{abstract}

Word count: 3,196

Keywords: Partisanship, Political Psychology, Happiness, Elections, Identity, Well-Being, Obama

The authors thank John Dick, Ross McGowan, and Zack Sharek at CivicScience, Inc. for providing the data, as well as Craig Fox, Francesca Gino, Eitan Hersh, Karim Kassam, Marc Meredith, Brendan Nyhan, Mike Norton, Erik Snowberg, and Kathleen Vohs for thoughtful comments and suggestions. Carly Robinson provided excellent research assistance.

${ }^{1}$ Washington University in St. Louis, Olin Business School, One Brookings Drive Box 1133, St. Louis MO 63130.

2 Harvard Kennedy School, Mailbox 124, 79 JFK Street, Cambridge MA 02138.

3 UCLA, Anderson School of Management, 110 Westwood Plaza, Cornell Hall, Suite D506, Los Angeles CA 90095.

-Authors contributed equally and listed alphabetically. Direct correspondence to pierce@wustl.edu. 
How important is partisan identity to happiness? It might be of considerable importance to the two-thirds of Americans who identify with a political party, given its powerful influence on other dimensions of people's lives. Partisan identity is stable across people’s lifetimes (Campbell et al, 1960; Green, Palmquist and Schickler, 2002), causally shaping political preferences and the factual qualities people associate with policies (Cohen, 2003). People more frequently live near (Glaeser and Ward, 2006; Gimpel and Schuknecht, 2004) and interact with (Grentzkow and Shapiro, 2001) those who share their partisan identity than with those who do not. Furthermore, partisan identity tends to define media consumption (Prior, 2007) and other economic behavior (Gerber and Huber, 2009), and can bias social perceptions and favoritism (Caruso, Mead and Belcetis, 2009; Rand et al, 2009). In short, social, mental, economic, and physical life is shaped by partisan identity.

Given this importance, political outcomes such as the 2012 U.S Presidential Election could profoundly impact the happiness of both partisan winners (Democrats) and partisan losers (Republicans). This research uses a novel dataset that tracks fluctuations in happiness and sadness to address two questions about the importance of partisan identity to well-being. First, are the shocks to happiness from winning and losing equivalent? Diverse research suggests they might not be. Bad events cause stronger reactions than comparable good ones (Baumeister et al, 2001; Rozin and Royzman, 2001), similar to predictions from prospect theory's value function about the gain-loss asymmetry (Kahneman and Tversky, 1979; McDermott, 2004).

Second, how strong is the shock of partisan loss to happiness? We compare the wellbeing consequences of partisan loss to that of two national tragedies that dominated the national news media for weeks. On December 14, 2012, twenty children and six adults were fatally shot at Sandy Hook Elementary School in Newtown, Connecticut ("Newtown 
shootings"). On April 15, 2013, three people were killed and 283 injured after terrorists attacked the Boston Marathon ("marathon bombings"). While such tragedies are qualitatively different than elections, comparing their well-being consequences to that of partisan loss illustrates simply the relative importance of partisan identity to well-being. Tragedies have both political repercussions (Gillis, 1996) and elicit emotional, financial, and civic responses from people not directly affected by the trauma (Preston and De Waal, 2002; Singer et al, 2004). Consequently, one might sensibly expect the hedonic (happiness-based) impact of partisan loss to pale in comparison.

Using daily responses from CivicScience, Inc., an online polling and data intelligence company, we employ a quasi-experimental regression discontinuity (RD) design to estimate the happiness shock of specific events. The RD design overcomes many of the sampling bias problems in survey-based studies of happiness by focusing on nearly identical respondents immediately before and after an independent shock (Shadish, Cook and Campbell, 2002; Imbens and Lemieux, 2008).

We find that the pain of losing an election is much larger than the joy of winning one, but that this happiness loss is short-lived. Election outcomes strongly affect the shortterm happiness/sadness of partisan losers, with minimal impact on partisan winners. This result is consistent with studies finding that "bad emotions, bad parents, and bad feedback have more impact than good ones...bad information is processed more thoroughly than good... [and] the self is more motivated to avoid bad self-definitions than to pursue good ones" (Baumeister et al, 2001). Despite the strength of the loss, happiness appears to recover within a week, consistent with research on people's tendency to adapt to bad events more quickly than expected (Gilbert et al, 2004). This temporariness suggests partisan loss impairs emotional well-being rather than broader life satisfaction (Kahneman and Deaton, 2010). 
The short-term strength of partisan loss is contrasted with responses to mass national tragedies; partisans are affected twice as much by their candidate losing the U.S. Presidential Election than both respondents with children were to the Newtown shootings and respondents in Boston were to the marathon bombings. The fact that the pain experienced by partisan losers is stronger than that of people for whom the tragedies were self-relevant benchmarks the centrality of partisan identity to the self and well-being.

\section{Method}

Data. CivicScience polls over 300,000 unique individuals daily across the United States on over 500 third-party websites. Unpaid volunteers answer three questions in embedded polls. Tracking technology allows the company to identify returning respondents across all partner websites, thereby collecting a panel of detailed demographic and attitudinal data for many respondents. One question that is randomly and continuously distributed across all partner websites each day asks "How happy are you today -- very happy, happy, so so, unhappy, or very unbappy?" This question is similar to one used in the Euro-Barometer Survey Series and the United States General Social Survey_-widely used to study happiness in economics (Easterlin, 2003; Argyle, 2003; Di Tella, MacCulloch, and Oswald, 2003; Alesina, Di Tella and MacColloch, 2004; Easterlin, 2006). Consistent with the prior literature we create an indicator variable "happy" equal to 1 if respondents reported being happy or very happy. ${ }^{4}$

CivicScience also collects extensive socio-demographic information (e.g., gender, income, race, age, and partisan identity) in a pre-determined sequence from return respondents over multiple visits to partner websites. We had access to data on all

\footnotetext{
${ }^{4}$ This dichotomized variable is easier to interpret and more meaningful than a 1-5 scale assuming each unit change is equal. Tables S7A and S7B in the supplementary materials present similar results with the scaled dependent variable.
} 
respondents who had answered the happiness and sadness questions, but not all of these respondents answered all socio-demographic, party affiliation, and parental status questions. For example, for the week before and after the election approximately $67 \%$ of respondents with happiness responses and full socio-demographic data had answered the partisan identity question; eighty five percent of such respondents from the week before and after Newtown had answered the parental status question. Missing responses for each of question yields a sparse data matrix, which makes imputing missing data very unreliable. We therefore restrict the data for each analysis to the respondents for whom there are no missing observations.

CivicScience asks "Politically, do you consider yourself more of a: Republican, Democrat, or Independent?" Like all surveys, the sample of these individuals is conditioned on the decision to participate in repeated CivicScience polls. CivicScience respondents were somewhat more Republican than the general population. We are unable to observe data on which respondents chose not to answer specific questions. Figure 1 previews our core results. During the two weeks surrounding Election Day, an average of 210 Republicans and 111 Democrats answered an online happiness question each day. Notice the little change in the likelihood that Democrats report being happy, while immediately following the election Republicans' self-reported happiness drops from approximately $60 \%$ to $30 \%$. These data are collected with enough frequency that daily shocks can be clearly identified, a feature unique to most research on happiness. We note, however, that our models' key identifying assumption is that the sample is similar before and after the election. Additionally, given the self-selection and uneven geographic distribution of the sample, one must be careful in extrapolating specific effect magnitudes to the general population. Finally, we note how days are coded. Across all studies we code days as being 24-hour periods immediately preceding and following focal events. For instance, the 2012 presidential election was called by the 
Associated Press at approximately 11PM EST on Election Day, so the previous day began at 11PM EST the day before Election Day.

Model. We use quasi-experimental regression discontinuity models to test how the happiness levels of Democrats and Republicans discretely change immediately following the presidential election. RD models assign observations to treatment and control groups based on a discrete threshold in a continuous assignment variable, which in our case is time (days). The discrete threshold is the focal event (e.g., Election Day or day of the tragedy). Any response after the focal event threshold is considered "treated," while prior days are in the “control." RD models are most commonly used in political science, economics, and psychology (Dal Bo, Dal Bo and Snyder, 2009; Snyder, 2010; Gerber, Kessler, and Meredith, 2011; Pierce, Dahl, and Nielsen, 2013; Hersh, 2014), with many examples applying RD models to time series data, as we do (Busse, Silvo-Risso, and Zettelmeyer, 2006; Pierce and Snyder, 2012).

$\mathrm{RD}$ models assume that observations just above and below the threshold are identical on all dimensions except the focal treatment. Table S1-S3 provides detailed evidence that respondents one week before and after the three events in our data are reasonably identical on observable dimensions. Simple t-tests of differences in pre/post means reveal few systematic demographic differences, nor do regression discontinuity models that replace Happiness with each demographic as the dependent variable in equation (1) below. Our base specification is as follows at the individual-level respondent:

$$
\begin{gathered}
\text { (1) } \text { Happiness }_{i}=\propto+\beta_{1} * \text { PostEvent }_{i}+\beta_{2} * \text { Linear Time Variable }_{i} \\
+\beta_{3} * \text { PostEvent }_{i} *{\text { Linear Time } \text { Variable }_{i}+\varepsilon_{i}}
\end{gathered}
$$

Linear Time Variable runs from -7 to 6, where 0 is the day immediately following the 
focal event. PostEvent is an indicator equal to 1 if the event has already occurred. Figure 2 illustrates this specification for Republican respondents' happiness in relation to the election. $\beta_{1}$ estimates the discrete jump between the two regression estimates. $\beta_{2}$ is the slope prior to the election and $\beta_{3}$ is the slope after the election. This specification therefore estimates the size of the break while controlling for the different time trends before and after the event. Other specifications include socio-demographic characteristics and higher order time polynomials for robustness. All results are clustered at the MSA level.

To test the persistence of the happiness effect, a second model relaxes the RD assumption to examine weekly happiness rates for Republicans and Democrats, conditioning on socio-demographic information and location. Although this model provides some evidence of effect persistence, we cannot observe the counterfactual time trend in weeks distant from Election Day. Any inference about effect length must assume that happiness would return to pre-election levels absent the election's effect.

(2) Happiness $_{i}=\propto+\boldsymbol{\beta}_{1} *$ Week Indicators In $_{i}+\beta_{2} *$ SocioDemographic Controls $+\varepsilon_{i}$

\section{Study 1: 2012 U.S. Presidential Election}

Tables $1 \mathrm{a}$ and $1 \mathrm{~b}$ report the results for happiness around the election depicted in Figures $1 \& 2$, splitting the sample by partisan winners (Democrats) and partisan losers (Republicans). Across specifications there is little robust evidence that Democrats' responses changed immediately after the election. The sign across specifications is positive, but the statistical significance is inconsistent across specifications. In contrast, partisan losers experienced significantly larger hedonic shocks than partisan winners. Table 1B shows a strong negative effect on the baseline level of happiness following the election. The models are robust to including extensive demographic (race, gender, age, income), geographic 
(metropolitan area fixed effects defined by IP address), and time control variables. This robustness across specifications casts doubt on concerns that results are driven by differences in the types of respondents before and after the election, as do the nearly identical respondent characteristics before and after the election presented in Table S1. The negative happiness impact to partisan losers, for example, actually increases from -.151 to .246 after all controls are added. Across each pair of columns from Tables $1 \mathrm{~A}$ and $1 \mathrm{~B}$, the coefficients are statistically different from each other at the 5\% confidence level.

Figures $3 \mathrm{~A}$ and $3 \mathrm{~B}$ depict parameter estimates and confidence intervals associated with equation (2). The weekly differences in happiness are all relative to the baseline $8^{\text {th }}$ week before the election and condition on the socio-demographic characteristics described earlier. Over the 8 weeks before and after the election happiness is relatively constant except for Republicans in the week immediately following the election. This evidence again shows that Republicans' well-being drops after the event, and also suggests that it recovers quickly.

Alternative Explanations. Three possible alternative explanations stand out. First, the asymmetric hedonic response could stem from rational responses to the election's policy implications for Democrats and Republicans (Gerber and Huber, 2009). This seems unlikely, however, since Figures 1 and 2 show happiness levels converging within one week following the election, becoming statistically indistinguishable within four weeks.

Second, the asymmetric hedonic response could reflect different outcome expectations. Overconfidence among partisan losers is common even in blowout elections (Granberg and Brent, 1983), partly because simply supporting a candidate causes people to believe that candidate will win (Krizan, Miller, and Johar, 2010). In this alternative explanation, Republicans would be more affected because they expected a victory and were 
disappointed, while Democrats, also expecting a victory, were unsurprised. Supplementary analysis suggests a similar asymmetric shock for only those respondents expecting their candidate to win, casting doubt on this expectations explanation.

Finally Republicans may simply become less happy after an election, regardless of the outcome. This alternative seems unlikely, but we cannot directly test this hypothesis with this data.

\section{Study 2: Newtown Shootings and Marathon Bombings}

Two major national tragedies that dominated the media for weeks occurred after the election: the Newtown shootings and the Boston Marathon bombings. Many respondents answered the happiness/sadness questions in the weeks surrounding the two tragedies, averaging 445/day for the Newtown shootings and 639/day for the marathon bombings. These data are analyzed using the same strategy as with the election data, defining the postevent treatment dummy by whether each response was before or after the precise time of the event's first news coverage. Of course, learning that one's party lost an election differs in important ways from observing a national tragedy. For example, partisans are personally invested in and occasionally involved in elections, while very few people are personally involved in national tragedies. That said, of the $60 \%$ of Americans who identify with a political party, only about $0.40 \%$ were personally involved in the 2012 election by donating over $\$ 200$ to a candidate, party, or PAC (Opensecrets.org). Nonetheless, comparing the hedonic impact of these two national tragedies to that of losing an election can be insightful because they were the most affectively intense events impacting the mass public during this period. This comparison serves simply to benchmark the hedonic intensity of partisan loss, and cannot account for other psychological impacts such as anxiety or fear. 
Both the Newtown shootings and marathon bombings caused significant negative hedonic shocks, but they are much smaller than those suffered by partisan losers in the election. Table 2 presents the RD estimates for respondent happiness in relation to the Newtown shootings. Across columns (1) - (5) the results are not consistently statistically significant. The fully-controlled model in column 2 estimates a 7.6\% happiness decrease immediately following the Newtown shootings_only one fifth the size of the decrease experienced by partisan losers. Likewise Table 3, column 4, shows that happiness decreases following the marathon bombings by only $4.8 \%$. The statistical significance varies across multiple reasonable specifications.

Election outcomes are relevant to partisans' identities. As such, it may not mean much to compare the hedonic impact of partisan loss to that of national tragedies to a broad swath of respondents. We therefore assess the hedonic impact of tragedies on those for whom the tragedies are identity-relevant: the Newtown shootings on self-reported parents and the marathon bombings on respondents using Boston-based IP addresses. The RD models are reported in columns (7) \& (8) of Tables $2 \& 3$. As one would predict, these subsamples show larger impacts than the more general sample. However, the effects are still only half those on partisan losers from the election $(\mathrm{ps}<.01)$. The differences between the coefficient on Post-Newtown in columns (7) \& (8) of Table 2 is significant at the $5 \%$ confidence level, while the difference between the Boston and Non-Boston region is not statistically significant.

Figure 4 presents the daily happiness and sadness results for all three events (Presidential election, Newtown shootings, and marathon bombings) for the identityrelevant groups (Republicans, parents, and Boston residents). The visual comparison, 
combined with the regression results, strongly suggests that Republicans' hedonic response to the election was larger than either response to the two tragedies.

\section{General Discussion}

People's social, physical, economic, and mental lives are shaped by their partisan identities - and these social identities are widely and deeply held. The current research vividly shows that these identities also have important consequences to people's hedonic lives. Winning an election is fine, but losing one is painful, at least in the short run. Losing an election appears to dominate the pain caused by national tragedies, even among those particularly connected to them. While enhancing our understanding of the centrality of people's partisanship to their lived experiences, these results also speak to the growing literature in economics, psychology, and other fields on the factors that affect well-being (Kahneman, Diener and Schwarz, 2003).

In addition to expanding our understanding of the well-being importance of partisan identity, this work makes several methodological contributions. First, it tackles a causal political psychology question by employing a research design (regression discontinuity) that is under-used in other political psychology research (Shadish, Cook, and Campbell, 2002). Second, it leverages digital technologies that allow large-scale, yet granular, data collection over time. One will notice in Figure 4 the rapid adaption of partisan losers to losing an election; of parents to the Newtown shootings; and of Boston residents to the marathon bombings. As far as we know, this is the first paper to map the contours of hedonic adaptation to societal events at this level of granularity. This type of data source provides new opportunities for scholars involved in the study and measurement of happiness (Kahneman and Krueger, 2006). Finally, by using hedonic reactions to multiple unrelated events that are each associated with distinct identities, we illustrate an approach to 
comparing the importance of different beliefs, ideologies, or events to people's identities with relatively high ecological validity (Settles, 2004).

One of our main findings is that the pain of losing the 2012 Presidential Election dominated the joy of winning it. A challenge to making a general claim is the many idiosyncrasies to this specific election. First, the impact of losing the election may be specific to Republicans since partisans appear to have systematic differences in how they process and respond to information (Jost, Federico, and Napier, 2009). Second, it is difficult for us to disentangle the role of party affiliation from simple candidate preferences. Third, since President Obama was the incumbent, partisan winners might have perceived retaining the presidency as maintaining the status quo, thereby muting the joy of winning. In this scenario, however, partisan losers would have viewed the status quo as not attaining the presidency (i.e., losing), making this status quo argument inconsistent with the results. It is also inconsistent with the robust finding that partisans expect their preferred candidates to win, even when the polls show that winning is unlikely (Granberg and Brent, 1983). The current findings should be replicated in future elections to resolve these questions.

Furthermore, the results appear inconsistent with research suggesting that prospect theory's gain-loss asymmetry arises when people forecast their hedonic reactions, but not when people actually experience gains and losses with monetary gambles (Kermer et al, 2006). One possible explanation for this inconsistency might be that partisans expect to win elections (Granberg and Brent, 1983; Krizan, Miller, and Johar, 2010), whereas overconfidence may be more muted for monetary gambles.

Finally, we note that although partisan losers appear to be only temporarily affected, such transitive emotional shocks have important personal and social implications. Card and 
Dahl (2011), for example, find that upset losses in football games increased local domestic violence reports for a short period following the game.

In sum, partisan identity is even more central to the self than past research suggests. In addition to affecting thinking, preferences, and behavior, it also has sizable hedonic consequences, especially when people experience partisan losses. 


\section{References}

Alesina, A., Di Tella, R., \& MacCulloch, R. (2004). Inequality and happiness: are Europeans and Americans different? Journal of Public Economics, 88(9), 2009-2042.

Argyle, M. (2003). 18 Causes and Correlates of Happiness. Well-Being: The Foundations of Hedonic Psychology, 353.

Baumeister, R. F., Bratslavsky, E., Finkenauer, C., \& Vohs, K. D. (2001). Bad is stronger than good. Review of General Psychology, 5(4), 323.

Busse, M., Silva-Risso, J and Zettelmeyer, F. (2006). "\$1,000 Cash Back: The pass-through of auto manufacturer promotions." American Economic Review, 96(4): 1253-1270.

Campbell, A., Converse, P. E., Miller, W. E., \& Donald, E. (1966). Stokes. 1960. The American Voter.

Card, D., \& G. Dahl. (2011). Family violence and football: The effect of unexpected emotional cues on violent behavior. Quarterly Journal of Economics, 126(1): 103-143.

Caruso, E., Mead, N., \& E. Balcetis. (2009). Political partisanship influences perception of biracial candidates' skin tone. Proceedings of National Academy of Sciences, 106(48): 2016820173.

Cohen, G. L. (2003). Party over policy: The dominating impact of group influence on political beliefs. Journal of Personality and Social Psychology, 85(5), 808-822.

Dal Bó, E., Dal Bó, P., \& Snyder, J. (2009). Political dynasties. The Review of Economic Studies, 76(1), 115-142.

Di Tella, R. D., MacCulloch, R. J., \& Oswald, A. J. (2003). The macroeconomics of happiness. Review of Economics and Statistics, 85(4), 809-827.

Easterlin R. A. (2003). Explaining happiness. PNAS 100: 11176-11183.

Easterlin, R. A. (2006). Life cycle happiness and its sources: Intersections of psychology, economics, and demography. Journal of Economic Psychology,27(4), 463-482.

Hersh, E. (2014). The long-term effect of September 11 on the political behavior of victims' families and neighbors. Proceedings of the National Academy of Sciences, 110 (52): 2095920963.

Gentzkow, M., \& Shapiro, J. M. (2011). Ideological segregation online and offline. The Quarterly Journal of Economics, 126(4), 1799-1839.

Gerber, A. S., \& Huber, G. A. (2009). Partisanship and economic behavior: Do partisan differences in economic forecasts predict real economic behavior? American Political Science Review, 103(3), 407-426.

Gerber, A. S., Kessler, D. P., \& Meredith, M. (2011). The persuasive effects of direct mail: A regression discontinuity based approach. Journal of Politics, 73(1), 140-155.

Gilbert, D. T., Lieberman, M. D., Morewedge, C. K., \& Wilson, T. D. (2004). The peculiar longevity of things not so bad. Psychological Science, 15, 14-19.

Gillis, J. R. (Ed.). (1996). Commemorations: The politics of national identity. Princeton University Press.

Gimpel, J. G., \& Schuknecht, J. E. (2004). Patchwork Nation: Sectionalism and Political Change in American Politics. University of Michigan Press.

Glaeser, E. L., \& Ward, B. A. (2006). Myths and realities of American political geography. Journal of Economic Perspectives, 20(2), 119-144.

Granberg, D., \& Brent, E. (1983). When prophecy bends: The preference-expectation link in US presidential elections, 1952-1980. Journal of Personality and Social Psychology, 45(3), 477. 
Green, D., Palmquist, B., \& Schickler, E. (2002). Partisan Hearts and Minds: Political Parties and the Social Identities of Voters. Yale University Press.

Imbens, G. W., \& Lemieux, T. (2008). Regression discontinuity designs: A guide to practice. Journal of Econometrics, 142(2), 615-635.

Jost, J. T., Federico, C. M., \& Napier, J. L. (2009). Political ideology: Its structure, functions, and elective affinities. Annual review of psychology, 60, 307-337.

Kahneman, D., \& Krueger, A. (2006). Developments in the measurement of subjective wellbeing. Journal of Economic Perspectives, 20(1), 3-24.

Kahneman, D., \& Tversky, A. (1979). Prospect theory: An analysis of decision under risk. Econometrica, 263-291.

Kahneman, D., \& Deaton, A. (2010). High income improves evaluation of life but not emotional well-being. Proceedings of the National Academy of Sciences, 107(38), 1648916493.

Kahneman, D., Diener, E., and Schwarz, N. (2003). Well-Being: The Foundations of Hedonic Psychology. Russell Sage Foundation.

Kermer, D. A., Driver-Linn, E., Wilson, T. D., \& Gilbert, D. T. (2006). Loss aversion is an affective forecasting error. Psychological Science, 17(8), 649-653.

Krizan, Z., Miller, J. C., \& Johar, O. (2010). Wishful thinking in the 2008 US presidential election. Psychological Science, 21(1), 140-146.

Langford, D. J., Crager, S. E., Shehzad, Z., Smith, S. B., Sotocinal, S. G., Levenstadt, J. S., Chanda, M. L., Levitin, D. J., \& Mogil, J. S. (2006). Social modulation of pain as evidence for empathy in mice. Science 312(5782), 1967-1970.

McDermott, R. (2004). Prospect theory in political science: Gains and losses from the first decade. Political Psychology, 25(2), 289-312.

Pierce, L, \& J.A. Snyder. (2012). Discretion and manipulation by experts: Evidence from a vehicle emissions policy change. B.E. Journal of Economic Analysis \& Policy, 13(3).

Pierce, L., Dahl, M. S., \& Nielsen, J. (2013). In sickness and in wealth: Psychological and sexual costs of income comparison in marriage. Personality and Social Psychology Bulletin, 39(3), 359-374.

Preston, S. D. \& De Waal, F. B. (2002). Empathy: Its ultimate and proximate bases. Behavioral and Brain Sciences, 25(1), 1-71.

Prior, M. (2007). Post-Broadcast Democracy: How Media Choice Increases Inequality in Political Involvement and Polarizes Elections. Cambridge University Press.

Rand, D., Pfeiffer, T., Dreber, A., Sheketoff, R., Wernerfelt, N., \& Benkler, Y. (2009). Dynamic remodeling of in-group bias during the 2008 presidential election. Proceedings of the National Academy of Sciences, 106(15): 6187-6191.

Rozin, P., \& Royzman, E. B. (2001). Negativity bias, negativity dominance, and contagion. Personality and Social Psychology Review, 5(4), 296-320.

Settles, I. H. (2004). When multiple identities interfere: The role of identity centrality. Personality and Social Psychology Bulletin, 30(4), 487-500.

Shadish, W.R, Cook, T.D., \& Campbell, D.T. (2002). Experimental and Quasi-Experimental Designs for Generalized Causal Inference. Boston: Houghton Mifflin.

Singer, T., Seymour, B., O’Doherty, J., Kaube, H., Dolan, R. J., \& Frith, C. D. (2004). Empathy for pain involves the affective but not sensory components of pain. Science, 303(5661), 1157-1162.

Snyder, J. (2010). Gaming the liver transplant market. Journal of Law, Economics, and Organization, 26(3), 546-568. 
West, S. G. (2009). Alternatives to randomized experiments. Current Directions in Psychological Science, 18(5), 299-304. 


\section{Table IA: Democrat happiness one week surrounding 2012 election}

\begin{tabular}{|c|c|c|c|c|c|}
\hline \multirow[b]{2}{*}{ Independent variables } & \multicolumn{5}{|c|}{ Dependent variable: Are you happy today? } \\
\hline & $(1)$ & $(2)$ & (3) & $(4)$ & $(5)$ \\
\hline Post-election & $\begin{array}{l}.039 \\
(.049)\end{array}$ & $\begin{array}{l}.033^{*} \\
(.019)\end{array}$ & $\begin{array}{c}.037 \\
(.047)\end{array}$ & $\begin{array}{c}.049 \\
(.052)\end{array}$ & $\begin{array}{c}.084 \\
(.137)\end{array}$ \\
\hline $\begin{array}{l}\text { Post-election } * \text { One de- } \\
\text { gree polynomial of days }\end{array}$ & No & No & Yes & Yes & No \\
\hline $\begin{array}{l}\text { Post-election }{ }^{*} \text { Three de- } \\
\text { gree polynomial of days }\end{array}$ & No & No & No & No & Yes \\
\hline $\begin{array}{l}\text { Socio - Demographic } \& \\
\text { MSA Controls }\end{array}$ & No & No & No & Yes & Yes \\
\hline Time restriction & + /- one day & +/- one week & +/- one week & +/- one week & + /- one week \\
\hline Observations & 265 & 1,553 & 1,553 & 1,553 & 1,553 \\
\hline
\end{tabular}

\section{Table IB: Republican happiness one week surrounding 2012 election}

\begin{tabular}{|c|c|c|c|c|c|}
\hline \multirow[b]{2}{*}{ Independent variables } & \multicolumn{5}{|c|}{ Dependent variable: Are you happy today? } \\
\hline & $(1)$ & $(2)$ & $(3)$ & $(4)$ & $(6)$ \\
\hline Post-election & $\begin{array}{c}-.310^{* * *} \\
(.040)\end{array}$ & $\begin{array}{c}-.151^{* * *} \\
(.016)\end{array}$ & $\begin{array}{c}-.243^{* * *} \\
(.035)\end{array}$ & $\begin{array}{c}-.246^{* * *} \\
(.039)\end{array}$ & $\begin{array}{c}-.316^{* * *} \\
(.096)\end{array}$ \\
\hline $\begin{array}{l}\text { Post-election * One de- } \\
\text { gree polynomial of days }\end{array}$ & No & No & Yes & Yes & No \\
\hline $\begin{array}{l}\text { Post-election } * \text { Three de- } \\
\text { gree polynomial of days }\end{array}$ & No & No & No & No & Yes \\
\hline $\begin{array}{l}\text { Socio - Demographic \& } \\
\text { MSA Controls }\end{array}$ & No & No & No & Yes & Yes \\
\hline Time restriction & + /- one day & + /- one week & + /- one week & +/- one week & +/- one week \\
\hline Observations & 465 & 2,934 & 2,934 & 2,934 & 2,934 \\
\hline
\end{tabular}

Note: ${ }^{*},{ }^{* *}$, and ${ }^{* * *}$ indicate significance at the $10 \%, 5 \%$, and $1 \%$ confidence levels, respectively. Standard errors are clustered at the Metropolitan level. Socio-demographic controls include gender, age indicators, race indicators, and income indicators. MSA controls included indicators for the metropolitan statistical area. 


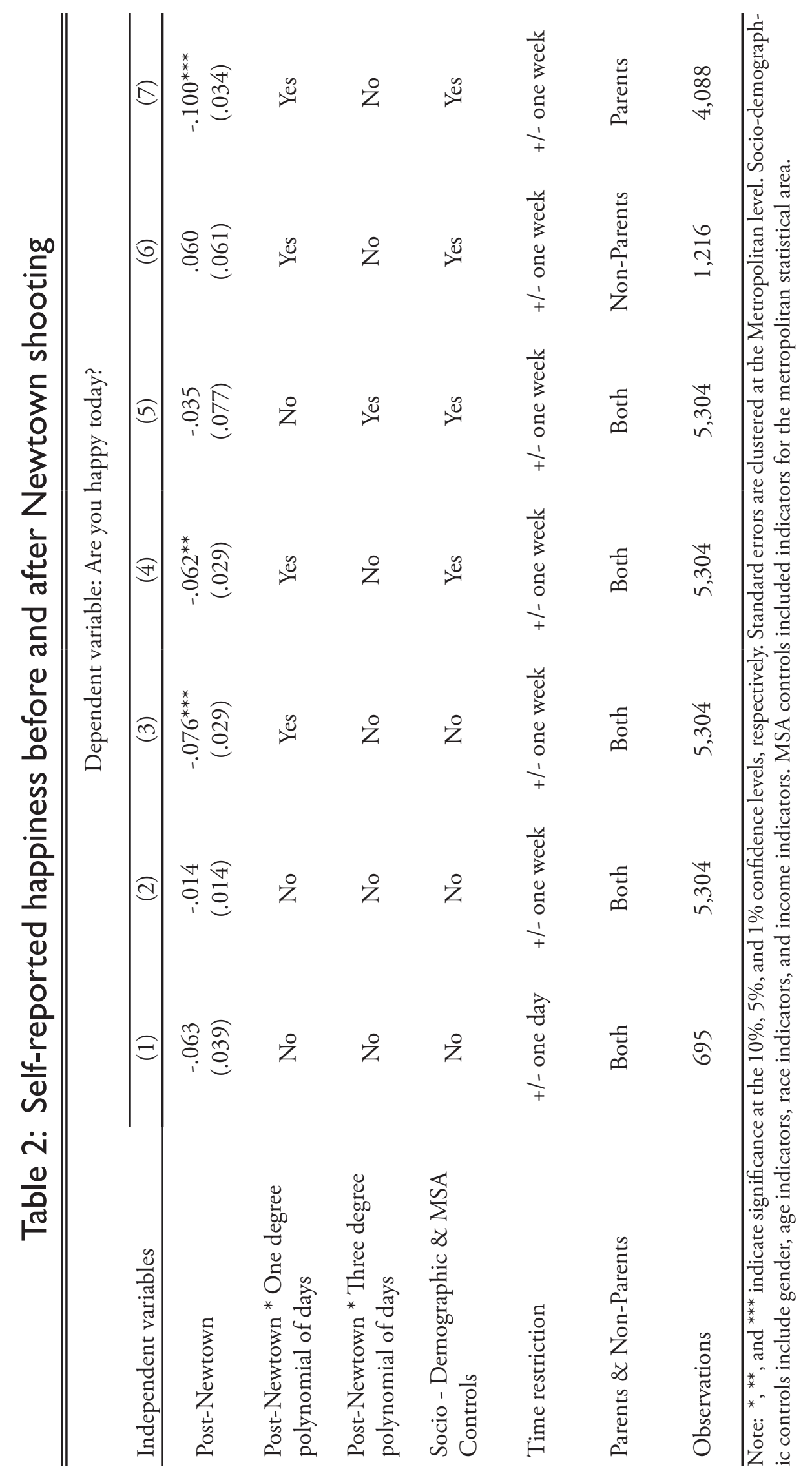




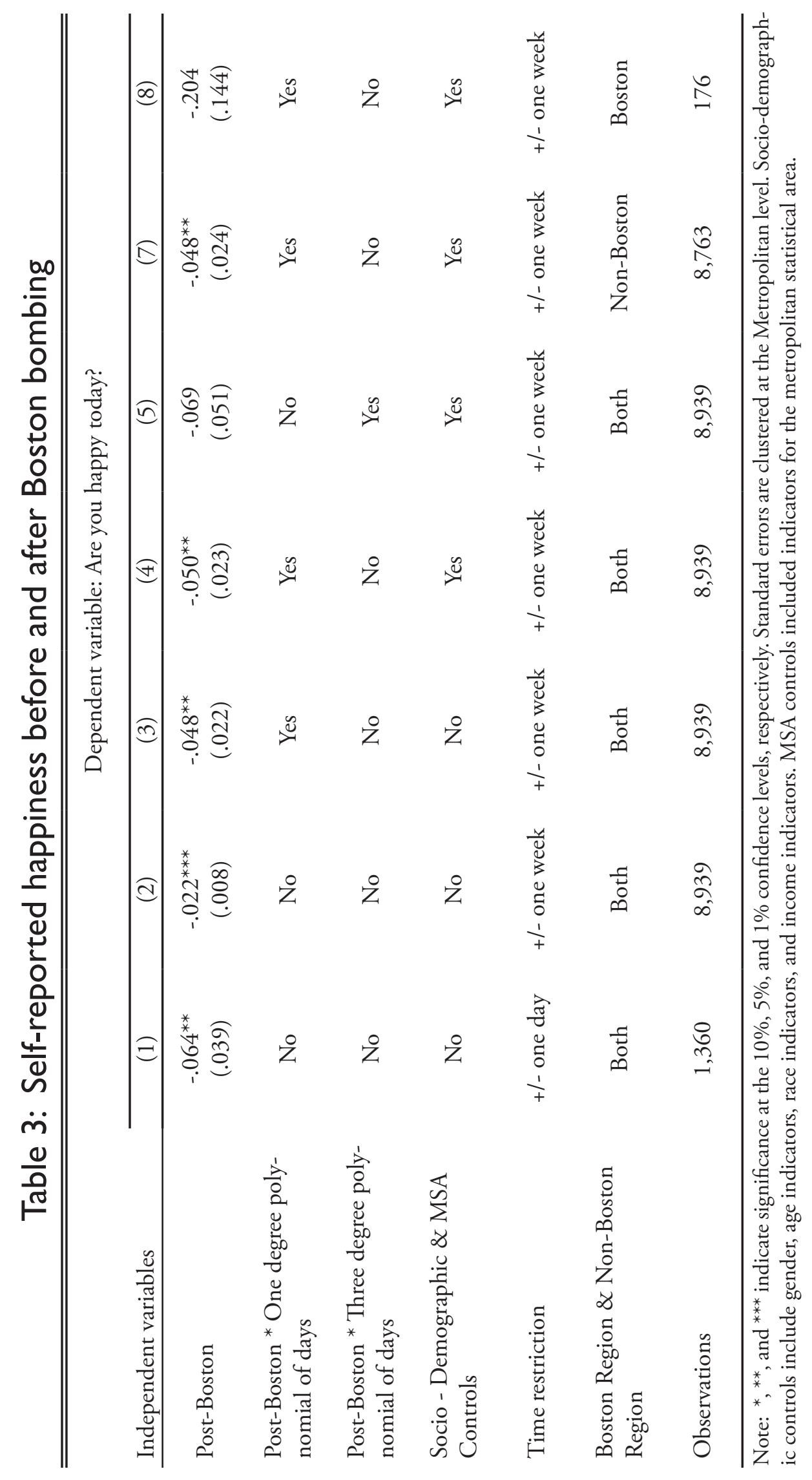




\section{Figure I:Self-reported happiness one week before and after the election}

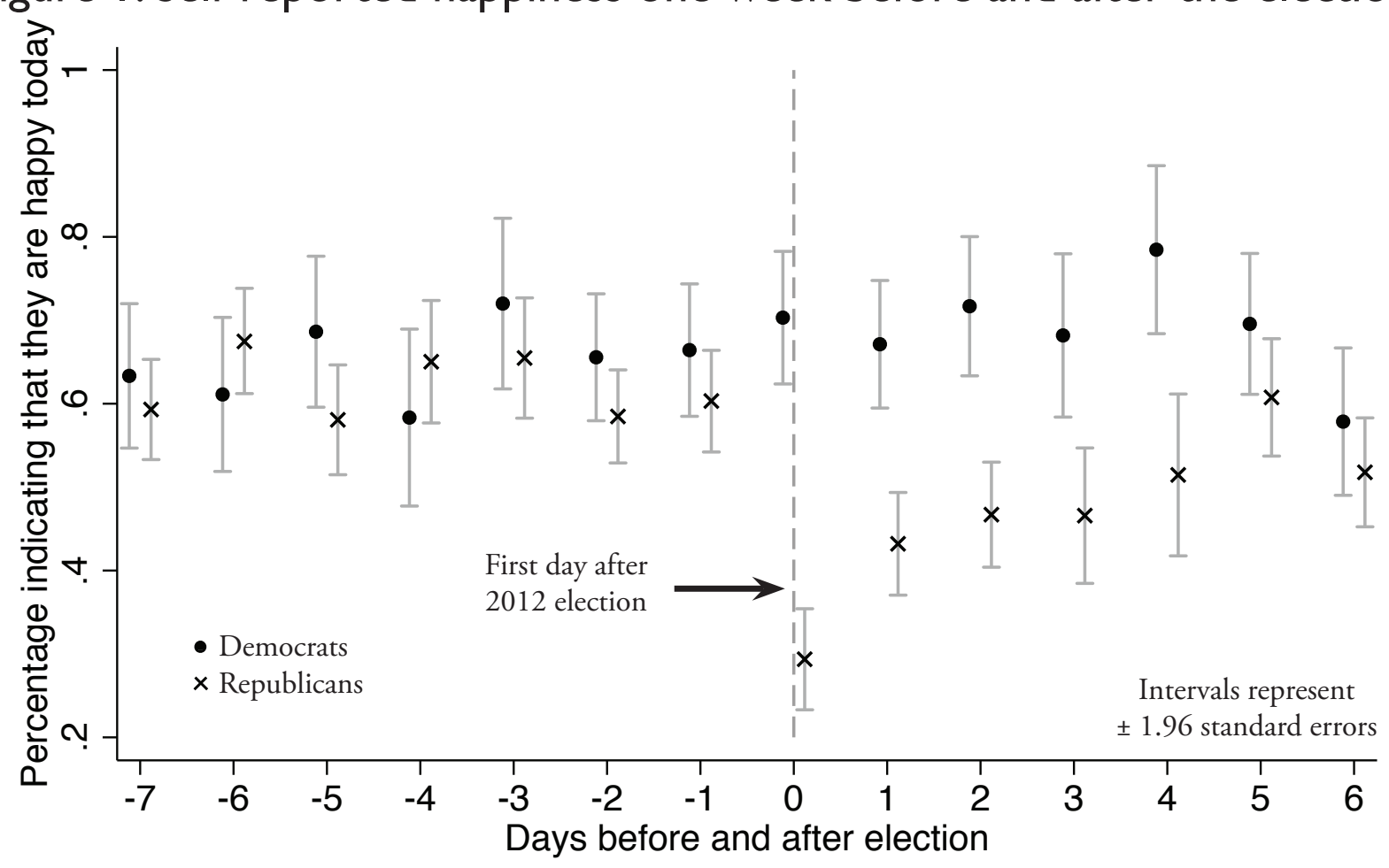

\section{Figure 2: Self-reported happiness one week before and after the election for Republicans with discontinuity model}

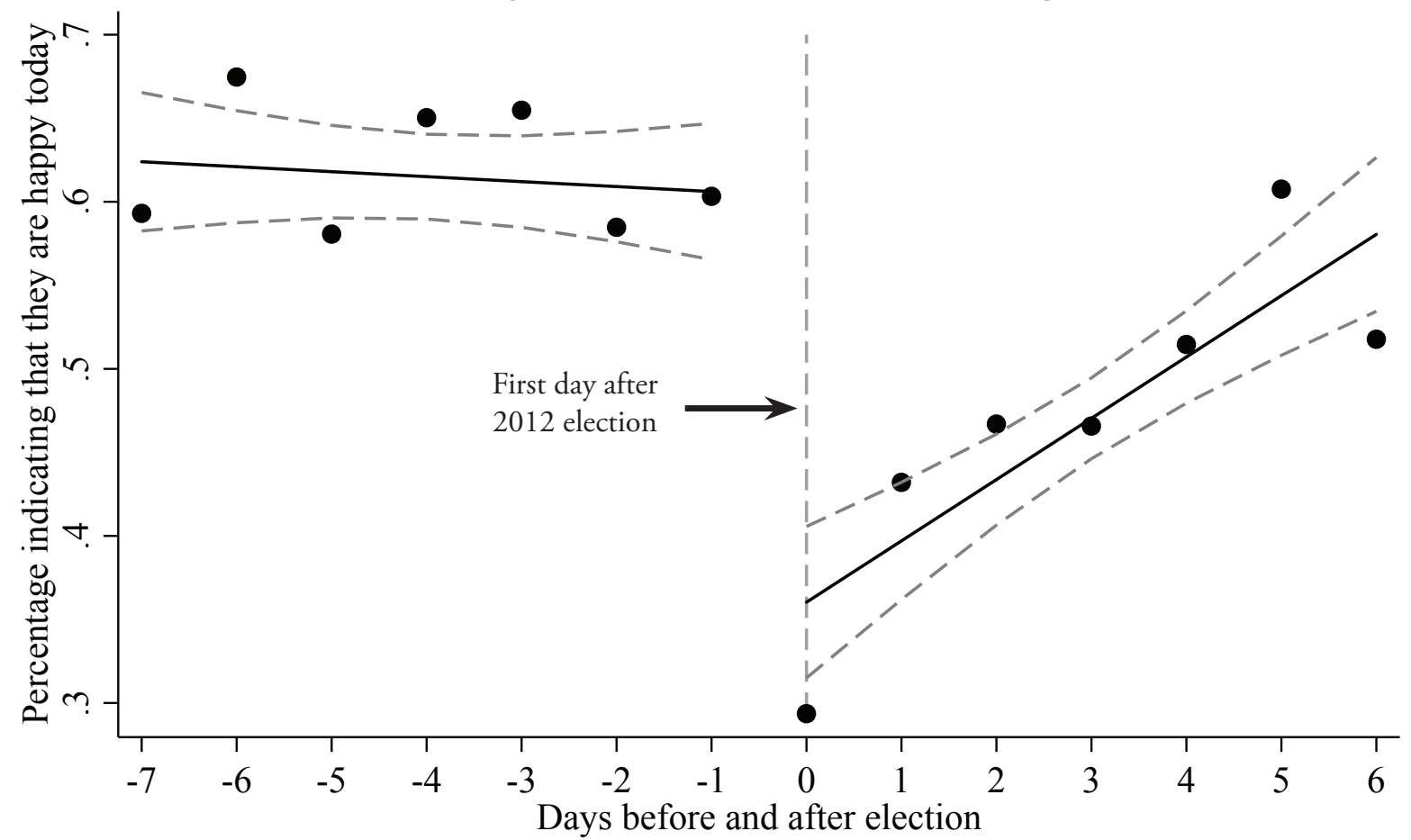

Note: Dashed lines are +/- 1.96 standard errors. The difference between the lines at the first day after the election corresponds to the $\beta_{1}$ in equation (1). The differences in slopes of the estimated line are the consequence of the interaction between the linear term and the post-election indicator. 


\section{Figure 3A: Self-reported happiness for Democrats eight weeks before and after the election}

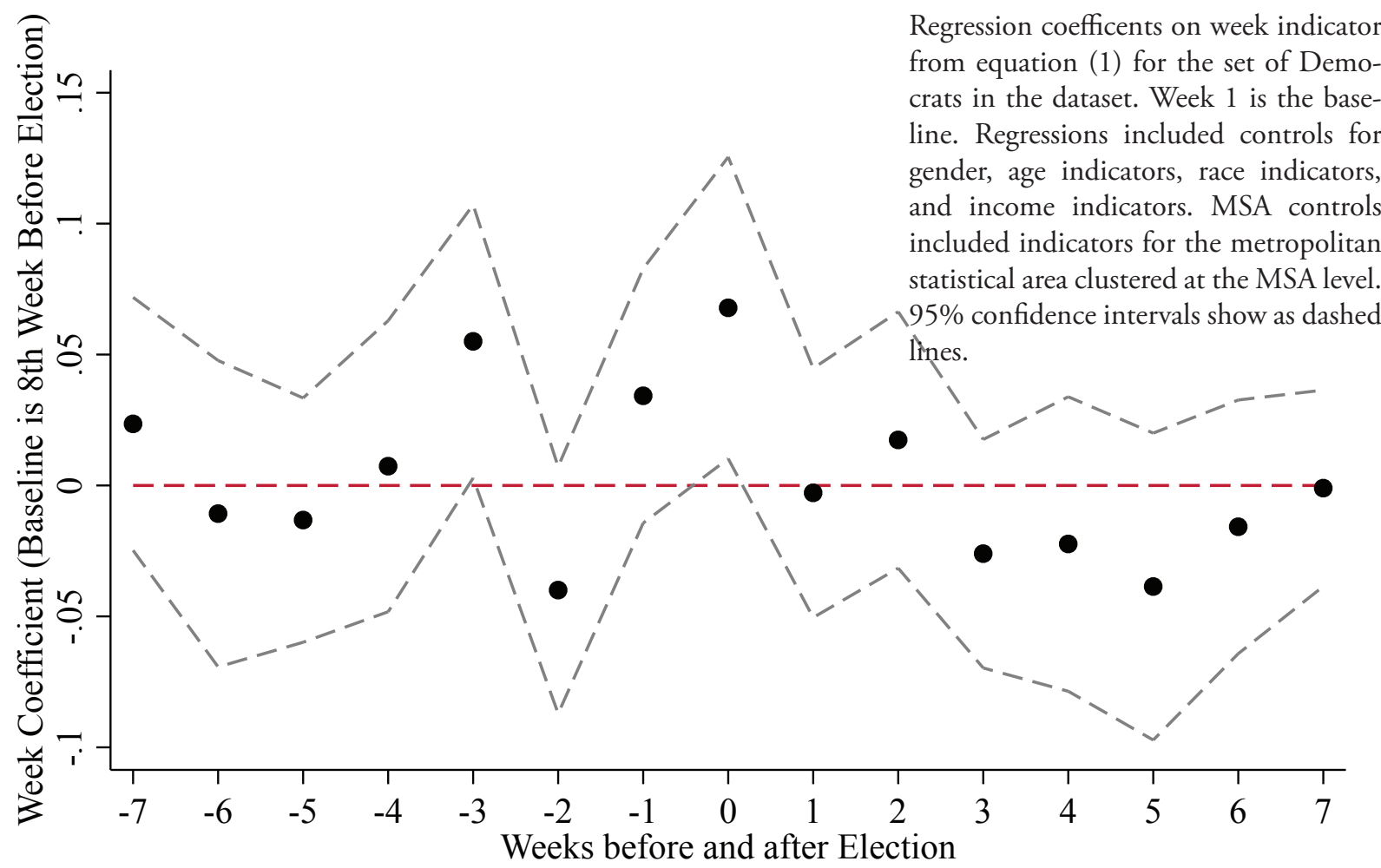

Figure 3B: Self-reported happiness for Republicans eight weeks before and after the election

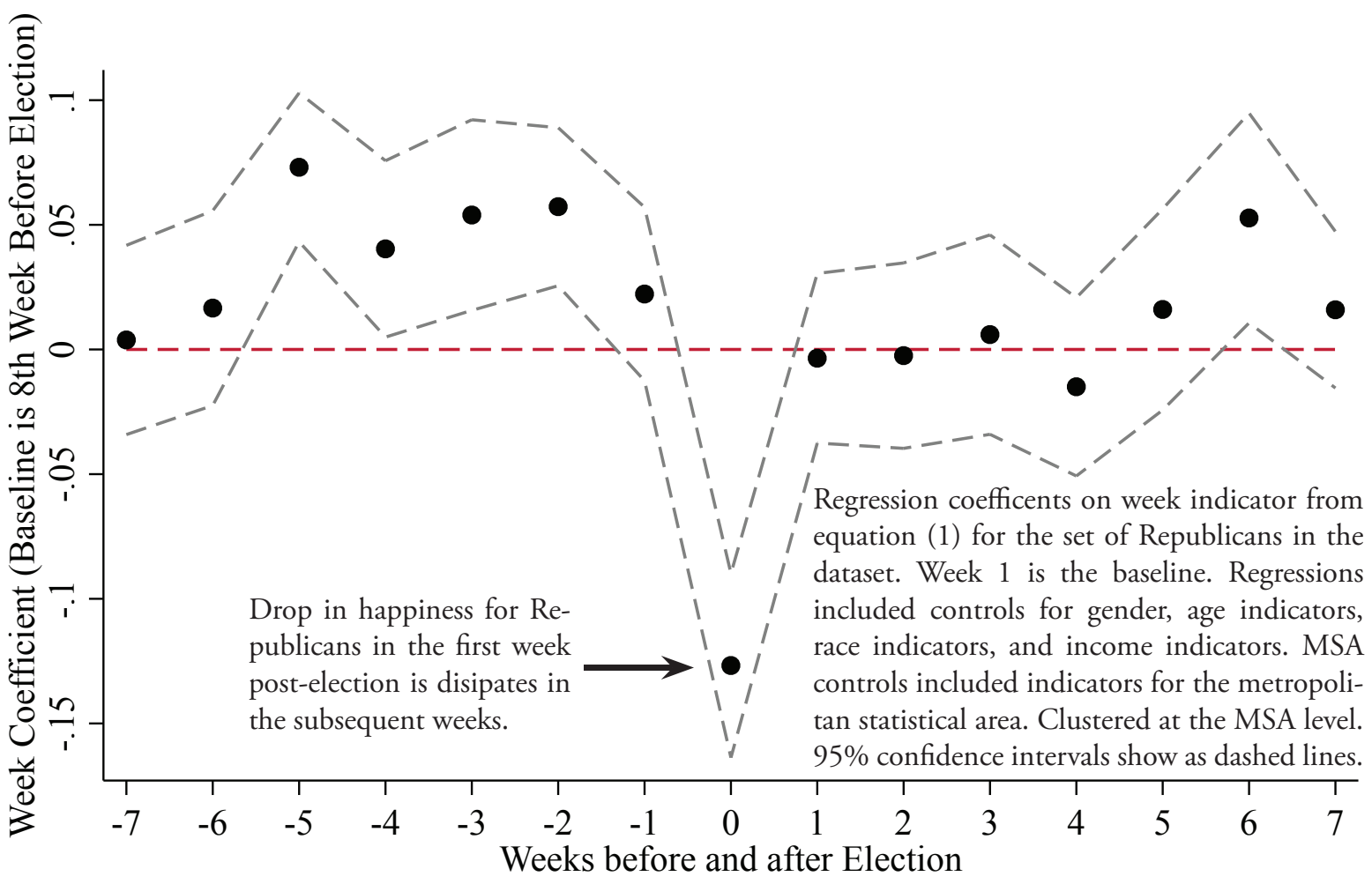


Figure 4: Comparison of salient groups before and after event

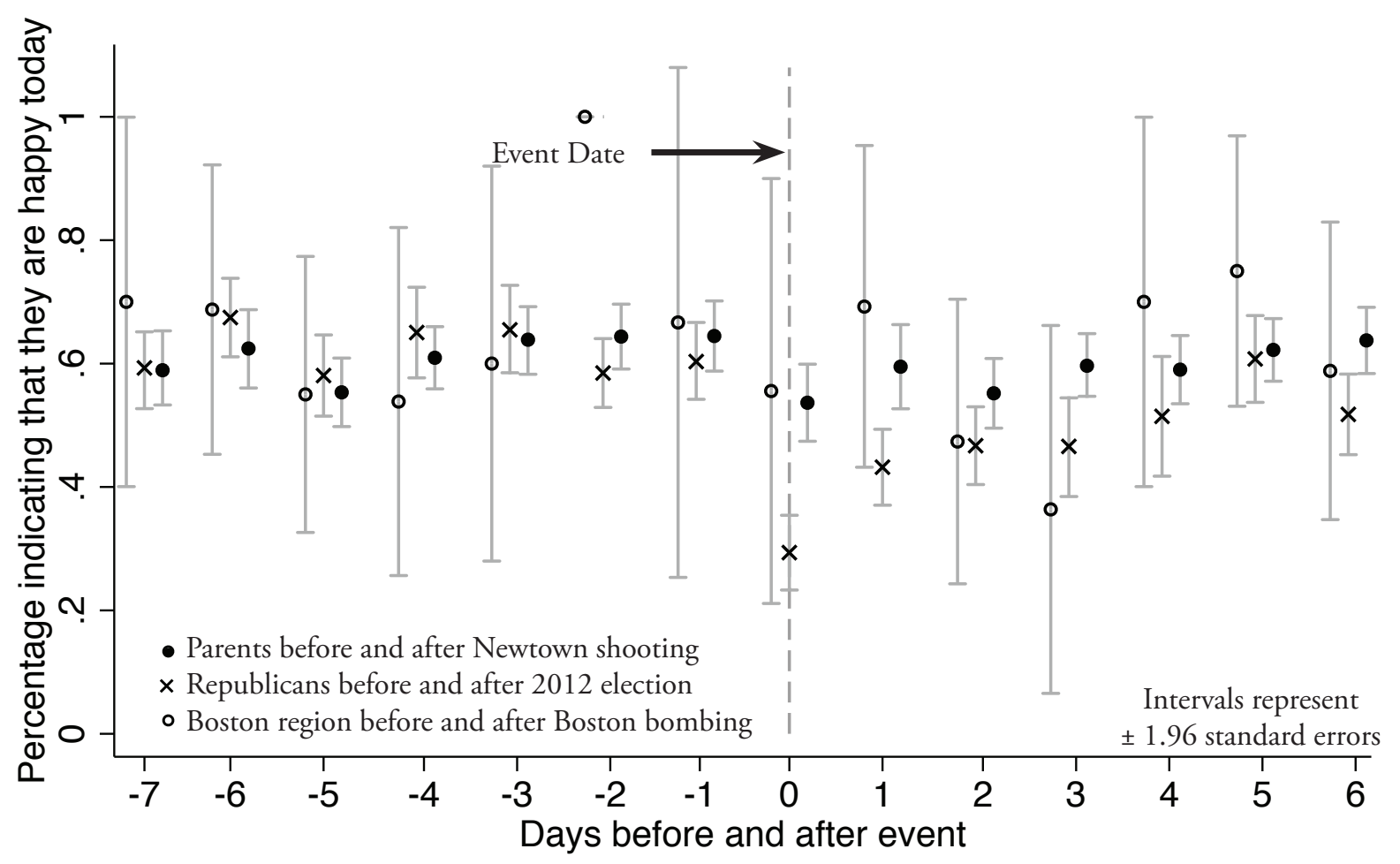




\title{
Supplementary Appendix
}

\author{
Losing Hurts: The Happiness Impact of Partisan Loss
}

\section{Addressing Alternative Expectations Explanation}

To address the concern that Democrats and Republicans suffered different happiness shocks because of different expectations about winning, another question that CivicScience asked before the election was analyzed: Who do you think will win the US Presidential election: Barack Obama, not sure but probably Obama, not sure but probably Romney, Mitt Romney, not sure? 286 respondents answered this question between October 31 and November $6.94 \%$ of partisan losers and $87 \%$ of partisan winners expected to win the election in the week before the election. Of these respondents, 210 were Republicans. Uncontrolled RD models run separately on the 197 (94\%) expecting a Republican victory and the $13(6 \%)$ expecting a Democrat victory. Partisan losers expecting to win experienced a similar negative hedonic shock to earlier results, $-0.47\left(p_{s}<.001\right)$; partisan losers anticipating losing also experienced a negative impact $(-0.88, p s<.05)$ that is larger but not statistically different from the shock to other Republicans. Similar analysis for partisan winners shows no meaningful difference in happiness gains. We must be cautious in drawing strong conclusions from such a sample of Republicans expecting to lose because it is both very small and may be fundamentally different than other Republicans. Still, these results cast some doubt on the alternative explanation of unmet expectations. 


\begin{tabular}{|c|c|c|c|c|c|c|}
\hline & Before & After & Difference & T-Stat & Coeff & T-Stat \\
\hline Self-Report: Happy today? & 0.613 & 0.529 & -0.084 & 7.010 & -0.143 & -6.065 \\
\hline Self-Report: Sad today? & 0.076 & 0.169 & 0.094 & -11.792 & 0.177 & 10.308 \\
\hline Democrat & 0.223 & 0.236 & 0.013 & -1.250 & 0.003 & 0.144 \\
\hline Independent & 0.328 & 0.347 & 0.019 & -1.674 & 0.018 & 0.775 \\
\hline Republican & 0.449 & 0.417 & -0.032 & 2.661 & -0.021 & -0.813 \\
\hline Female & 0.425 & 0.419 & -0.006 & 0.507 & 0.004 & 0.156 \\
\hline Age: Under 18 & 0.006 & 0.008 & 0.002 & -0.783 & 0.001 & 0.506 \\
\hline Age: $18-24$ & 0.020 & 0.026 & 0.006 & -1.662 & -0.006 & -0.749 \\
\hline Age: $25-29$ & 0.022 & 0.029 & 0.007 & -1.917 & 0.003 & 0.329 \\
\hline Age: $30-34$ & 0.037 & 0.043 & 0.006 & -1.284 & 0.005 & 0.480 \\
\hline Age: $35-44$ & 0.119 & 0.108 & -0.011 & 1.423 & -0.018 & -1.277 \\
\hline Age: $45-54$ & 0.251 & 0.233 & -0.018 & 1.738 & -0.033 & -1.502 \\
\hline Age: $55-64$ & 0.295 & 0.298 & 0.004 & -0.324 & 0.006 & 0.288 \\
\hline Age: 65 \& Older & 0.251 & 0.256 & 0.004 & -0.416 & 0.042 & 2.095 \\
\hline Caucasian & 0.864 & 0.855 & -0.009 & 1.051 & -0.014 & -0.867 \\
\hline Hispanic & 0.029 & 0.029 & -0.001 & 0.175 & 0.002 & 0.229 \\
\hline African American & 0.044 & 0.046 & 0.002 & -0.391 & -0.001 & -0.052 \\
\hline American Indian & 0.012 & 0.017 & 0.004 & -1.499 & -0.001 & -0.193 \\
\hline Aleut Eskimo & 0.006 & 0.005 & 0.000 & 0.149 & 0.002 & 0.796 \\
\hline Asian or Pacific Islander & 0.009 & 0.010 & 0.001 & -0.229 & -0.006 & -1.349 \\
\hline Other & 0.035 & 0.038 & 0.003 & -0.651 & 0.017 & 1.677 \\
\hline Income: Under $\$ 25 \mathrm{k}$ & 0.127 & 0.126 & -0.001 & 0.165 & -0.003 & -0.205 \\
\hline Income: $\$ 25 \mathrm{k}-\$ 35 \mathrm{k}$ & 0.094 & 0.094 & -0.001 & 0.078 & -0.017 & -1.406 \\
\hline Income: $\$ 35 \mathrm{k}-\$ 50 \mathrm{k}$ & 0.156 & 0.166 & 0.010 & -1.159 & -0.015 & -0.797 \\
\hline Income: $\$ 50 \mathrm{k}-\$ 75 \mathrm{k}$ & 0.205 & 0.199 & -0.006 & 0.574 & -0.012 & -0.570 \\
\hline Income: $\$ 75 \mathrm{k}-\$ 100 \mathrm{k}$ & 0.169 & 0.161 & -0.007 & 0.825 & 0.011 & 0.697 \\
\hline Income: $\$ 100 \mathrm{k}-\$ 125 \mathrm{k}$ & 0.096 & 0.102 & 0.006 & -0.815 & 0.031 & 2.062 \\
\hline Income: $\$ 125 \mathrm{k}-\$ 150 \mathrm{k}$ & 0.053 & 0.059 & 0.006 & -0.993 & 0.017 & 1.837 \\
\hline Income: $\$ 150 \mathrm{k}$ or more & 0.100 & 0.093 & -0.007 & 0.962 & -0.012 & -0.739 \\
\hline Observations & 3,483 & 3,290 & & & & \\
\hline
\end{tabular}

Note: Standard deviations omitted because dummies means and observations describe all moments of the distribution. Columns (3) \& (4) calculate the raw differences. Columns (5) \& (6) apply a discontinuity specification from to equation (1) using the set of controls as the dependent variables. Coeff corresponds to the coefficient, similar to specification (3) in table (1). See supplemental figure S1A for the distribution of the t-statistics on the differences and S1B for the distribution of the t-statistics on the coefficients. 


\section{Table SIB: Summary statistics one week before and after the the elec- tion (Democrats only)}

\begin{tabular}{|c|c|c|c|c|c|c|}
\hline & Before & After & Difference & T-Stat & Coeff & T-Stat \\
\hline Self-Report: Happy today? & 0.650 & 0.683 & 0.033 & -1.381 & 0.037 & 0.794 \\
\hline Self-Report: Sad today? & 0.057 & 0.055 & -0.001 & 0.104 & 0.014 & 0.602 \\
\hline Democrat & 1.000 & 1.000 & 0.000 & & 0.000 & \\
\hline Independent & 0.000 & 0.000 & 0.000 & & 0.000 & \\
\hline Republican & 0.000 & 0.000 & 0.000 & & 0.000 & \\
\hline Female & 0.557 & 0.534 & -0.024 & 0.940 & 0.034 & 0.792 \\
\hline Age: Under 18 & 0.010 & 0.008 & -0.003 & 0.534 & 0.011 & 1.599 \\
\hline Age: $18-24$ & 0.032 & 0.041 & 0.009 & -0.949 & -0.026 & -1.627 \\
\hline Age: $25-29$ & 0.031 & 0.034 & 0.003 & -0.292 & 0.015 & 0.999 \\
\hline Age: $30-34$ & 0.041 & 0.064 & 0.023 & -2.050 & 0.008 & 0.292 \\
\hline Age: $35-44$ & 0.129 & 0.134 & 0.005 & -0.310 & -0.022 & -0.723 \\
\hline Age: $45-54$ & 0.264 & 0.241 & -0.023 & 1.036 & 0.016 & 0.427 \\
\hline Age: $55-64$ & 0.318 & 0.302 & -0.016 & 0.696 & -0.015 & -0.424 \\
\hline Age: 65 \& Older & 0.175 & 0.177 & 0.002 & -0.078 & 0.012 & 0.352 \\
\hline Caucasian & 0.767 & 0.767 & 0.000 & 0.014 & -0.001 & -0.013 \\
\hline Hispanic & 0.049 & 0.036 & -0.013 & 1.253 & -0.030 & -1.170 \\
\hline African American & 0.134 & 0.135 & 0.001 & -0.084 & 0.007 & 0.220 \\
\hline American Indian & 0.006 & 0.008 & 0.001 & -0.305 & 0.003 & 0.362 \\
\hline Aleut Eskimo & 0.005 & 0.006 & 0.001 & -0.336 & 0.000 & 0.056 \\
\hline Asian or Pacific Islander & 0.009 & 0.013 & 0.004 & -0.734 & 0.004 & 0.513 \\
\hline Other & 0.030 & 0.035 & 0.005 & -0.579 & 0.016 & 0.990 \\
\hline Income: Under $\$ 25 \mathrm{k}$ & 0.147 & 0.142 & -0.005 & 0.278 & 0.042 & 1.146 \\
\hline Income: $\$ 25 \mathrm{k}-\$ 35 \mathrm{k}$ & 0.112 & 0.111 & -0.001 & 0.072 & -0.039 & -1.494 \\
\hline Income: $\$ 35 \mathrm{k}-\$ 50 \mathrm{k}$ & 0.167 & 0.144 & -0.023 & 1.248 & -0.049 & -1.354 \\
\hline Income: $\$ 50 \mathrm{k}-\$ 75 \mathrm{k}$ & 0.229 & 0.227 & -0.002 & 0.107 & -0.022 & -0.480 \\
\hline Income: $\$ 75 \mathrm{k}-\$ 100 \mathrm{k}$ & 0.148 & 0.165 & 0.017 & -0.919 & 0.056 & 1.696 \\
\hline Income: $\$ 100 \mathrm{k}-\$ 125 \mathrm{k}$ & 0.084 & 0.086 & 0.003 & -0.190 & 0.028 & 1.066 \\
\hline Income: $\$ 125 \mathrm{k}-\$ 150 \mathrm{k}$ & 0.035 & 0.046 & 0.012 & -1.162 & 0.003 & 0.174 \\
\hline Income: $\$ 150 \mathrm{k}$ or more & 0.079 & 0.079 & 0.000 & -0.007 & -0.019 & -0.797 \\
\hline Observations & 777 & 776 & & & & \\
\hline
\end{tabular}

Note: Standard deviations omitted because dummies means and observations describe all moments of the distribution. Columns (3) \& (4) calculate the raw differences. Columns (5) \& (6) apply a discontinuity specification from to equation (1) using the set of controls as the dependent variables. Coeff corresponds to the coefficient, similar to specification (3) in table (1). See supplemental figure S1C for the distribution of the t-statistics on the differences and S1D for the distribution of the t-statistics on the coefficients. 


\section{Table SIC: Summary statistics one week before and after the the elec- tion (Republicans only)}

\begin{tabular}{|c|c|c|c|c|c|c|}
\hline & Before & After & Difference & T-Stat & Coeff & T-Stat \\
\hline Self-Report: Happy today? & 0.615 & 0.464 & -0.151 & 8.270 & -0.243 & -6.846 \\
\hline Self-Report: Sad today? & 0.075 & 0.225 & 0.149 & -11.379 & 0.273 & 9.634 \\
\hline Democrat & 0.000 & 0.000 & 0.000 & & 0.000 & \\
\hline Independent & 0.000 & 0.000 & 0.000 & & 0.000 & \\
\hline Republican & 1.000 & 1.000 & 0.000 & & 0.000 & \\
\hline Female & 0.393 & 0.377 & -0.016 & 0.874 & -0.006 & -0.156 \\
\hline Age: Under 18 & 0.004 & 0.010 & 0.006 & -2.033 & 0.006 & 1.624 \\
\hline Age: $18-24$ & 0.013 & 0.018 & 0.005 & -1.037 & 0.010 & 0.967 \\
\hline Age: $25-29$ & 0.019 & 0.027 & 0.008 & -1.395 & -0.007 & -0.557 \\
\hline Age: $30-34$ & 0.032 & 0.034 & 0.002 & -0.237 & 0.000 & -0.037 \\
\hline Age: $35-44$ & 0.120 & 0.093 & -0.028 & 2.433 & -0.044 & -1.969 \\
\hline Age: $45-54$ & 0.245 & 0.225 & -0.020 & 1.301 & -0.059 & -1.853 \\
\hline Age: 55-64 & 0.298 & 0.287 & -0.011 & 0.683 & 0.009 & 0.242 \\
\hline Age: $65 \&$ Older & 0.269 & 0.308 & 0.039 & -2.331 & 0.085 & 2.644 \\
\hline Caucasian & 0.936 & 0.921 & -0.015 & 1.548 & -0.026 & -1.333 \\
\hline Hispanic & 0.019 & 0.023 & 0.003 & -0.644 & 0.008 & 0.717 \\
\hline African American & 0.004 & 0.013 & 0.009 & -2.465 & 0.009 & 1.416 \\
\hline American Indian & 0.006 & 0.012 & 0.005 & -1.492 & 0.003 & 0.386 \\
\hline Aleut Eskimo & 0.004 & 0.005 & 0.001 & -0.511 & 0.009 & 2.218 \\
\hline Asian or Pacific Islander & 0.010 & 0.007 & -0.002 & 0.683 & -0.003 & -0.479 \\
\hline Other & 0.020 & 0.019 & -0.002 & 0.294 & 0.001 & 0.062 \\
\hline Income: Under $\$ 25 \mathrm{k}$ & 0.094 & 0.114 & 0.020 & -1.743 & 0.022 & 1.050 \\
\hline Income: $\$ 25 \mathrm{k}-\$ 35 \mathrm{k}$ & 0.081 & 0.085 & 0.004 & -0.392 & -0.007 & -0.430 \\
\hline Income: $\$ 35 \mathrm{k}-\$ 50 \mathrm{k}$ & 0.146 & 0.177 & 0.031 & -2.247 & -0.010 & -0.424 \\
\hline Income: $\$ 50 \mathrm{k}-\$ 75 \mathrm{k}$ & 0.205 & 0.201 & -0.004 & 0.279 & 0.003 & 0.107 \\
\hline Income: $\$ 75 \mathrm{k}-\$ 100 \mathrm{k}$ & 0.198 & 0.150 & -0.047 & 3.400 & -0.032 & -1.128 \\
\hline Income: $\$ 100 \mathrm{k}-\$ 125 \mathrm{k}$ & 0.103 & 0.105 & 0.002 & -0.179 & 0.006 & 0.249 \\
\hline Income: $\$ 125 \mathrm{k}-\$ 150 \mathrm{k}$ & 0.065 & 0.064 & -0.001 & 0.118 & 0.020 & 1.409 \\
\hline Income: $\$ 150 \mathrm{k}$ or more & 0.109 & 0.105 & -0.004 & 0.327 & -0.002 & -0.115 \\
\hline Observations & 1,563 & 1,371 & & & & \\
\hline
\end{tabular}

Note: Standard deviations omitted because dummies means and observations describe all moments of the distribution. Columns (3) \& (4) calculate the raw differences. Columns (5) \& (6) apply a discontinuity specification from to equation (1) using the set of controls as the dependent variables. Coeff corresponds to the coefficient, similar to specification (3) in table (1). See supplemental figure S1E for the distribution of the t-statistics on the differences and S1F for the distribution of the t-statistics on the coefficients. 


\section{Table S2A: Summary statistics before and after the Newtown shootings}

\begin{tabular}{|c|c|c|c|c|c|c|}
\hline & Before & After & Difference & T-Stat & Coeff & T-Stat \\
\hline Self-Report: Happy today? & 0.584 & 0.571 & -0.014 & 1.012 & -0.076 & -2.627 \\
\hline Self-Report: Sad today? & 0.082 & 0.091 & 0.008 & -1.086 & 0.030 & 2.045 \\
\hline Parent & 0.774 & 0.768 & -0.006 & 0.520 & -0.016 & -0.784 \\
\hline Female & 0.388 & 0.376 & -0.012 & 0.871 & 0.007 & 0.281 \\
\hline Age: Under 18 & 0.006 & 0.006 & 0.001 & -0.308 & 0.004 & 0.804 \\
\hline Age: $18-24$ & 0.023 & 0.021 & -0.001 & 0.371 & -0.001 & -0.152 \\
\hline Age: $25-29$ & 0.028 & 0.025 & -0.003 & 0.700 & -0.008 & -0.776 \\
\hline Age: $30-34$ & 0.031 & 0.038 & 0.007 & -1.467 & 0.001 & 0.110 \\
\hline Age: $35-44$ & 0.092 & 0.098 & 0.006 & -0.787 & -0.003 & -0.190 \\
\hline Age: $45-54$ & 0.200 & 0.223 & 0.023 & -2.007 & 0.028 & 1.019 \\
\hline Age: $55-64$ & 0.300 & 0.306 & 0.006 & -0.469 & 0.019 & 0.714 \\
\hline Age: 65 \& Older & 0.321 & 0.283 & -0.038 & 3.031 & -0.040 & -1.394 \\
\hline Caucasian & 0.856 & 0.859 & 0.003 & -0.325 & 0.003 & 0.115 \\
\hline Hispanic & 0.019 & 0.022 & 0.003 & -0.784 & 0.004 & 0.516 \\
\hline African American & 0.056 & 0.047 & -0.008 & 1.321 & -0.019 & -1.529 \\
\hline American Indian & 0.013 & 0.018 & 0.005 & -1.382 & -0.005 & -0.723 \\
\hline Aleut Eskimo & 0.006 & 0.003 & -0.003 & 1.841 & 0.002 & 0.325 \\
\hline Asian or Pacific Islander & 0.007 & 0.009 & 0.001 & -0.566 & 0.000 & 0.026 \\
\hline Other & 0.043 & 0.043 & -0.001 & 0.128 & 0.016 & 1.291 \\
\hline Income: Under $\$ 25 \mathrm{k}$ & 0.146 & 0.145 & -0.002 & 0.171 & 0.040 & 2.392 \\
\hline Income: $\$ 25 \mathrm{k}-\$ 35 \mathrm{k}$ & 0.117 & 0.113 & -0.004 & 0.433 & 0.031 & 1.720 \\
\hline Income: $\$ 35 \mathrm{k}-\$ 50 \mathrm{k}$ & 0.167 & 0.166 & -0.001 & 0.086 & 0.022 & 1.032 \\
\hline Income: $\$ 50 \mathrm{k}-\$ 75 \mathrm{k}$ & 0.203 & 0.202 & -0.001 & 0.065 & -0.009 & -0.398 \\
\hline Income: $\$ 75 \mathrm{k}-\$ 100 \mathrm{k}$ & 0.148 & 0.153 & 0.005 & -0.476 & -0.039 & -1.577 \\
\hline Income: $\$ 100 \mathrm{k}-\$ 125 \mathrm{k}$ & 0.082 & 0.084 & 0.002 & -0.316 & -0.024 & -1.612 \\
\hline Income: $\$ 125 \mathrm{k}-\$ 150 \mathrm{k}$ & 0.054 & 0.049 & -0.005 & 0.763 & -0.042 & -3.233 \\
\hline Income: $\$ 150 \mathrm{k}$ or more & 0.084 & 0.088 & 0.005 & -0.598 & 0.021 & 1.203 \\
\hline Observations & 2,630 & 2,674 & & & & \\
\hline
\end{tabular}

Note: Standard deviations omitted because dummies means and observations describe all moments of the distribution. Columns (3) \& (4) calculate the raw differences. Columns (5) \& (6) apply a discontinuity specification from to equation (1) using the set of controls as the dependent variables. Coeff corresponds to the coefficient, similar to specification (3) in table (1). See supplemental figure S2A for the distribution of the t-statistics on the differences and S2B for the distribution of the t-statistics on the coefficients. 


\section{Table S2B: Summary statistics before and after the Newtown shootings (Non-Parents only)}

\begin{tabular}{|c|c|c|c|c|c|c|}
\hline & Before & After & Difference & T-Stat & Coeff & T-Stat \\
\hline Self-Report: Happy today? & 0.481 & 0.499 & 0.019 & -0.645 & 0.056 & 1.067 \\
\hline Self-Report: Sad today? & 0.113 & 0.130 & 0.018 & -0.951 & 0.023 & 0.564 \\
\hline Parent & 0.000 & 0.000 & 0.000 & & 0.000 & \\
\hline Female & 0.370 & 0.372 & 0.002 & -0.081 & -0.033 & -0.566 \\
\hline Age: Under 18 & 0.024 & 0.024 & 0.001 & -0.071 & 0.017 & 0.802 \\
\hline Age: $18-24$ & 0.086 & 0.079 & -0.007 & 0.431 & -0.011 & -0.295 \\
\hline Age: $25-29$ & 0.086 & 0.079 & -0.007 & 0.431 & -0.050 & -1.524 \\
\hline Age: $30-34$ & 0.055 & 0.072 & 0.017 & -1.213 & 0.022 & 0.958 \\
\hline Age: $35-44$ & 0.116 & 0.106 & -0.010 & 0.537 & -0.025 & -0.544 \\
\hline Age: $45-54$ & 0.190 & 0.237 & 0.047 & -1.995 & 0.047 & 1.036 \\
\hline Age: 55-64 & 0.259 & 0.254 & -0.004 & 0.175 & 0.024 & 0.384 \\
\hline Age: $65 \&$ Older & 0.185 & 0.148 & -0.037 & 1.718 & -0.024 & -0.571 \\
\hline Caucasian & 0.844 & 0.820 & -0.024 & 1.121 & -0.090 & -1.525 \\
\hline Hispanic & 0.037 & 0.026 & -0.011 & 1.119 & 0.008 & 0.357 \\
\hline African American & 0.040 & 0.050 & 0.010 & -0.805 & 0.007 & 0.259 \\
\hline American Indian & 0.013 & 0.018 & 0.004 & -0.601 & -0.008 & -0.447 \\
\hline Aleut Eskimo & 0.013 & 0.006 & -0.007 & 1.226 & -0.004 & -0.255 \\
\hline Asian or Pacific Islander & 0.008 & 0.014 & 0.006 & -1.000 & 0.002 & 0.124 \\
\hline Other & 0.044 & 0.066 & 0.022 & -1.713 & 0.085 & 3.135 \\
\hline Income: Under $\$ 25 \mathrm{k}$ & 0.218 & 0.203 & -0.016 & 0.666 & 0.059 & 1.392 \\
\hline Income: $\$ 25 \mathrm{k}-\$ 35 \mathrm{k}$ & 0.118 & 0.124 & 0.006 & -0.339 & -0.003 & -0.105 \\
\hline Income: $\$ 35 \mathrm{k}-\$ 50 \mathrm{k}$ & 0.175 & 0.184 & 0.009 & -0.399 & 0.057 & 1.438 \\
\hline Income: $\$ 50 \mathrm{k}-\$ 75 \mathrm{k}$ & 0.175 & 0.172 & -0.002 & 0.114 & -0.049 & -1.145 \\
\hline Income: $\$ 75 \mathrm{k}-\$ 100 \mathrm{k}$ & 0.118 & 0.111 & -0.007 & 0.358 & -0.005 & -0.158 \\
\hline Income: $\$ 100 \mathrm{k}$ - \$125k & 0.071 & 0.093 & 0.023 & -1.451 & 0.021 & 0.615 \\
\hline Income: $\$ 125 \mathrm{k}-\$ 150 \mathrm{k}$ & 0.040 & 0.050 & 0.010 & -0.805 & -0.033 & -1.289 \\
\hline Income: $\$ 150 \mathrm{k}$ or more & 0.086 & 0.063 & -0.023 & 1.521 & -0.047 & -1.432 \\
\hline Observations & 595 & 621 & & & & \\
\hline
\end{tabular}

Note: Standard deviations omitted because dummies means and observations describe all moments of the distribution. Columns (3) \& (4) calculate the raw differences. Columns (5) \& (6) apply a discontinuity specification from to equation (1) using the set of controls as the dependent variables. Coeff corresponds to the coefficient, similar to specification (3) in table (1). See supplemental figure S2C for the distribution of the t-statistics on the differences and S2D for the distribution of the t-statistics on the coefficients. 


\section{Table S2C: Summary statistics before and after the Newtown shootings (Parents only)}

\begin{tabular}{|c|c|c|c|c|c|c|}
\hline & Before & After & Difference & T-Stat & Coeff & T-Stat \\
\hline Self-Report: Happy today? & 0.615 & 0.592 & -0.022 & 1.466 & -0.115 & -3.506 \\
\hline Self-Report: Sad today? & 0.073 & 0.078 & 0.005 & -0.628 & 0.031 & 1.881 \\
\hline Parent & 1.000 & 1.000 & 0.000 & & 0.000 & \\
\hline Female & 0.393 & 0.377 & -0.016 & 1.026 & 0.019 & 0.708 \\
\hline Age: Under 18 & 0.000 & 0.001 & 0.000 & -0.571 & 0.000 & -0.137 \\
\hline Age: $18-24$ & 0.004 & 0.004 & -0.001 & 0.261 & 0.000 & -0.043 \\
\hline Age: $25-29$ & 0.011 & 0.008 & -0.003 & 0.832 & 0.003 & 0.530 \\
\hline Age: $30-34$ & 0.024 & 0.028 & 0.004 & -0.844 & -0.006 & -0.607 \\
\hline Age: $35-44$ & 0.085 & 0.096 & 0.011 & -1.220 & 0.004 & 0.202 \\
\hline Age: $45-54$ & 0.203 & 0.219 & 0.015 & -1.196 & 0.022 & 0.702 \\
\hline Age: $55-64$ & 0.312 & 0.321 & 0.009 & -0.649 & 0.019 & 0.643 \\
\hline Age: 65 \& Older & 0.361 & 0.323 & -0.037 & 2.512 & -0.041 & -1.262 \\
\hline Caucasian & 0.859 & 0.870 & 0.011 & -1.071 & 0.032 & 1.411 \\
\hline Hispanic & 0.014 & 0.021 & 0.007 & -1.760 & 0.003 & 0.374 \\
\hline African American & 0.060 & 0.047 & -0.013 & 1.876 & -0.027 & -1.632 \\
\hline American Indian & 0.013 & 0.018 & 0.005 & -1.246 & -0.004 & -0.586 \\
\hline Aleut Eskimo & 0.004 & 0.002 & -0.002 & 1.402 & 0.003 & 0.797 \\
\hline Asian or Pacific Islander & 0.007 & 0.007 & 0.000 & 0.023 & 0.000 & -0.093 \\
\hline Other & 0.043 & 0.036 & -0.008 & 1.263 & -0.006 & -0.486 \\
\hline Income: Under $\$ 25 \mathrm{k}$ & 0.125 & 0.127 & 0.002 & -0.176 & 0.032 & 1.679 \\
\hline Income: $\$ 25 \mathrm{k}$ - $\$ 35 \mathrm{k}$ & 0.116 & 0.110 & -0.007 & 0.693 & 0.041 & 1.877 \\
\hline Income: $\$ 35 \mathrm{k}-\$ 50 \mathrm{k}$ & 0.165 & 0.161 & -0.004 & 0.336 & 0.011 & 0.485 \\
\hline Income: $\$ 50 \mathrm{k}-\$ 75 \mathrm{k}$ & 0.211 & 0.211 & 0.000 & -0.007 & 0.004 & 0.165 \\
\hline Income: $\$ 75 \mathrm{k}-\$ 100 \mathrm{k}$ & 0.157 & 0.165 & 0.008 & -0.728 & -0.048 & -1.727 \\
\hline Income: $\$ 100 \mathrm{k}-\$ 125 \mathrm{k}$ & 0.085 & 0.081 & -0.004 & 0.424 & -0.037 & -2.471 \\
\hline Income: $\$ 125 \mathrm{k}-\$ 150 \mathrm{k}$ & 0.057 & 0.049 & -0.009 & 1.252 & -0.045 & -3.275 \\
\hline Income: $\$ 150 \mathrm{k}$ or more & 0.083 & 0.096 & 0.013 & -1.446 & 0.042 & 2.037 \\
\hline Observations & 2,035 & 2,053 & & & & \\
\hline
\end{tabular}

Note: Standard deviations omitted because dummies means and observations describe all moments of the distribution. Columns (3) \& (4) calculate the raw differences. Columns (5) \& (6) apply a discontinuity specification from to equation (1) using the set of controls as the dependent variables. Coeff corresponds to the coefficient, similar to specification (3) in table (1). See supplemental figure S2E for the distribution of the t-statistics on the differences and S2F for the distribution of the t-statistics on the coefficients. 


\section{Table S3A: Summary statistics before and after the Boston bombings}

\begin{tabular}{|c|c|c|c|c|c|c|}
\hline & Before & After & Difference & T-Stat & Coeff & T-Stat \\
\hline Self-Report: Happy today? & 0.619 & 0.596 & -0.022 & 2.155 & -0.048 & -2.162 \\
\hline Self-Report: Sad today? & 0.070 & 0.077 & 0.007 & -1.284 & 0.006 & 0.470 \\
\hline Boston Region & 0.019 & 0.021 & 0.002 & -0.607 & 0.001 & 0.123 \\
\hline Female & 0.445 & 0.439 & -0.005 & 0.504 & -0.014 & -0.650 \\
\hline Age: Under 18 & 0.019 & 0.018 & -0.001 & 0.290 & -0.016 & -2.758 \\
\hline Age: $18-24$ & 0.049 & 0.053 & 0.004 & -0.832 & 0.010 & 0.999 \\
\hline Age: $25-29$ & 0.051 & 0.051 & 0.000 & -0.023 & 0.005 & 0.516 \\
\hline Age: $30-34$ & 0.055 & 0.049 & -0.006 & 1.378 & 0.015 & 1.598 \\
\hline Age: $35-44$ & 0.134 & 0.143 & 0.010 & -1.301 & 0.038 & 2.501 \\
\hline Age: $45-54$ & 0.222 & 0.232 & 0.010 & -1.170 & 0.030 & 1.914 \\
\hline Age: $55-64$ & 0.261 & 0.245 & -0.016 & 1.693 & -0.026 & -1.331 \\
\hline Age: $65 \&$ Older & 0.210 & 0.209 & -0.001 & 0.112 & -0.057 & -3.359 \\
\hline Caucasian & 0.839 & 0.838 & -0.001 & 0.125 & -0.001 & -0.058 \\
\hline Hispanic & 0.034 & 0.031 & -0.003 & 0.712 & 0.006 & 0.809 \\
\hline African American & 0.055 & 0.056 & 0.001 & -0.182 & -0.003 & -0.258 \\
\hline American Indian & 0.014 & 0.012 & -0.002 & 0.837 & -0.003 & -0.705 \\
\hline Aleut Eskimo & 0.007 & 0.006 & -0.001 & 0.392 & -0.003 & -0.989 \\
\hline Asian or Pacific Islander & 0.014 & 0.009 & -0.005 & 2.023 & -0.004 & -0.919 \\
\hline Other & 0.038 & 0.048 & 0.010 & -2.348 & 0.008 & 0.940 \\
\hline Income: Under $\$ 25 \mathrm{k}$ & 0.140 & 0.151 & 0.011 & -1.420 & -0.035 & -2.589 \\
\hline Income: $\$ 25 \mathrm{k}-\$ 35 \mathrm{k}$ & 0.100 & 0.104 & 0.004 & -0.623 & 0.003 & 0.275 \\
\hline Income: $\$ 35 \mathrm{k}-\$ 50 \mathrm{k}$ & 0.157 & 0.157 & 0.000 & -0.054 & 0.011 & 0.698 \\
\hline Income: $\$ 50 \mathrm{k}-\$ 75 \mathrm{k}$ & 0.204 & 0.194 & -0.011 & 1.273 & 0.002 & 0.097 \\
\hline Income: $\$ 75 \mathrm{k}-\$ 100 \mathrm{k}$ & 0.161 & 0.160 & -0.001 & 0.120 & 0.022 & 1.470 \\
\hline Income: $\$ 100 \mathrm{k}-\$ 125 \mathrm{k}$ & 0.095 & 0.091 & -0.004 & 0.635 & -0.017 & -1.088 \\
\hline Income: $\$ 125 \mathrm{k}-\$ 150 \mathrm{k}$ & 0.058 & 0.058 & -0.001 & 0.172 & 0.007 & 0.675 \\
\hline Income: $\$ 150 \mathrm{k}$ or more & 0.086 & 0.087 & 0.001 & -0.243 & 0.007 & 0.582 \\
\hline Observations & 4,316 & 4,623 & & & & \\
\hline
\end{tabular}

Note: Standard deviations omitted because dummies means and observations describe all moments of the distribution. Columns (3) \& (4) calculate the raw differences. Columns (5) \& (6) apply a discontinuity specification from to equation (1) using the set of controls as the dependent variables. Coeff corresponds to the coefficient, similar to specification (3) in table (1). See supplemental figure S3A for the distribution of the t-statistics on the differences and S3B for the distribution of the t-statistics on the coefficients. 


\section{Table S3B: Summary statistics before and after the Boston bombings (Non-Boston region only)}

\begin{tabular}{|c|c|c|c|c|c|c|}
\hline & Before & After & Difference & T-Stat & Coeff & T-Stat \\
\hline Self-Report: Happy today? & 0.618 & 0.597 & -0.022 & 2.077 & -0.047 & -2.065 \\
\hline Self-Report: Sad today? & 0.069 & 0.076 & 0.007 & -1.185 & 0.004 & 0.330 \\
\hline Boston Region & 0.000 & 0.000 & 0.000 & & 0.000 & \\
\hline Female & 0.442 & 0.437 & -0.005 & 0.469 & -0.010 & -0.486 \\
\hline Age: Under 18 & 0.019 & 0.017 & -0.002 & 0.745 & -0.016 & -2.830 \\
\hline Age: $18-24$ & 0.048 & 0.053 & 0.005 & -1.043 & 0.013 & 1.314 \\
\hline Age: $25-29$ & 0.049 & 0.050 & 0.002 & -0.369 & 0.005 & 0.459 \\
\hline Age: $30-34$ & 0.055 & 0.049 & -0.006 & 1.309 & 0.014 & 1.459 \\
\hline Age: $35-44$ & 0.136 & 0.144 & 0.009 & -1.200 & 0.038 & 2.468 \\
\hline Age: $45-54$ & 0.223 & 0.231 & 0.008 & -0.876 & 0.031 & 1.910 \\
\hline Age: 55-64 & 0.261 & 0.246 & -0.015 & 1.628 & -0.027 & -1.391 \\
\hline Age: $65 \&$ Older & 0.209 & 0.209 & 0.000 & -0.021 & -0.056 & -3.328 \\
\hline Caucasian & 0.839 & 0.839 & -0.001 & 0.111 & -0.001 & -0.040 \\
\hline Hispanic & 0.033 & 0.031 & -0.002 & 0.566 & 0.006 & 0.736 \\
\hline African American & 0.055 & 0.057 & 0.002 & -0.354 & -0.003 & -0.264 \\
\hline American Indian & 0.014 & 0.012 & -0.002 & 1.015 & -0.003 & -0.629 \\
\hline Aleut Eskimo & 0.007 & 0.006 & -0.001 & 0.518 & -0.004 & -1.313 \\
\hline Asian or Pacific Islander & 0.014 & 0.009 & -0.005 & 2.148 & -0.003 & -0.591 \\
\hline Other & 0.038 & 0.047 & 0.009 & -2.193 & 0.008 & 0.860 \\
\hline Income: Under $\$ 25 \mathrm{k}$ & 0.140 & 0.151 & 0.011 & -1.407 & -0.033 & -2.416 \\
\hline Income: $\$ 25 \mathrm{k}-\$ 35 \mathrm{k}$ & 0.100 & 0.105 & 0.005 & -0.741 & 0.004 & 0.338 \\
\hline Income: $\$ 35 \mathrm{k}-\$ 50 \mathrm{k}$ & 0.155 & 0.157 & 0.001 & -0.184 & 0.010 & 0.657 \\
\hline Income: $\$ 50 \mathrm{k}-\$ 75 \mathrm{k}$ & 0.205 & 0.193 & -0.012 & 1.398 & 0.001 & 0.079 \\
\hline Income: $\$ 75 \mathrm{k}-\$ 100 \mathrm{k}$ & 0.162 & 0.161 & -0.001 & 0.153 & 0.022 & 1.446 \\
\hline Income: $\$ 100 \mathrm{k}-\$ 125 \mathrm{k}$ & 0.095 & 0.091 & -0.004 & 0.669 & -0.019 & -1.168 \\
\hline Income: $\$ 125 \mathrm{k}-\$ 150 \mathrm{k}$ & 0.058 & 0.057 & 0.000 & 0.086 & 0.007 & 0.723 \\
\hline Income: $\$ 150 \mathrm{k}$ or more & 0.085 & 0.086 & 0.001 & -0.151 & 0.006 & 0.502 \\
\hline Observations & 4,235 & 4,528 & & & & \\
\hline
\end{tabular}

Note: Standard deviations omitted because dummies means and observations describe all moments of the distribution. Columns (3) \& (4) calculate the raw differences. Columns (5) \& (6) apply a discontinuity specification from to equation (1) using the set of controls as the dependent variables. Coeff corresponds to the coefficient, similar to specification (3) in table (1). See supplemental figure S3C for the distribution of the t-statistics on the differences and S3D for the distribution of the t-statistics on the coefficients. 


\section{Table S3C: Summary statistics before and after the Boston bombings (Boston region only)}

\begin{tabular}{|c|c|c|c|c|c|c|}
\hline & Before & After & Difference & T-Stat & Coeff & T-Stat \\
\hline Self-Report: Happy today? & 0.642 & 0.589 & -0.053 & 0.711 & -0.165 & -1.881 \\
\hline Self-Report: Sad today? & 0.086 & 0.116 & 0.029 & -0.645 & 0.119 & 3.567 \\
\hline Boston Region & 1.000 & 1.000 & 0.000 & & 0.000 & \\
\hline Female & 0.580 & 0.547 & -0.033 & 0.436 & -0.245 & -3.996 \\
\hline Age: Under 18 & 0.000 & 0.063 & 0.063 & -2.517 & 0.014 & 0.235 \\
\hline Age: $18-24$ & 0.123 & 0.074 & -0.050 & 1.092 & -0.206 & -1.867 \\
\hline Age: $25-29$ & 0.148 & 0.063 & -0.085 & 1.809 & 0.044 & 1.965 \\
\hline Age: $30-34$ & 0.062 & 0.042 & -0.020 & 0.578 & 0.124 & 1.030 \\
\hline Age: $35-44$ & 0.037 & 0.084 & 0.047 & -1.326 & 0.060 & 1.013 \\
\hline Age: $45-54$ & 0.136 & 0.274 & 0.138 & -2.304 & 0.023 & 0.165 \\
\hline Age: $55-64$ & 0.222 & 0.189 & -0.033 & 0.532 & 0.067 & 0.738 \\
\hline Age: 65 \& Older & 0.272 & 0.211 & -0.061 & 0.938 & -0.126 & -0.509 \\
\hline Caucasian & 0.802 & 0.800 & -0.002 & 0.041 & -0.041 & -0.520 \\
\hline Hispanic & 0.074 & 0.042 & -0.032 & 0.891 & 0.049 & 0.839 \\
\hline African American & 0.062 & 0.021 & -0.041 & 1.324 & 0.008 & 0.155 \\
\hline American Indian & 0.000 & 0.021 & 0.021 & -1.422 & -0.018 & -1.631 \\
\hline Aleut Eskimo & 0.012 & 0.021 & 0.009 & -0.452 & 0.068 & 1.098 \\
\hline Asian or Pacific Islander & 0.025 & 0.032 & 0.007 & -0.275 & -0.115 & -1.213 \\
\hline Other & 0.025 & 0.063 & 0.038 & -1.261 & 0.049 & 1.704 \\
\hline Income: Under $\$ 25 \mathrm{k}$ & 0.148 & 0.158 & 0.010 & -0.178 & -0.170 & -2.665 \\
\hline Income: $\$ 25 \mathrm{k}-\$ 35 \mathrm{k}$ & 0.086 & 0.053 & -0.034 & 0.867 & -0.053 & -1.061 \\
\hline Income: $\$ 35 \mathrm{k}-\$ 50 \mathrm{k}$ & 0.222 & 0.168 & -0.054 & 0.890 & 0.046 & 0.416 \\
\hline Income: $\$ 50 \mathrm{k}-\$ 75 \mathrm{k}$ & 0.173 & 0.221 & 0.048 & -0.801 & 0.021 & 0.119 \\
\hline Income: $\$ 75 \mathrm{k}-\$ 100 \mathrm{k}$ & 0.086 & 0.105 & 0.019 & -0.423 & 0.028 & 0.845 \\
\hline Income: $\$ 100 \mathrm{k}-\$ 125 \mathrm{k}$ & 0.074 & 0.084 & 0.010 & -0.247 & 0.100 & 5.703 \\
\hline Income: $\$ 125 \mathrm{k}-\$ 150 \mathrm{k}$ & 0.086 & 0.063 & -0.023 & 0.579 & -0.037 & -0.170 \\
\hline Income: $\$ 150 \mathrm{k}$ or more & 0.123 & 0.147 & 0.024 & -0.461 & 0.066 & 0.494 \\
\hline Observations & 81 & 95 & & & & \\
\hline
\end{tabular}

Note: Standard deviations omitted because dummies means and observations describe all moments of the distribution. Columns (3) \& (4) calculate the raw differences. Columns (5) \& (6) apply a discontinuity specification from to equation (1) using the set of controls as the dependent variables. Coeff corresponds to the coefficient, similar to specification (3) in table (1). See supplemental figure S3E for the distribution of the t-statistics on the differences and S3F for the distribution of the t-statistics on the coefficients. 


\section{Table S4A: Democrat sadness one week surrounding 2012 election}

\begin{tabular}{|c|c|c|c|c|c|}
\hline \multirow[b]{2}{*}{ Independent variables } & \multicolumn{5}{|c|}{ Dependent variable: Are you sad today? } \\
\hline & $(1)$ & $(2)$ & (3) & $(4)$ & $(5)$ \\
\hline Post-election & $\begin{array}{l}.036 \\
(.030)\end{array}$ & $\begin{array}{l}-.001 \\
(.011)\end{array}$ & $\begin{array}{c}.014 \\
(.023)\end{array}$ & $\begin{array}{l}.013 \\
(.026)\end{array}$ & $\begin{array}{l}-.051 \\
(.056)\end{array}$ \\
\hline $\begin{array}{l}\text { Post-election } * \text { One de- } \\
\text { gree polynomial of days }\end{array}$ & No & No & Yes & Yes & Yes \\
\hline $\begin{array}{l}\text { Post-election }{ }^{*} \text { Three de- } \\
\text { gree polynomial of days }\end{array}$ & No & No & No & No & Yes \\
\hline $\begin{array}{l}\text { Socio - Demographic } \& \\
\text { MSA Controls }\end{array}$ & No & No & No & Yes & Yes \\
\hline Time restriction & + /- one day & +/- one week & +/- one week & +/- one week & +/- one week \\
\hline Observations & 265 & 1,553 & 1,553 & 1,553 & 1,553 \\
\hline
\end{tabular}

\section{Table S4B: Republican sadness one week surrounding 2012 election}

\begin{tabular}{|c|c|c|c|c|c|}
\hline \multirow[b]{2}{*}{ Independent variables } & \multicolumn{5}{|c|}{ Dependent variable: Are you sad today? } \\
\hline & $(1)$ & $(2)$ & $(3)$ & $(4)$ & $(6)$ \\
\hline Post-election & $\begin{array}{l}.423^{* * *} \\
(.039)\end{array}$ & $\begin{array}{c}.149^{* * *} \\
(.012)\end{array}$ & $\begin{array}{l}.273^{* * *} \\
(.028)\end{array}$ & $\begin{array}{c}.268^{* * *} \\
(.031)\end{array}$ & $\begin{array}{l}.450^{* * *} \\
(.064)\end{array}$ \\
\hline $\begin{array}{l}\text { Post-election * One de- } \\
\text { gree polynomial of days }\end{array}$ & No & No & Yes & Yes & No \\
\hline $\begin{array}{l}\text { Post-election * Three de- } \\
\text { gree polynomial of days }\end{array}$ & No & No & No & No & Yes \\
\hline $\begin{array}{l}\text { Socio - Demographic \& } \\
\text { MSA Controls }\end{array}$ & No & No & No & Yes & Yes \\
\hline Time restriction & + /- one day & +/- one week & +/- one week & + /- one week & +/- one week \\
\hline Observations & 465 & 2,934 & 2,934 & 2,934 & 2,934 \\
\hline
\end{tabular}

Note: ${ }^{*},{ }^{* *}$, and ${ }^{* * *}$ indicate significance at the $10 \%, 5 \%$, and $1 \%$ confidence levels, respectively. Standard errors are clustered at the Metropolitan level. Socio-demographic controls include gender, age indicators, race indicators, and income indicators. MSA controls included indicators for the metropolitan statistical area. 


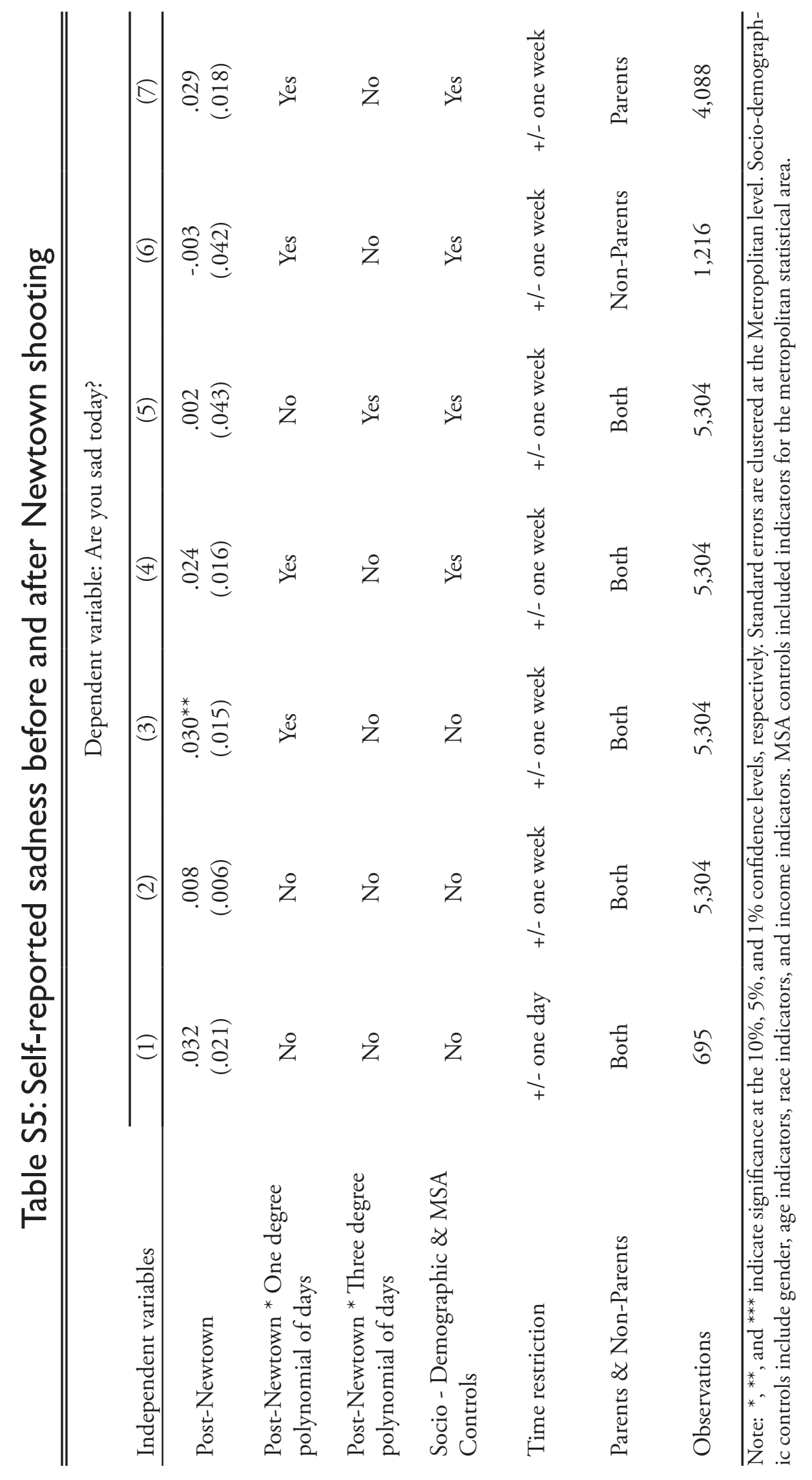




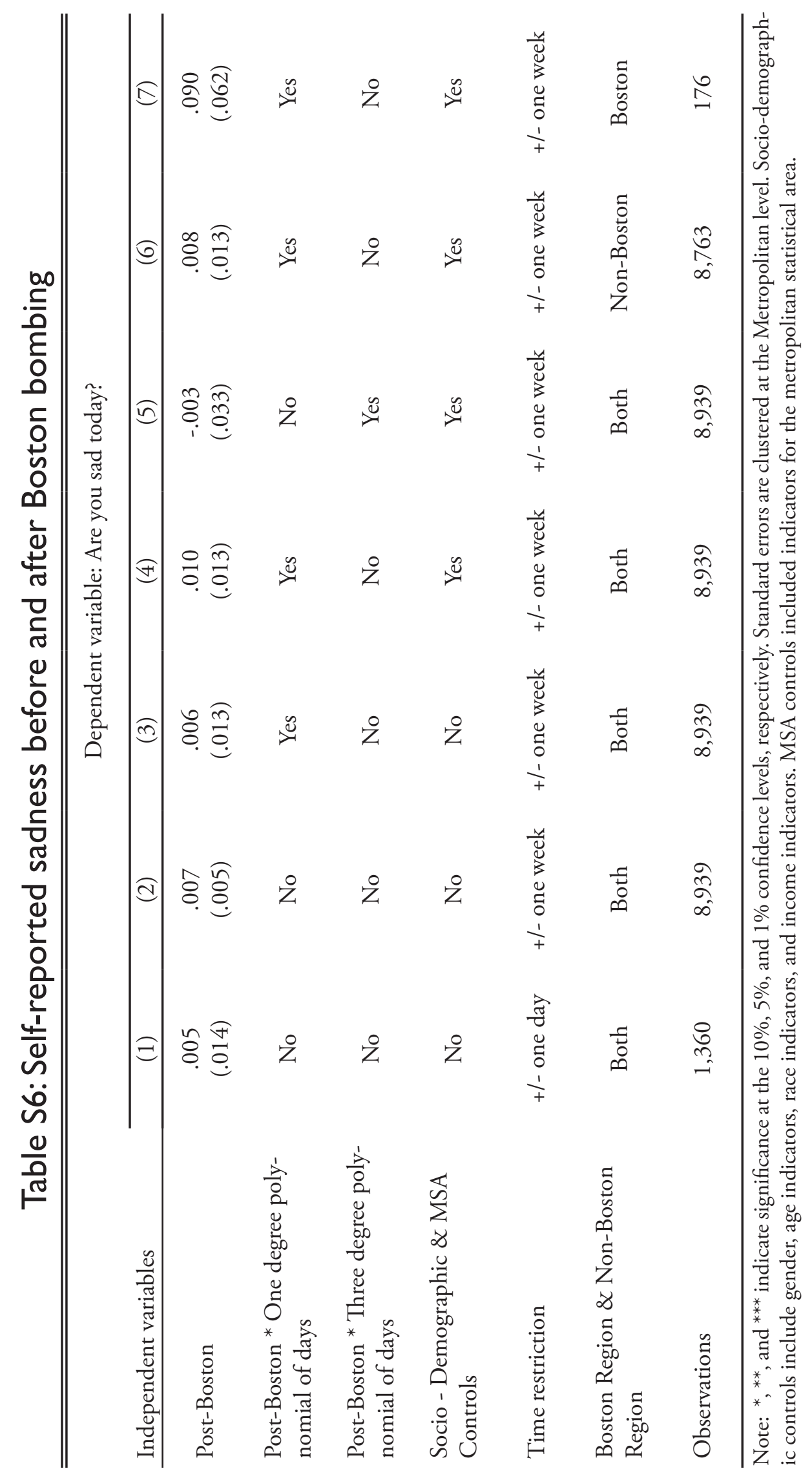




\section{Table S7A: Democrat happiness one week surrounding 2012 election}

\begin{tabular}{|c|c|c|c|c|c|}
\hline \multirow[b]{2}{*}{ Independent variables } & \multicolumn{5}{|c|}{ Dependent variable: Happiness on scale of 1-5 } \\
\hline & $(1)$ & $(2)$ & (3) & $(4)$ & $(5)$ \\
\hline Post-election & $\begin{array}{l}.073 \\
(.106)\end{array}$ & $\begin{array}{l}.073^{*} \\
(.037)\end{array}$ & $\begin{array}{l}.088 \\
(.096)\end{array}$ & $\begin{array}{l}.097 \\
(.110)\end{array}$ & $\begin{array}{l}.226 \\
(.247)\end{array}$ \\
\hline $\begin{array}{l}\text { Post-election * One de- } \\
\text { gree polynomial of days }\end{array}$ & No & No & Yes & Yes & No \\
\hline $\begin{array}{l}\text { Post-election }{ }^{*} \text { Three de- } \\
\text { gree polynomial of days }\end{array}$ & No & No & No & No & Yes \\
\hline $\begin{array}{l}\text { Socio - Demographic \& } \\
\text { MSA Controls }\end{array}$ & No & No & No & Yes & Yes \\
\hline Time restriction & $+/$ one day & +/- one week & +/- one week & +/- one week & +/- one week \\
\hline Observations & 265 & 1,553 & 1,553 & 1,553 & 1,553 \\
\hline
\end{tabular}

\section{Table S7B: Republican happiness one week surrounding 2012 election}

\begin{tabular}{|c|c|c|c|c|c|}
\hline \multirow[b]{2}{*}{ Independent variables } & \multicolumn{5}{|c|}{ Dependent variable: Happiness on scale of 1-5 } \\
\hline & $(1)$ & $(2)$ & (3) & $(4)$ & $(6)$ \\
\hline Post-election & $\begin{array}{c}-1.139^{* * *} \\
(.104)\end{array}$ & $\begin{array}{c}-.448^{* * *} \\
(.034)\end{array}$ & $\begin{array}{c}-.796^{* * *} \\
(.074)\end{array}$ & $\begin{array}{c}-.789^{* * *} \\
(.081)\end{array}$ & $\begin{array}{l}-1.231^{* * *} \\
(.217)\end{array}$ \\
\hline $\begin{array}{l}\text { Post-election * One de- } \\
\text { gree polynomial of days }\end{array}$ & No & No & Yes & Yes & No \\
\hline $\begin{array}{l}\text { Post-election }{ }^{*} \text { Three de- } \\
\text { gree polynomial of days }\end{array}$ & No & No & No & No & Yes \\
\hline $\begin{array}{l}\text { Socio - Demographic \& } \\
\text { MSA Controls }\end{array}$ & No & No & No & Yes & Yes \\
\hline Time restriction & +/- one day & +/- one week & +/- one week & +/- one week & +/- one week \\
\hline Observations & 465 & 2,934 & 2,934 & 2,934 & 2,934 \\
\hline
\end{tabular}


Figure SIA: Kernel density distribution for mean differences t-statistics from Table SIA

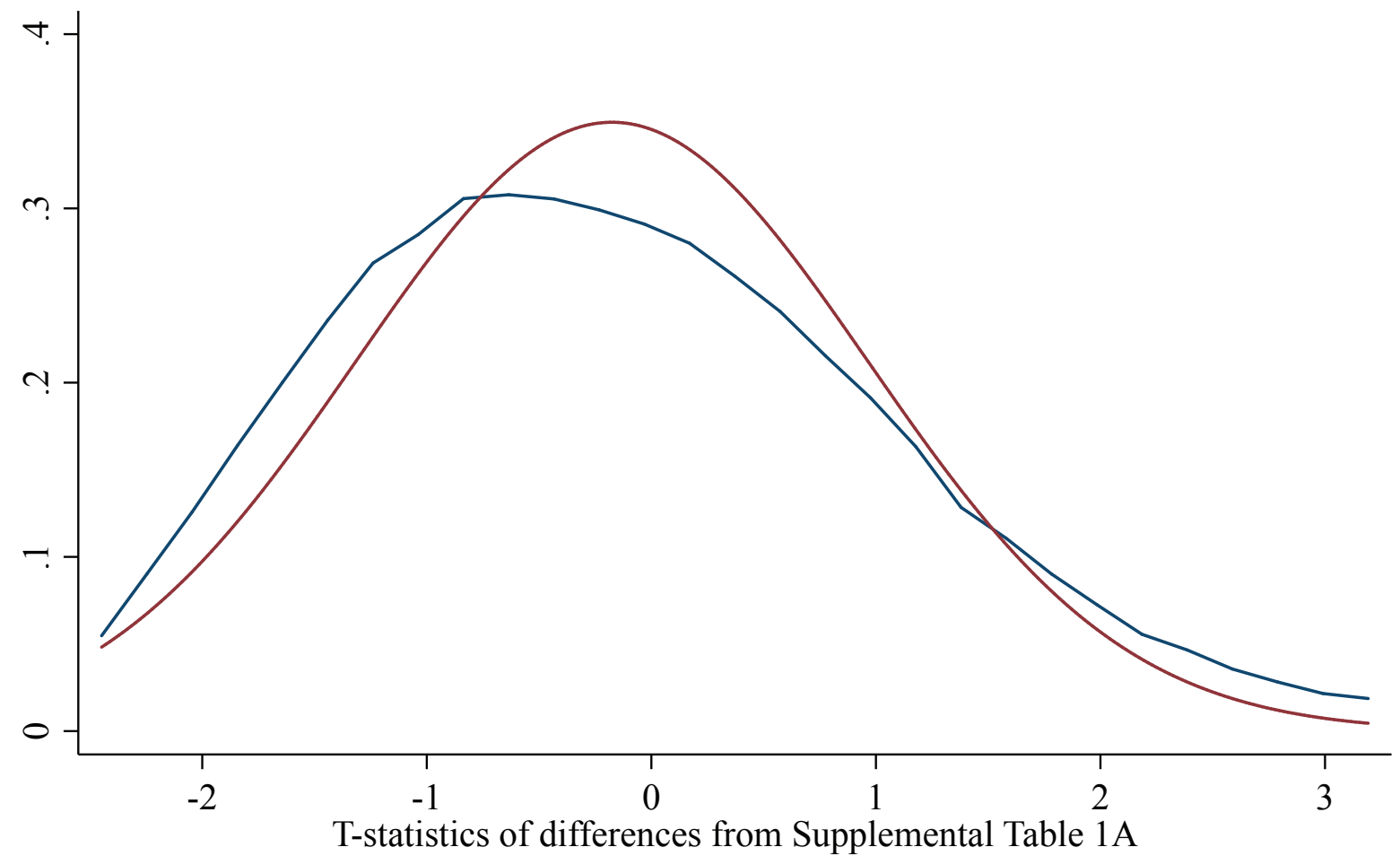

Figure SIB: Kernel density distribution for coefficient t-statistics from Table SIA

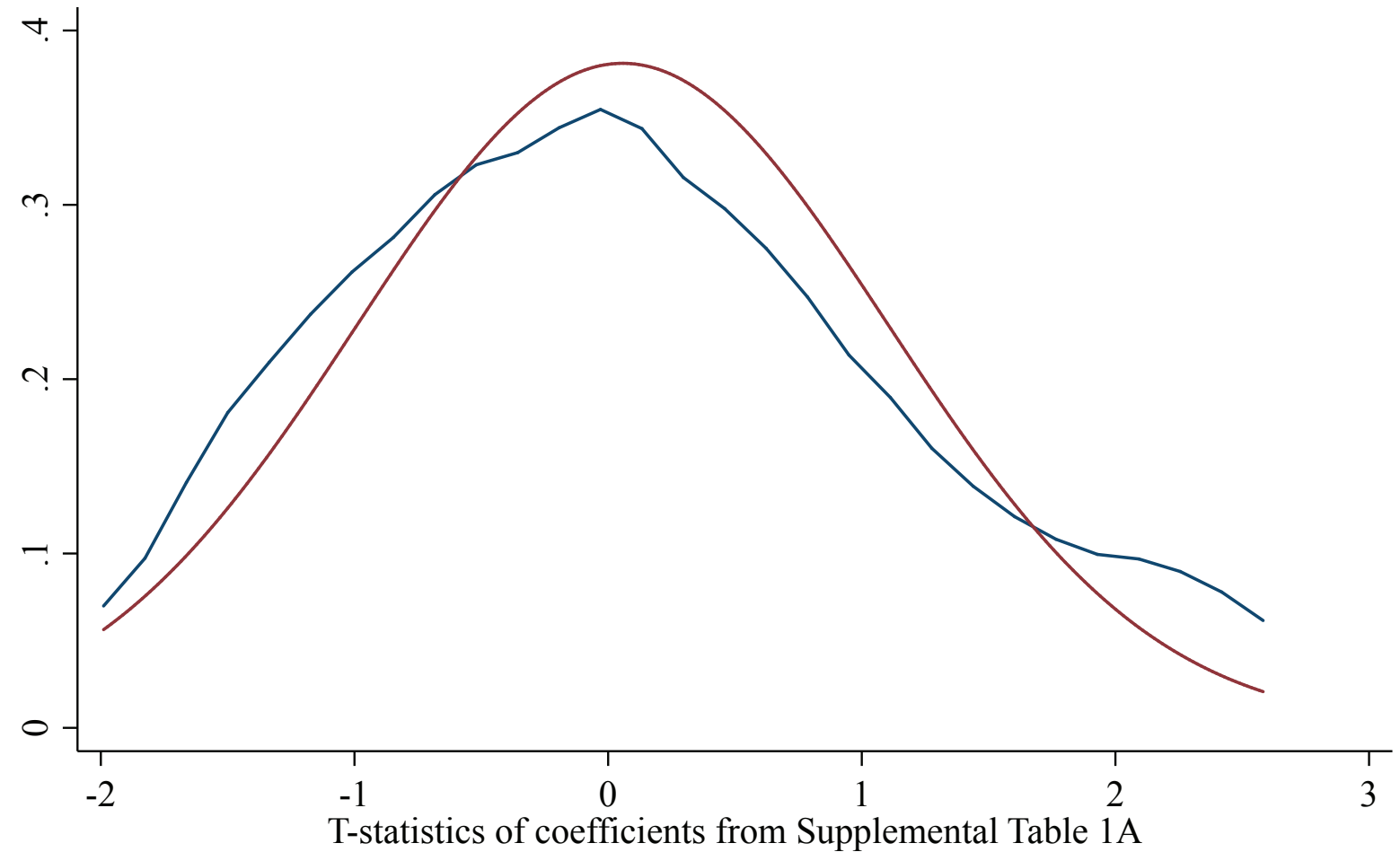

Note: Normal approximation shown with kernel density estimate. Variables Happy \& Sad omitted from density estimation because they are dependent variables. 
Figure SIC: Kernel density distribution for mean differences t-statistics from Table SIB

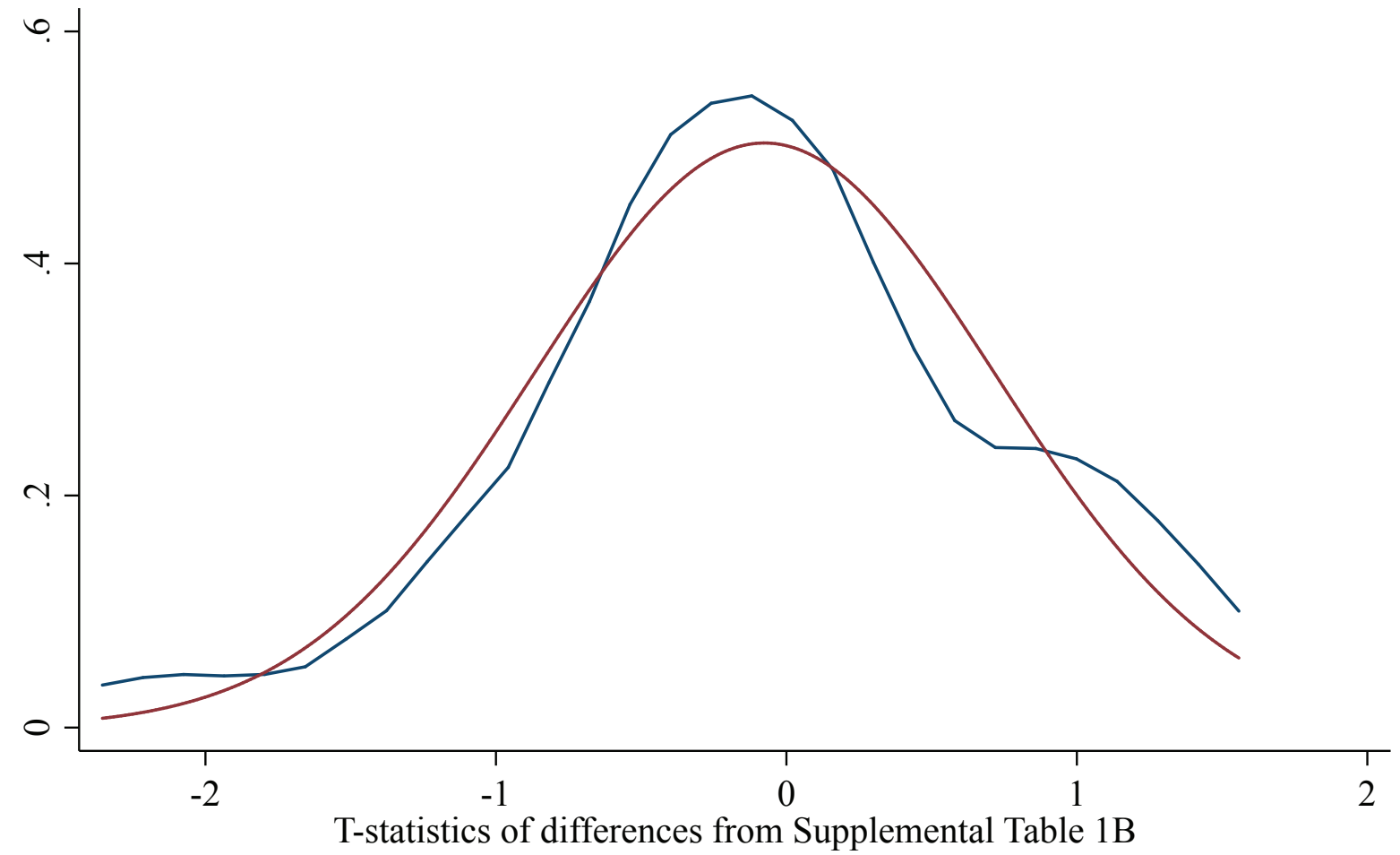

Figure SID: Kernel density distribution for coefficient t-statistics from Table SIB

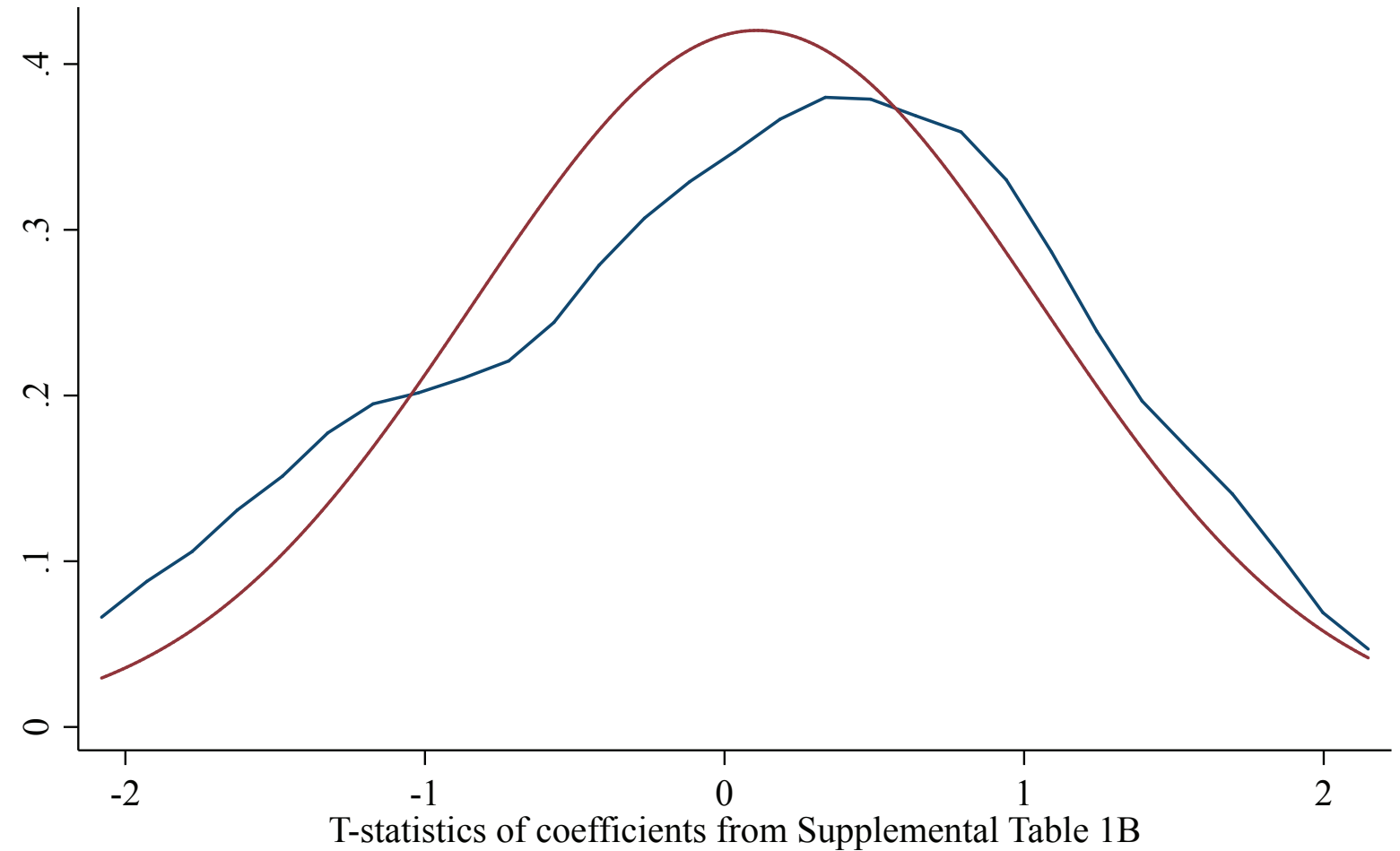

Note: Normal approximation shown with kernel density estimate. Variables Happy \& Sad omitted from density estimation because they are dependent variables. 
Figure SIE: Kernel density distribution for mean differences t-statistics from Table SIC

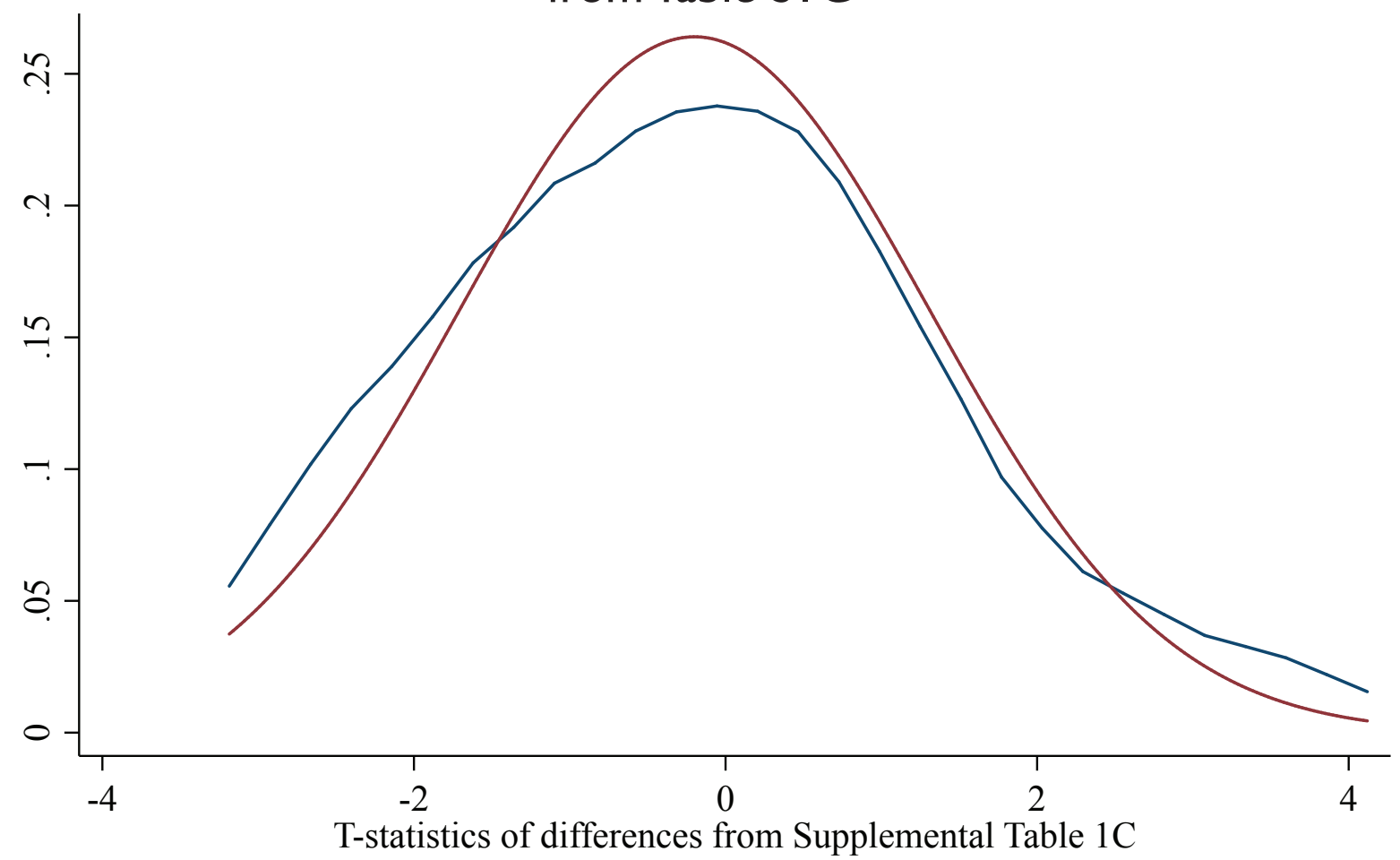

Figure SIF: Kernel density distribution for coefficient t-statistics from Table SIC

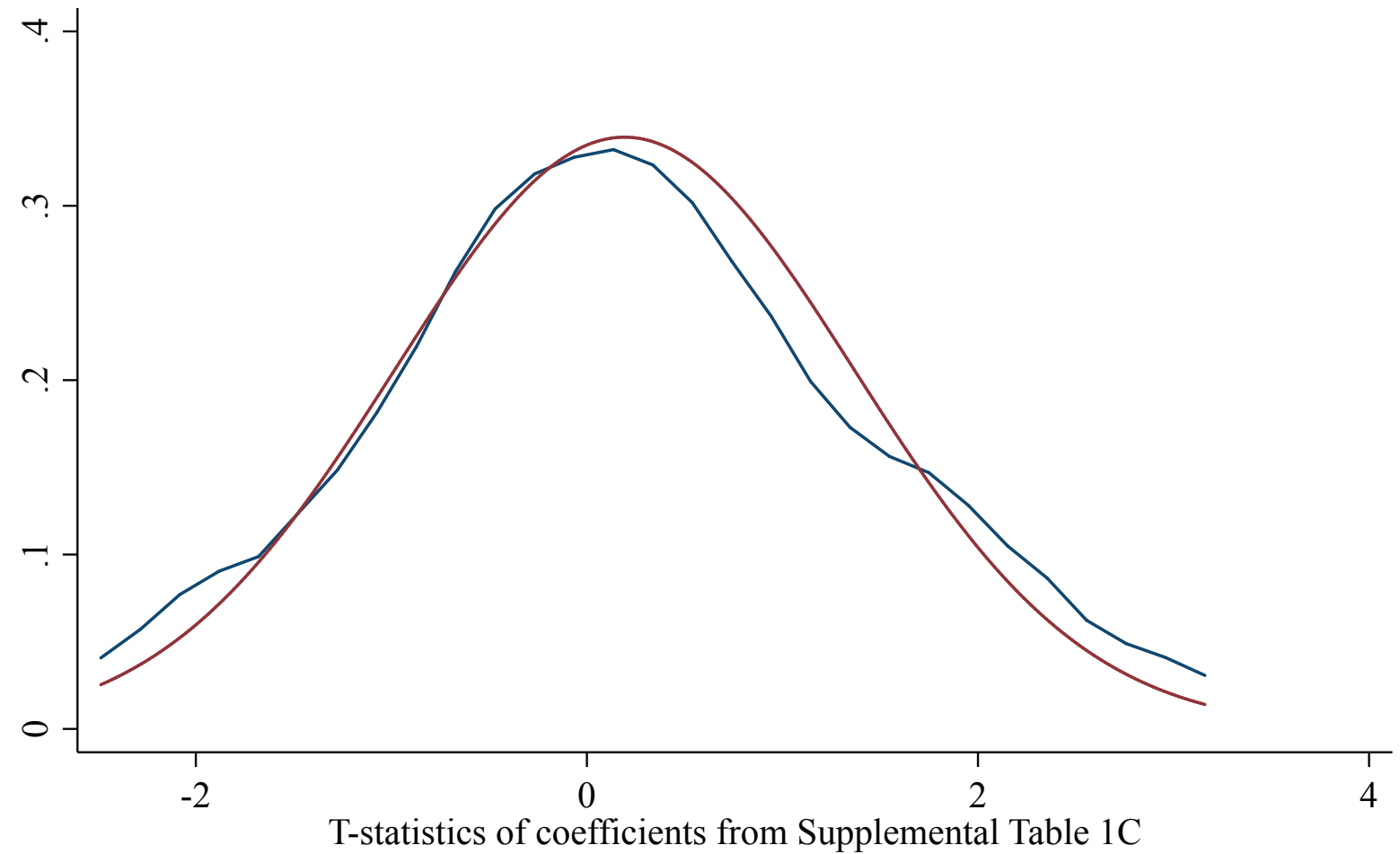

Note: Normal approximation shown with kernel density estimate. Variables Happy \& Sad omitted from density estimation because they are dependent variables. 
Figure S2A: Kernel density distribution for mean differences t-statistics from Table S2A

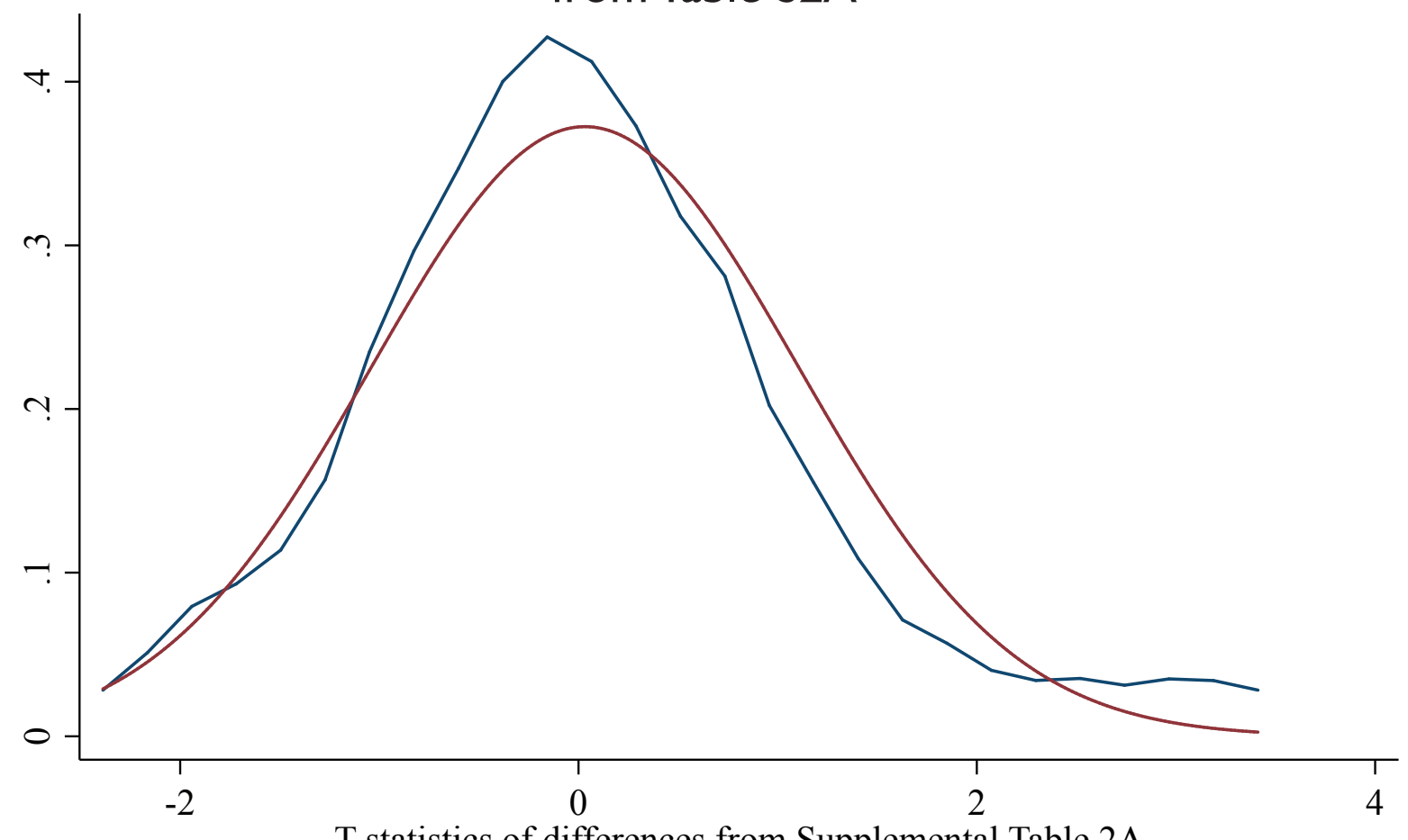

T-statistics of differences from Supplemental Table 2A

Figure S2B: Kernel density distribution for coefficient t-statistics from Table S2A

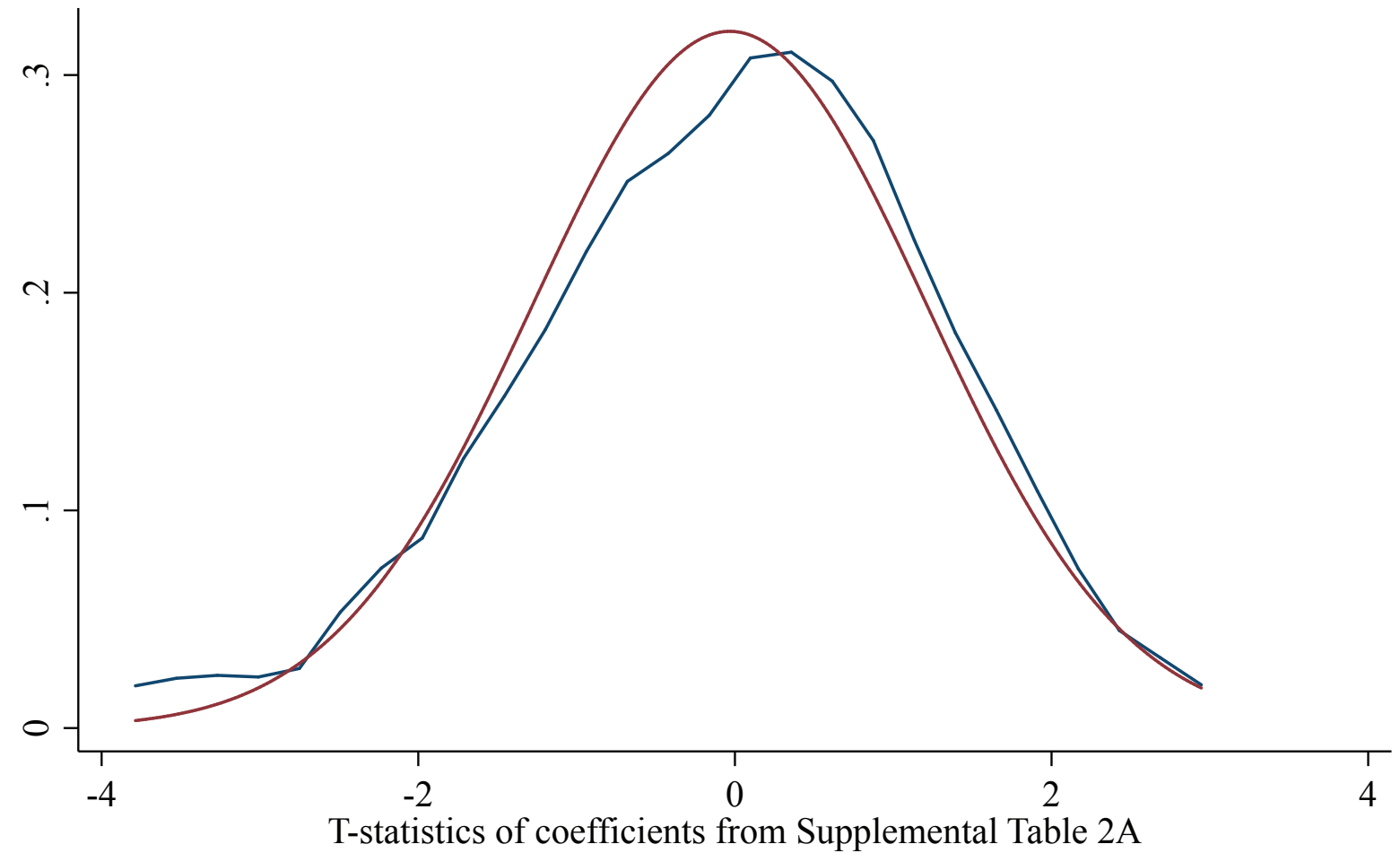

Note: Normal approximation shown with kernel density estimate. Variables Happy \& Sad omitted from density estimation because they are dependent variables. 
Figure S2C: Kernel density distribution for mean differences t-statistics from Table S2B

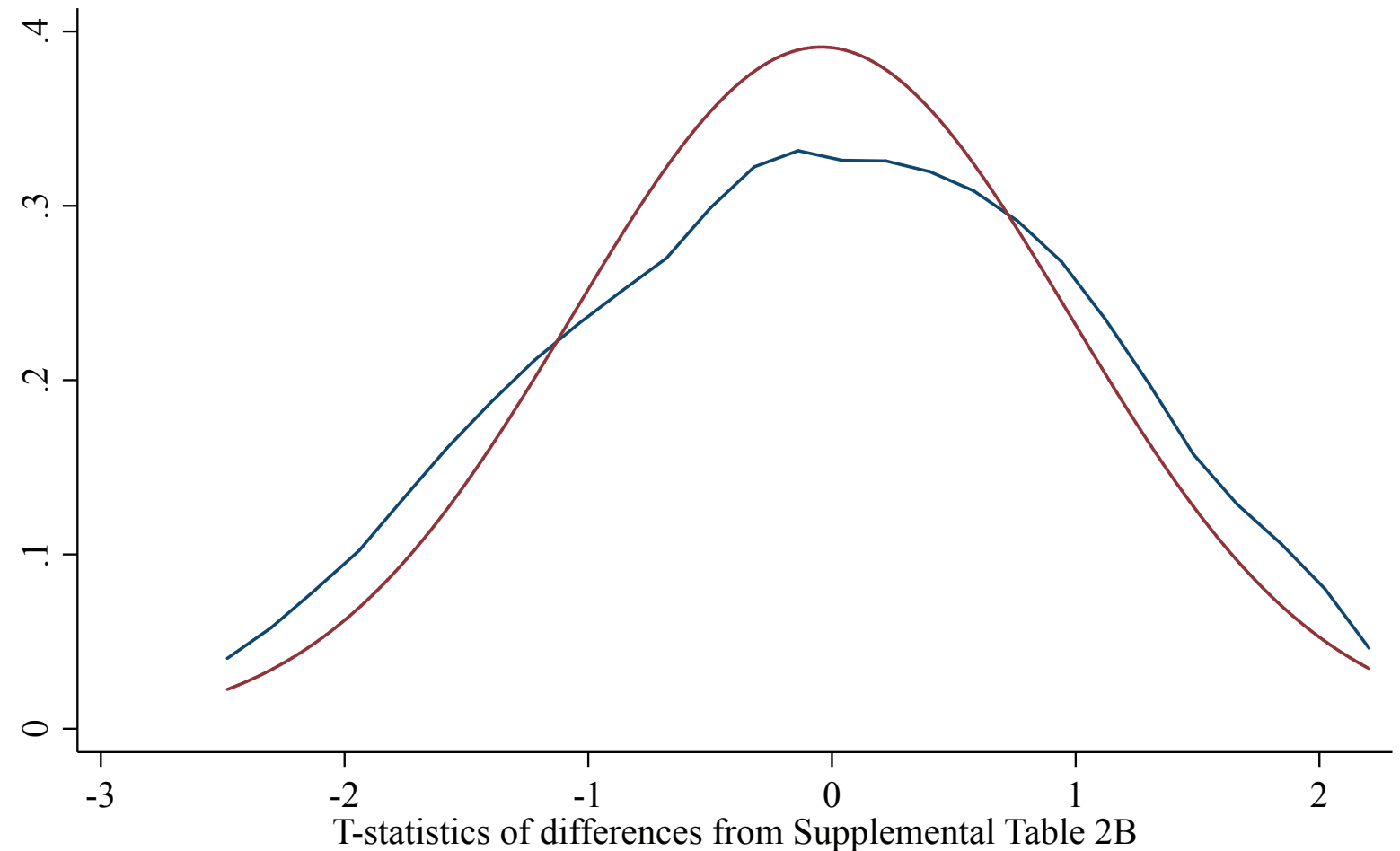

Figure S2D: Kernel density distribution for coefficient t-statistics from Table S2B

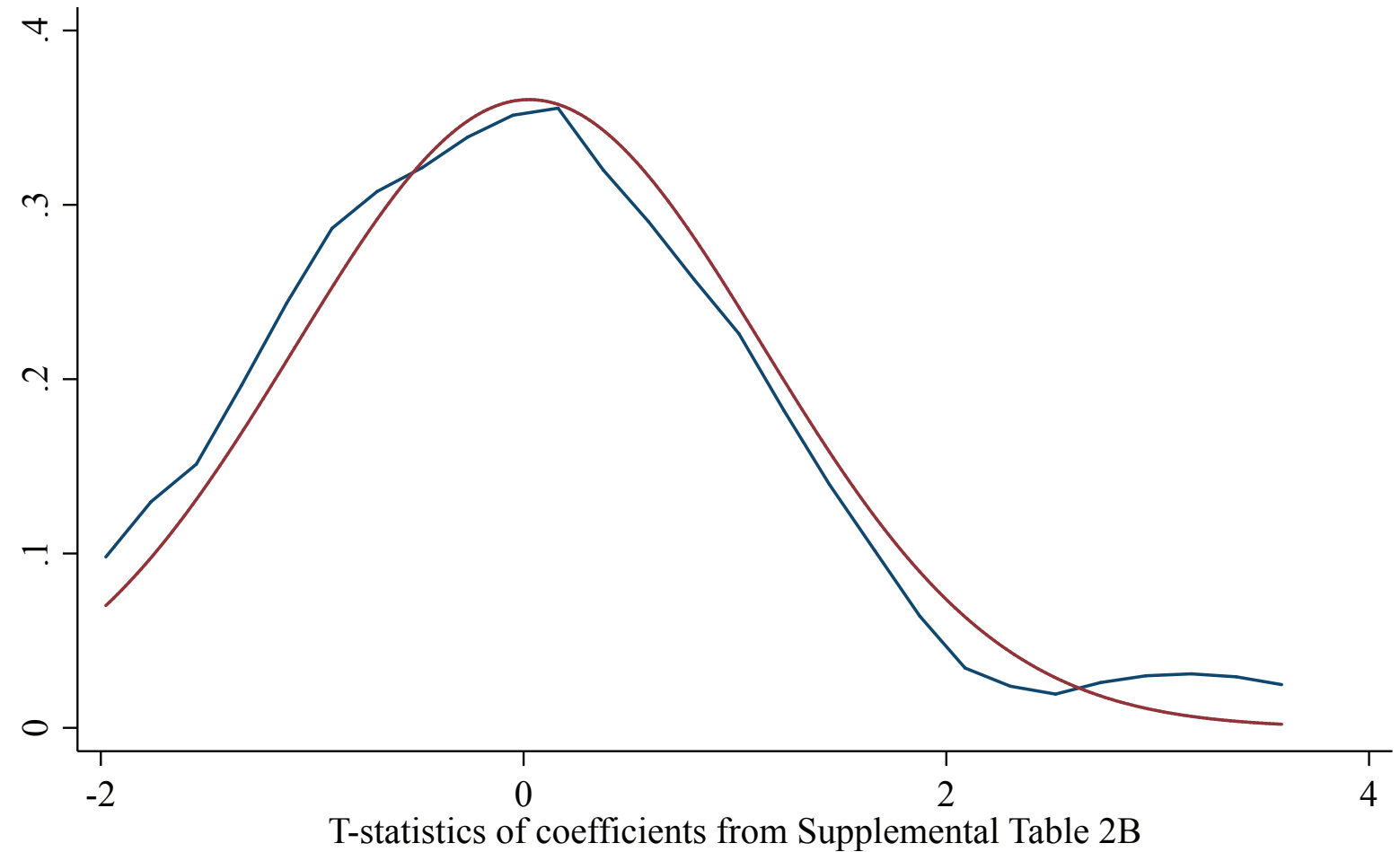

Note: Normal approximation shown with kernel density estimate. Variables Happy \& Sad omitted from density estimation because they are dependent variables. 
Figure S2E: Kernel density distribution for mean differences t-statistics from Table S2C

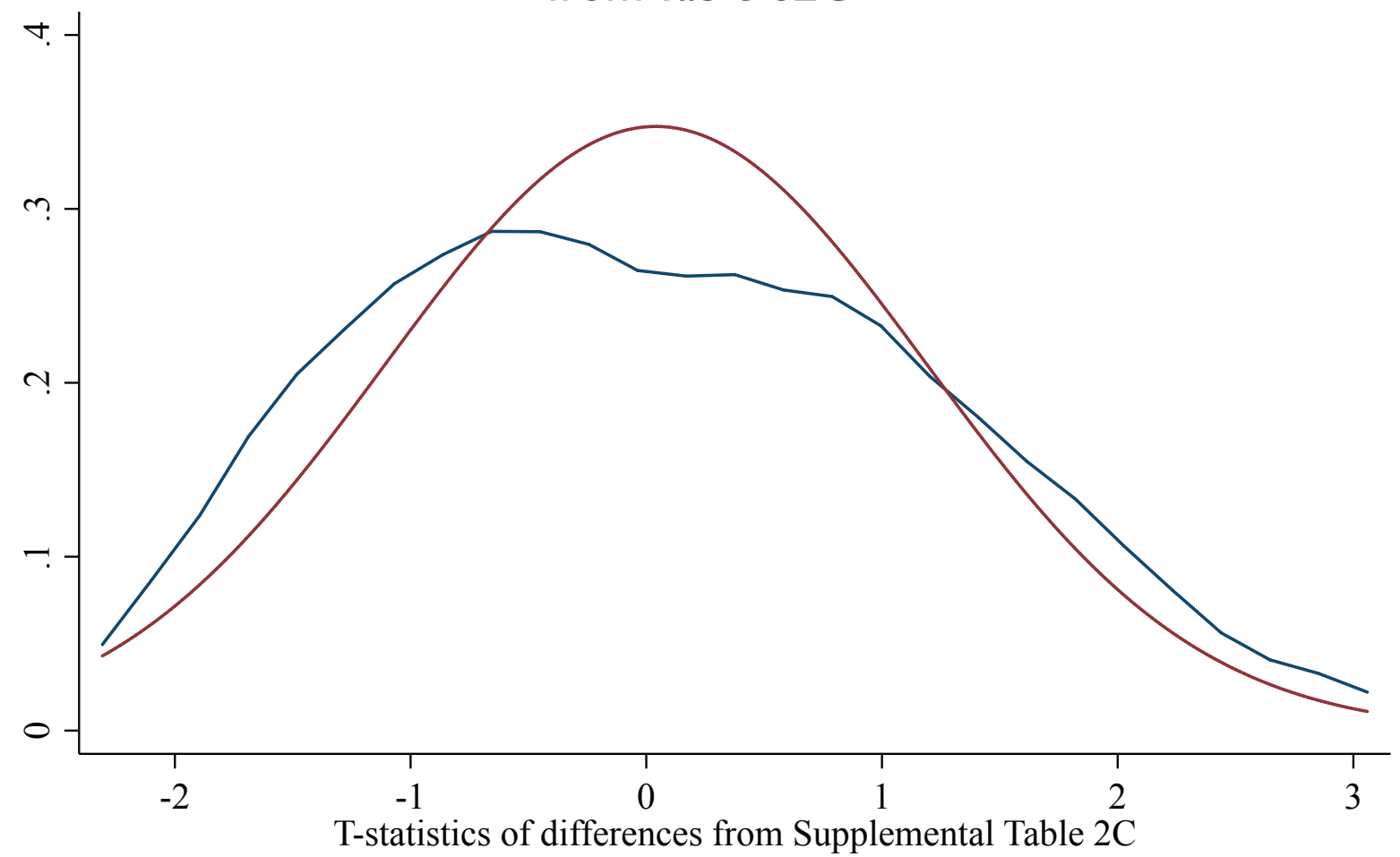

Figure S2F: Kernel density distribution for coefficient t-statistics from

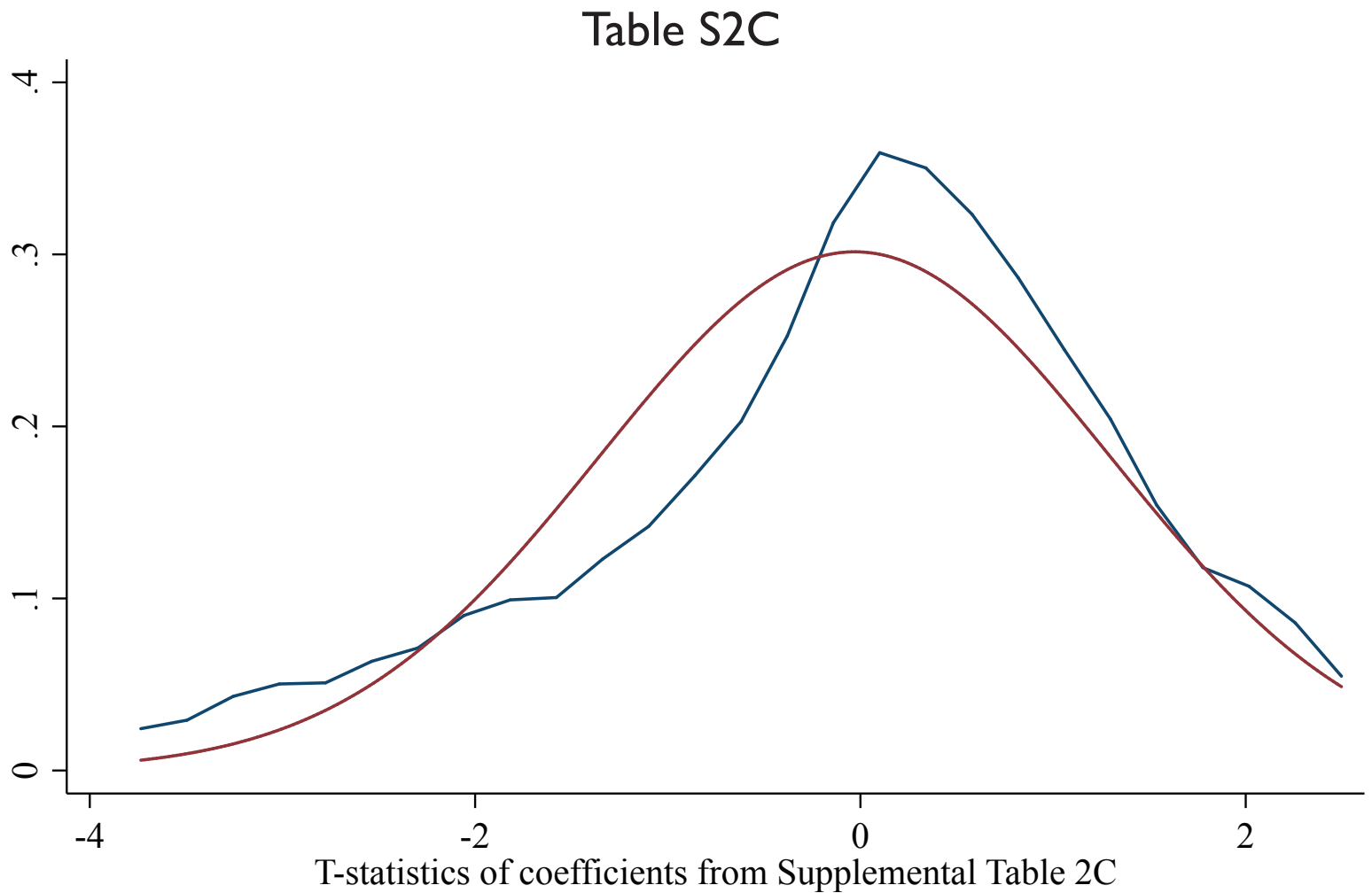

Note: Normal approximation shown with kernel density estimate. Variables Happy \& Sad omitted from density estimation because they are dependent variables. 
Figure S3A: Kernel density distribution for mean differences t-statistics from Table S3A

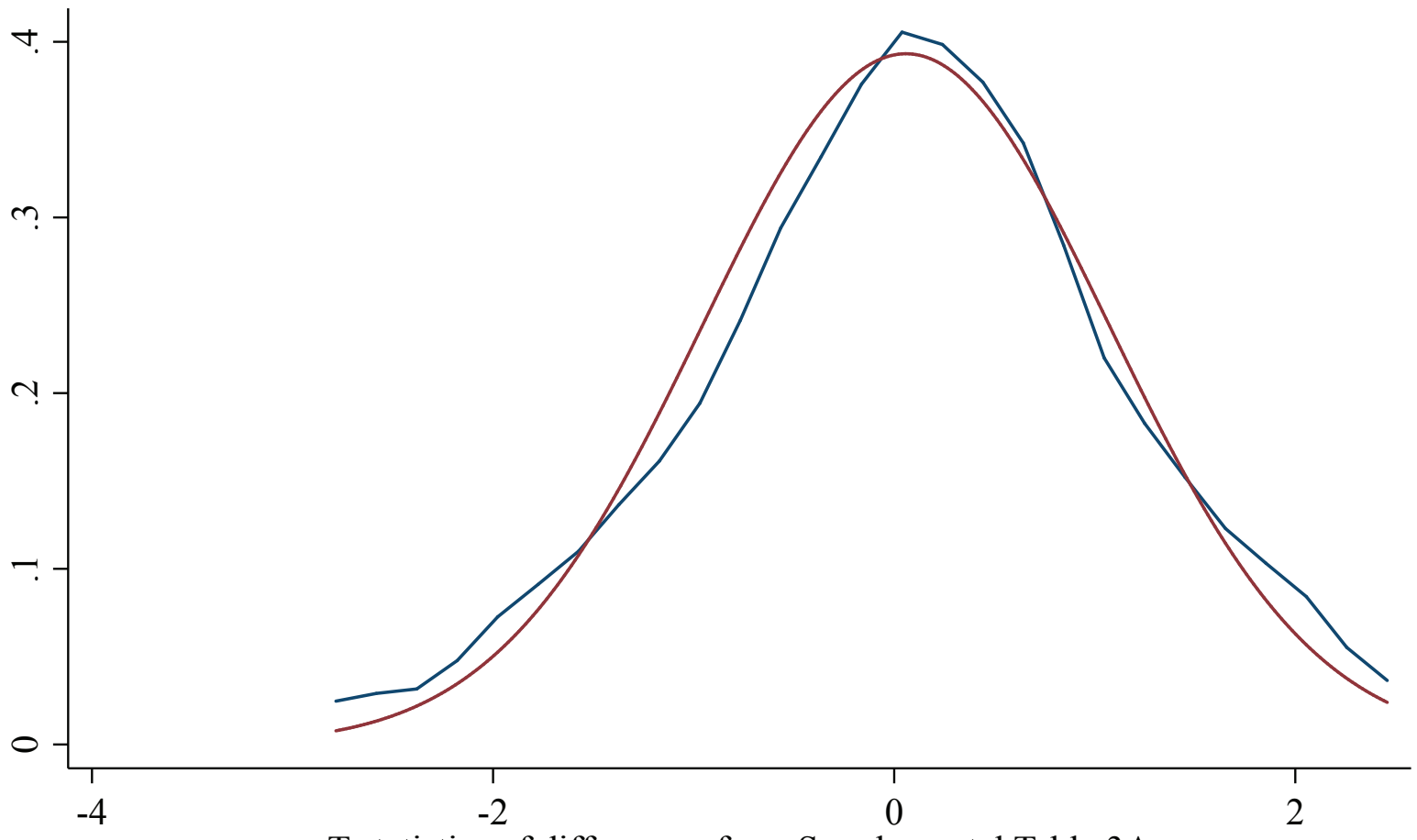

T-statistics of differences from Supplemental Table 3A

Figure S3B: Kernel density distribution for coefficient t-statistics from Table S3A

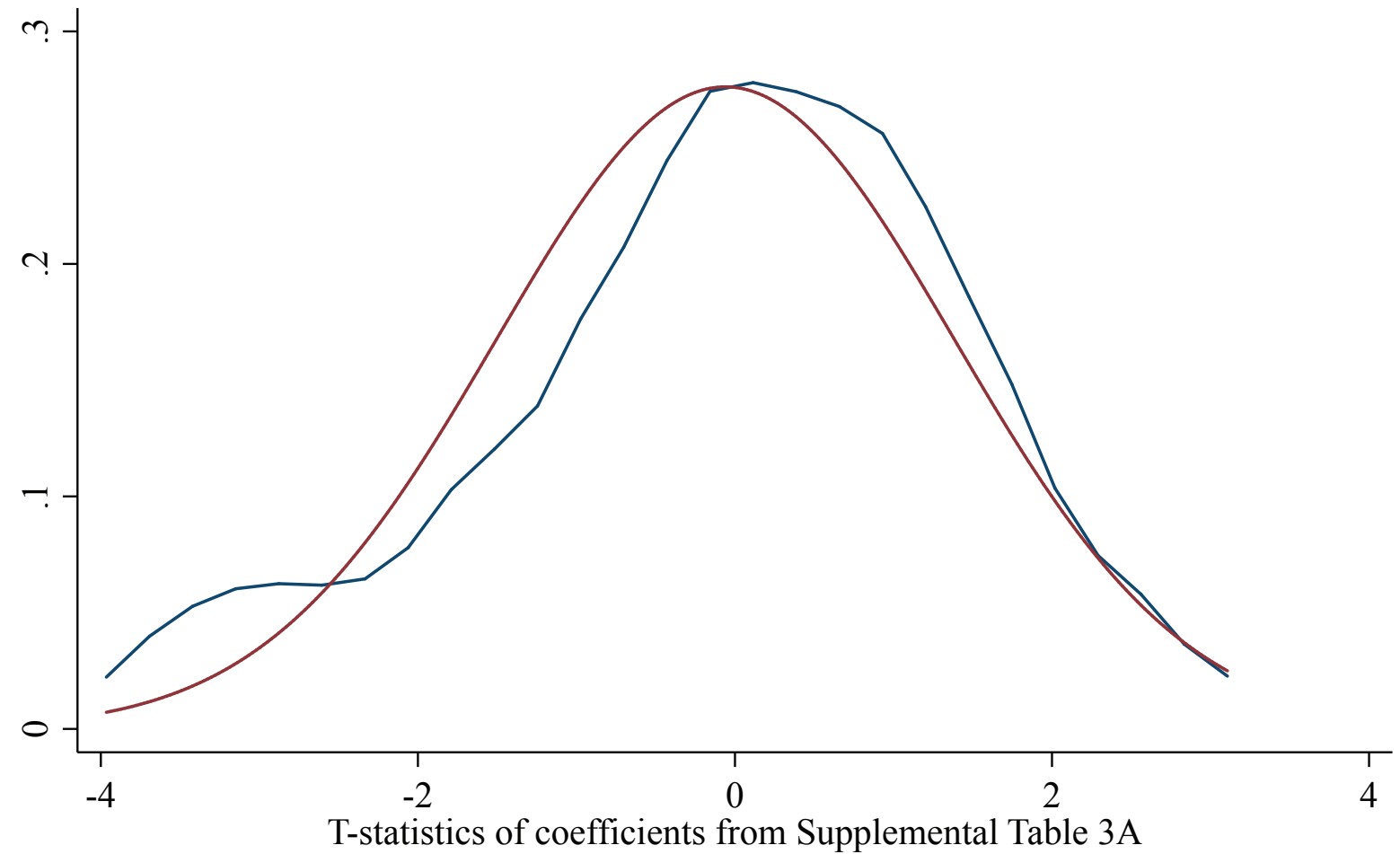

Note: Normal approximation shown with kernel density estimate. Variables Happy \& Sad omitted from density estimation because they are dependent variables. 
Figure S3C: Kernel density distribution for mean differences t-statistics from Table S3B

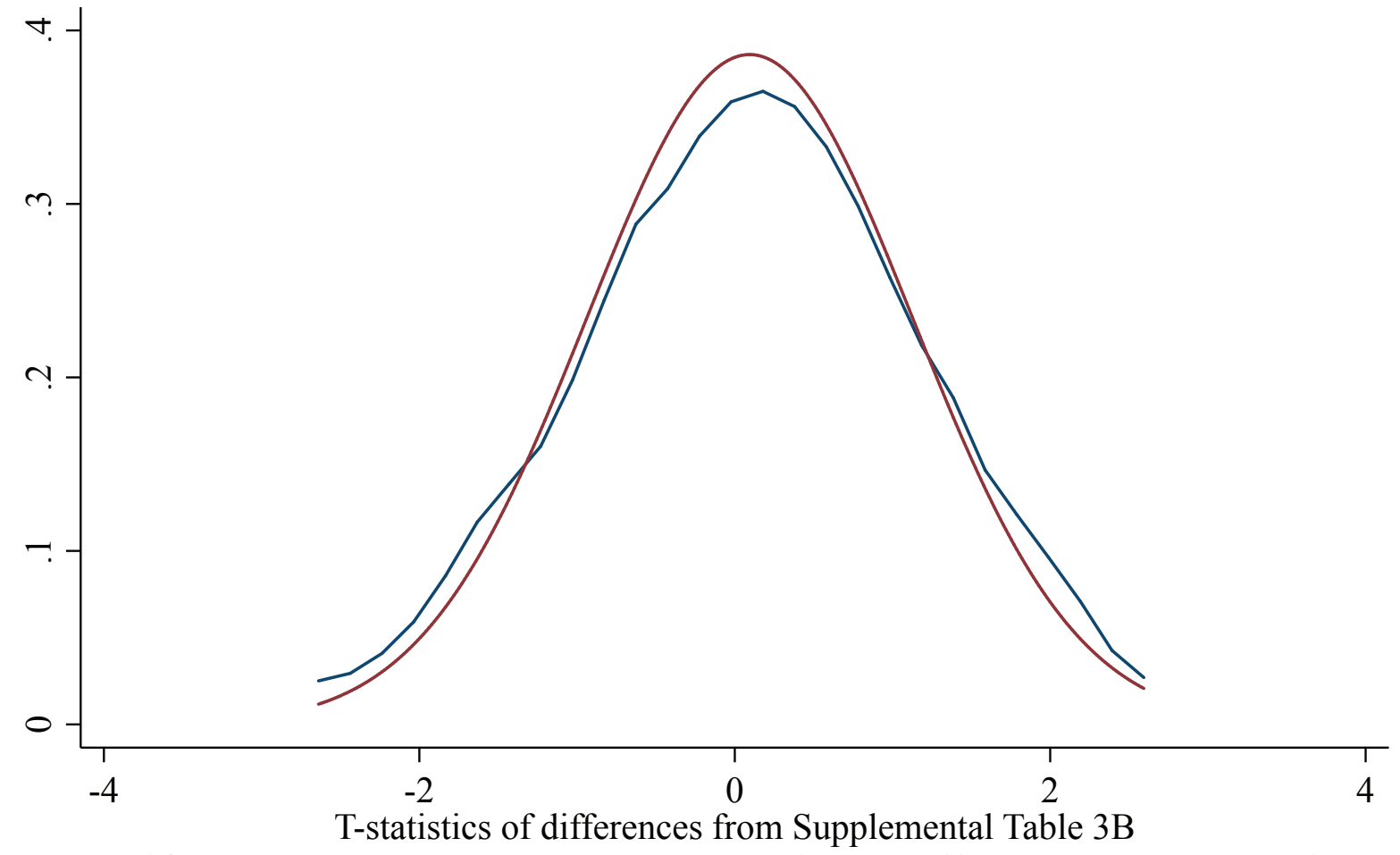

Figure S3D: Kernel density distribution for coefficient t-statistics from Table S3B

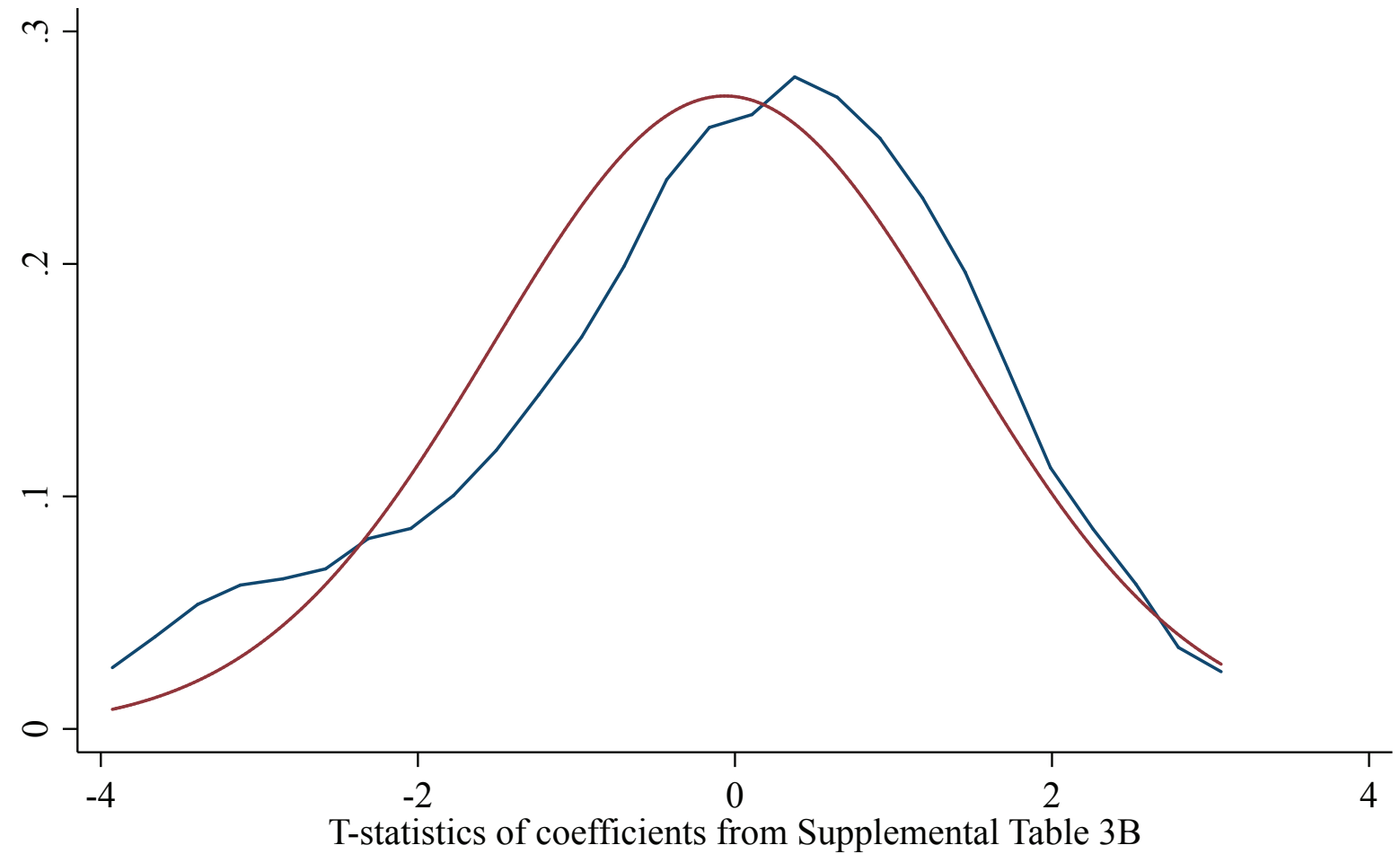

Note: Normal approximation shown with kernel density estimate. Variables Happy \& Sad omitted from density estimation because they are dependent variables. 
Figure S3E: Kernel density distribution for mean differences t-statistics from Table S3C

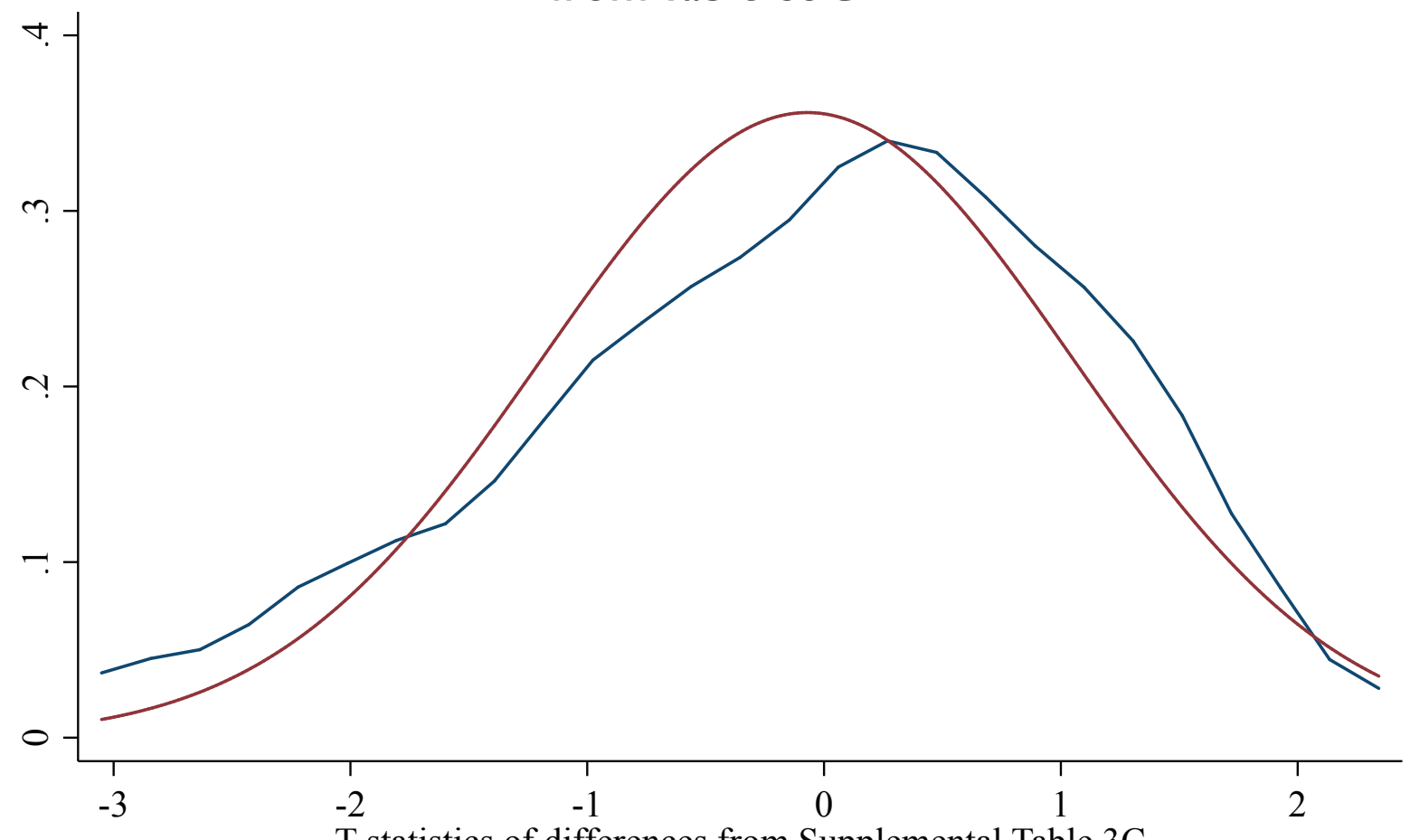

T-statistics of differences from Supplemental Table 3C

Figure S3F: Kernel density distribution for coefficient $t$-statistics from Table S3C

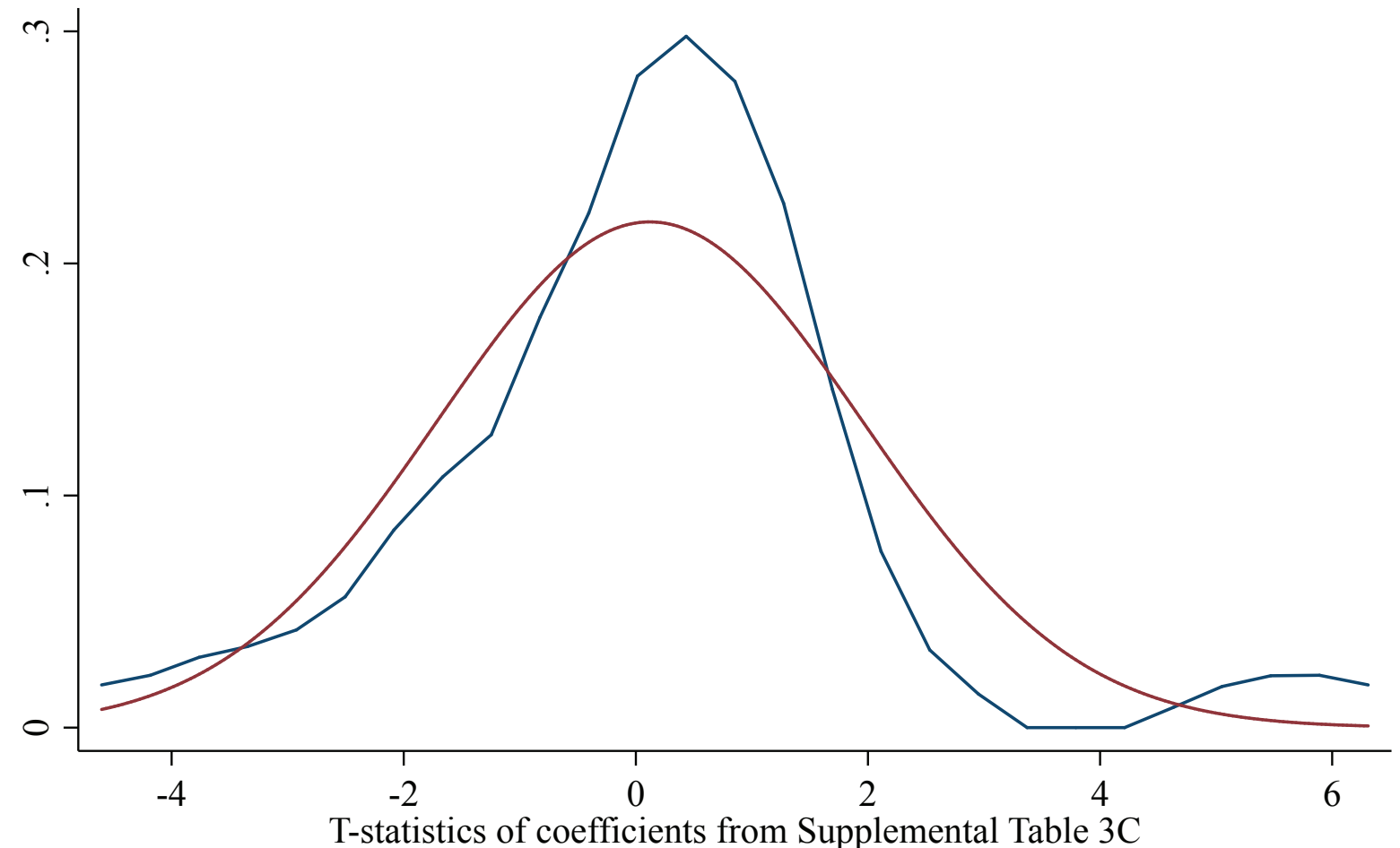

Note: Normal approximation shown with kernel density estimate. Variables Happy \& Sad omitted from density estimation because they are dependent variables. 
Supplemental Figure S4A:Table (IA) column (4) regression where time window changes

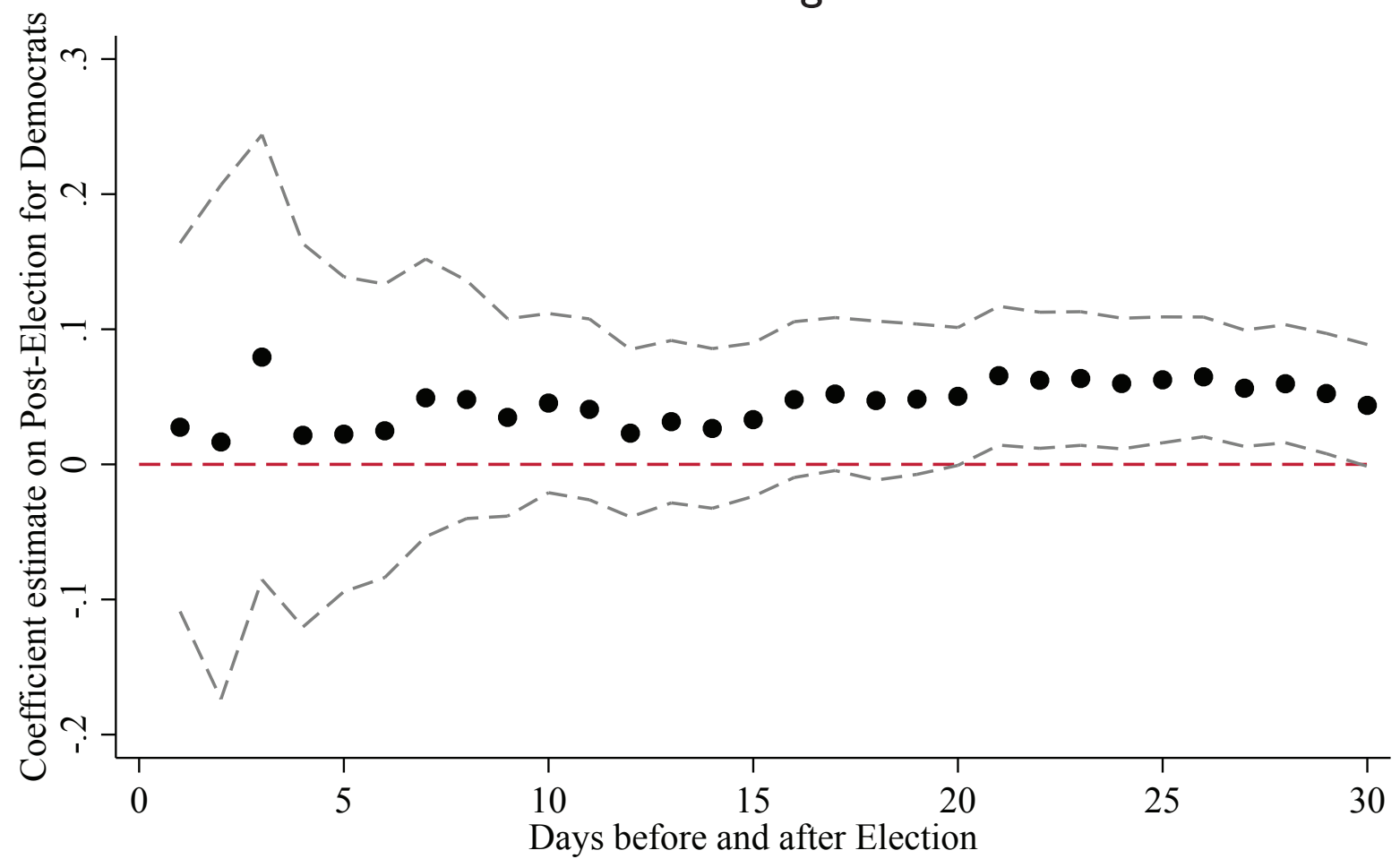

Supplemental Figure S4B:Table (IB) column (4) regression where time window changes

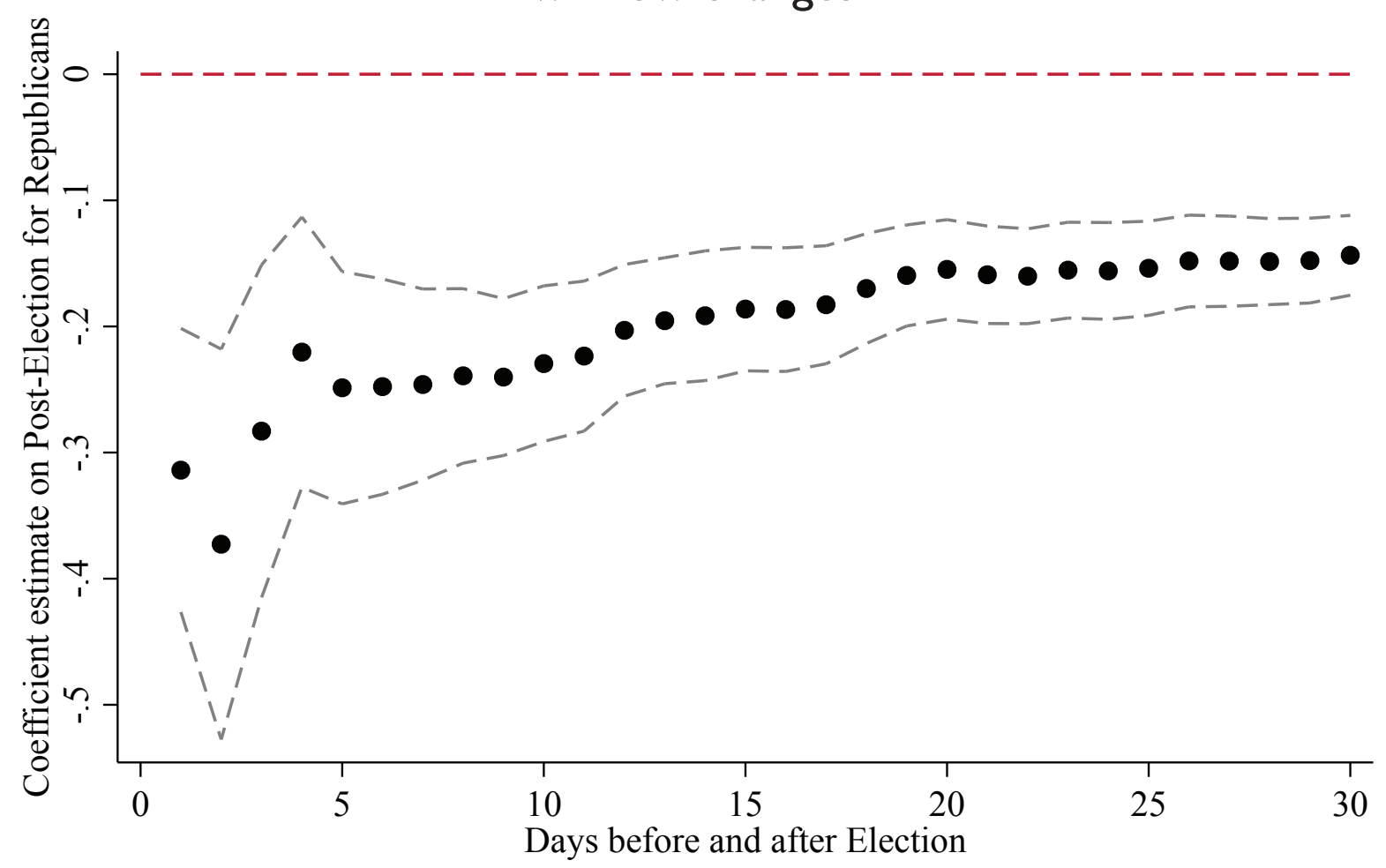


Supplemental Figure S4C:Table (2) column (4) regression where time window changes

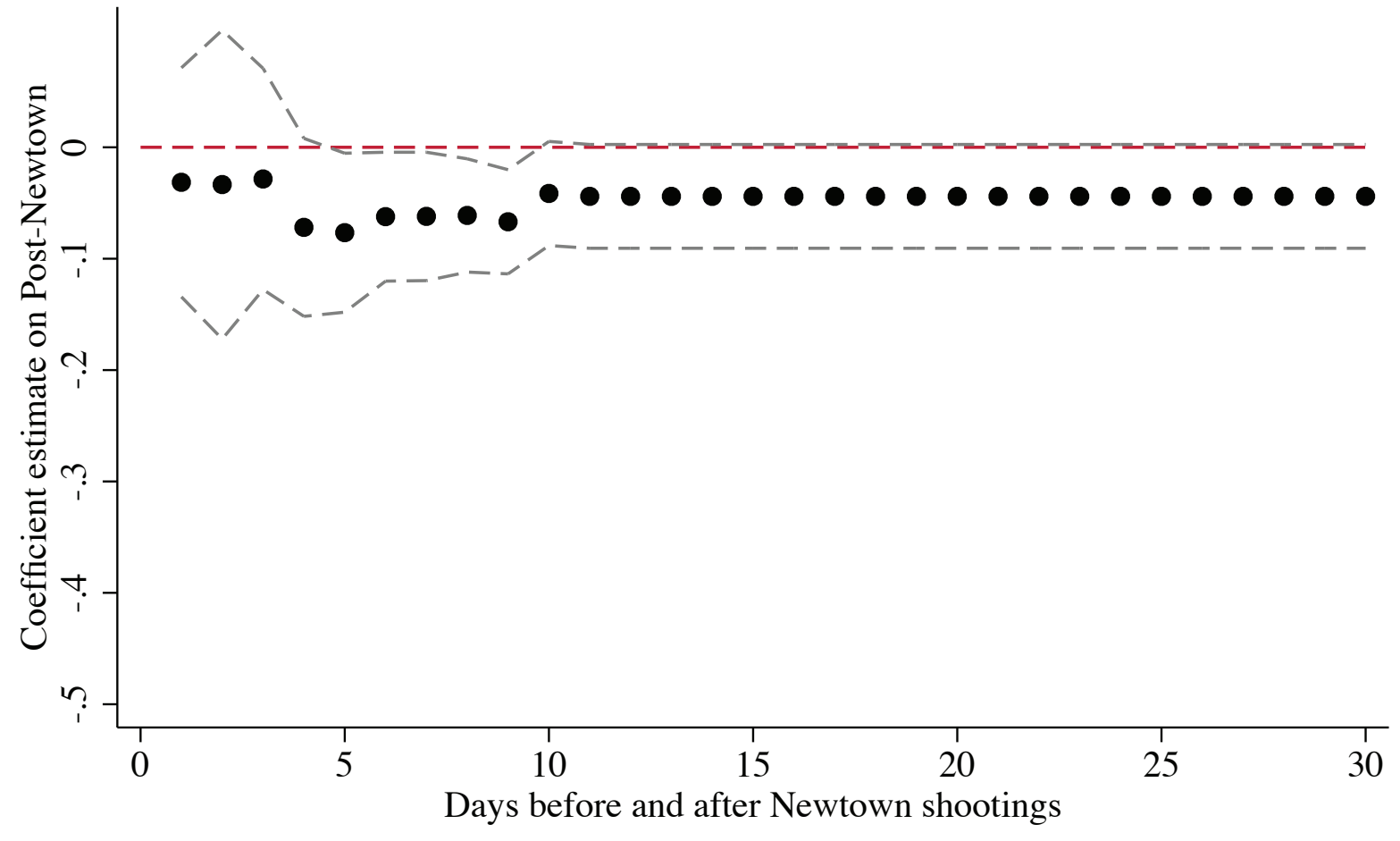

Supplemental Figure S4D:Table (3) column (4) regression where time window changes

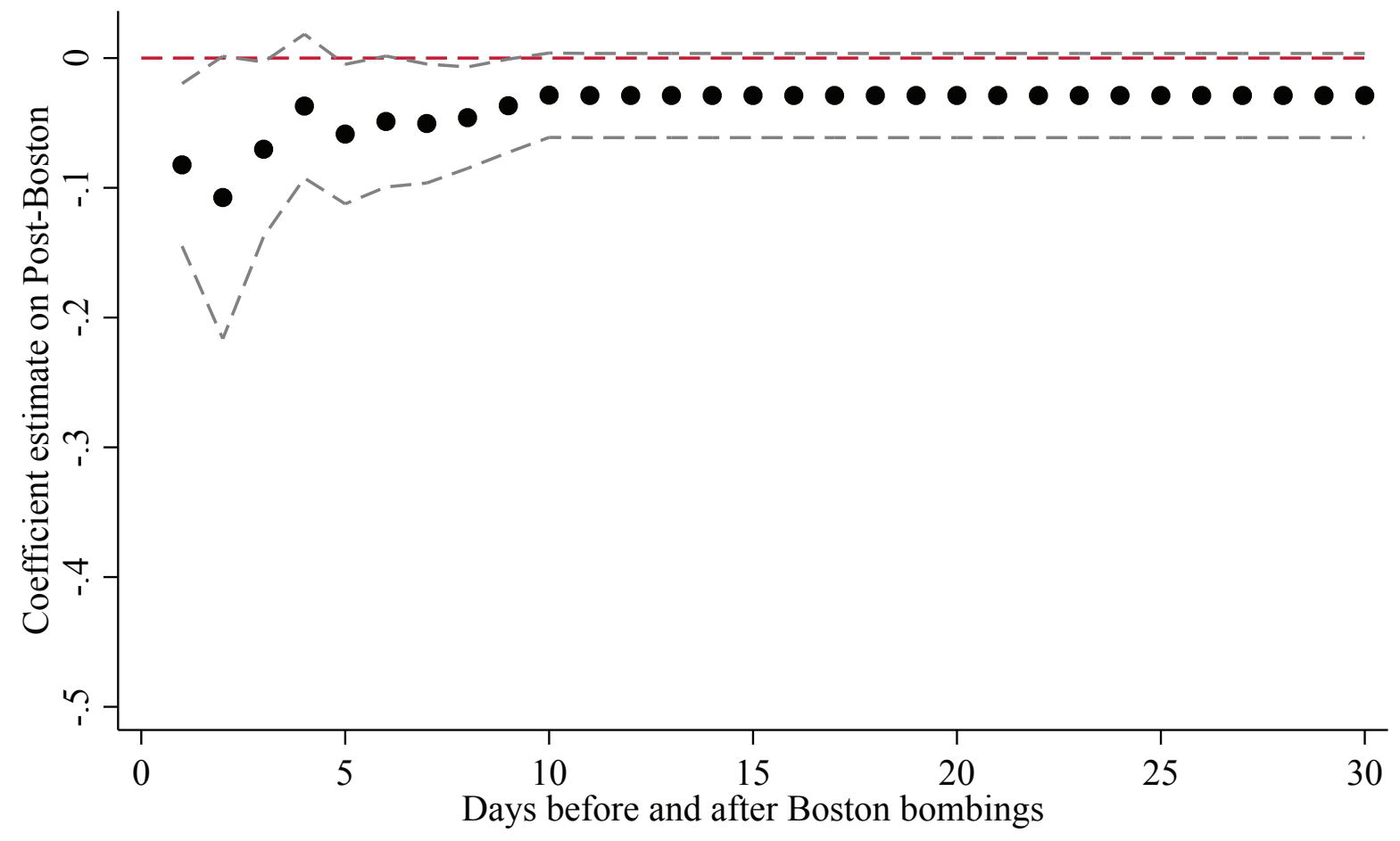




\section{Supplemental Figure S5A: Democrat self-reported emotional state two}

months before and after the election:"Are you happy today?"

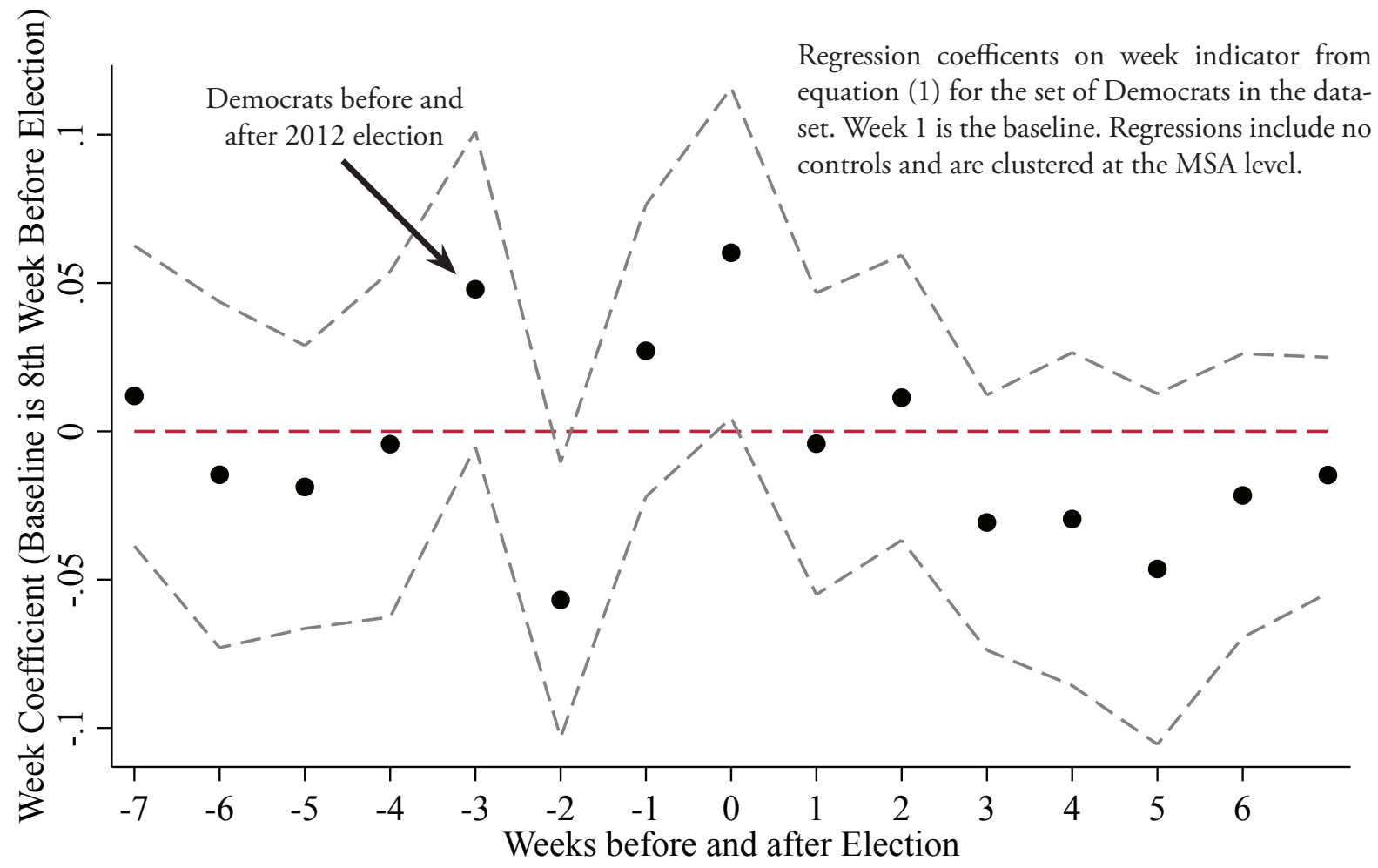

\section{Supplemental Figure S5B: Republican self-reported emotional state two} months before and after the election:"Are you happy today?"

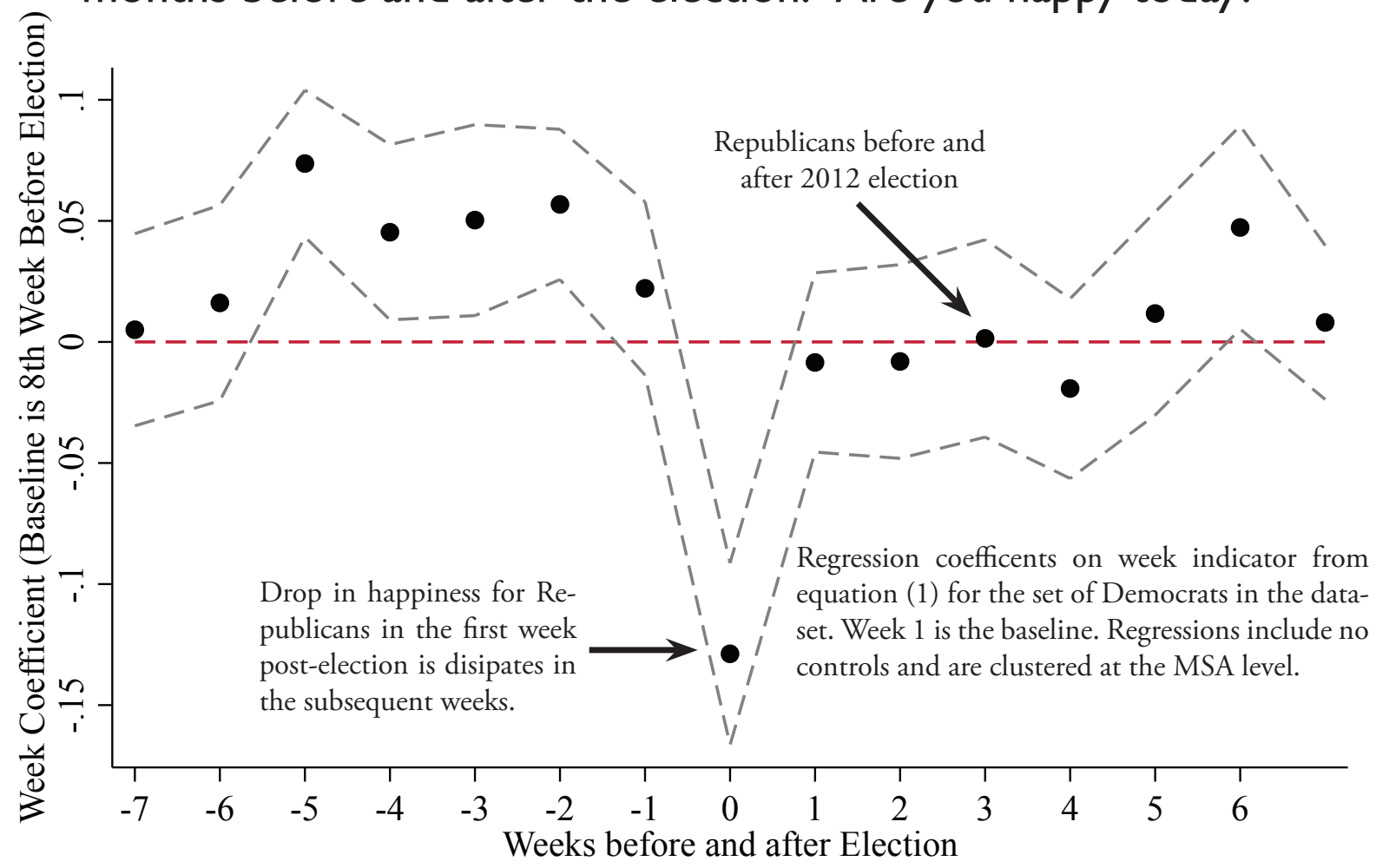


Supplemental Figure S6A: Count of responses before and after the Election

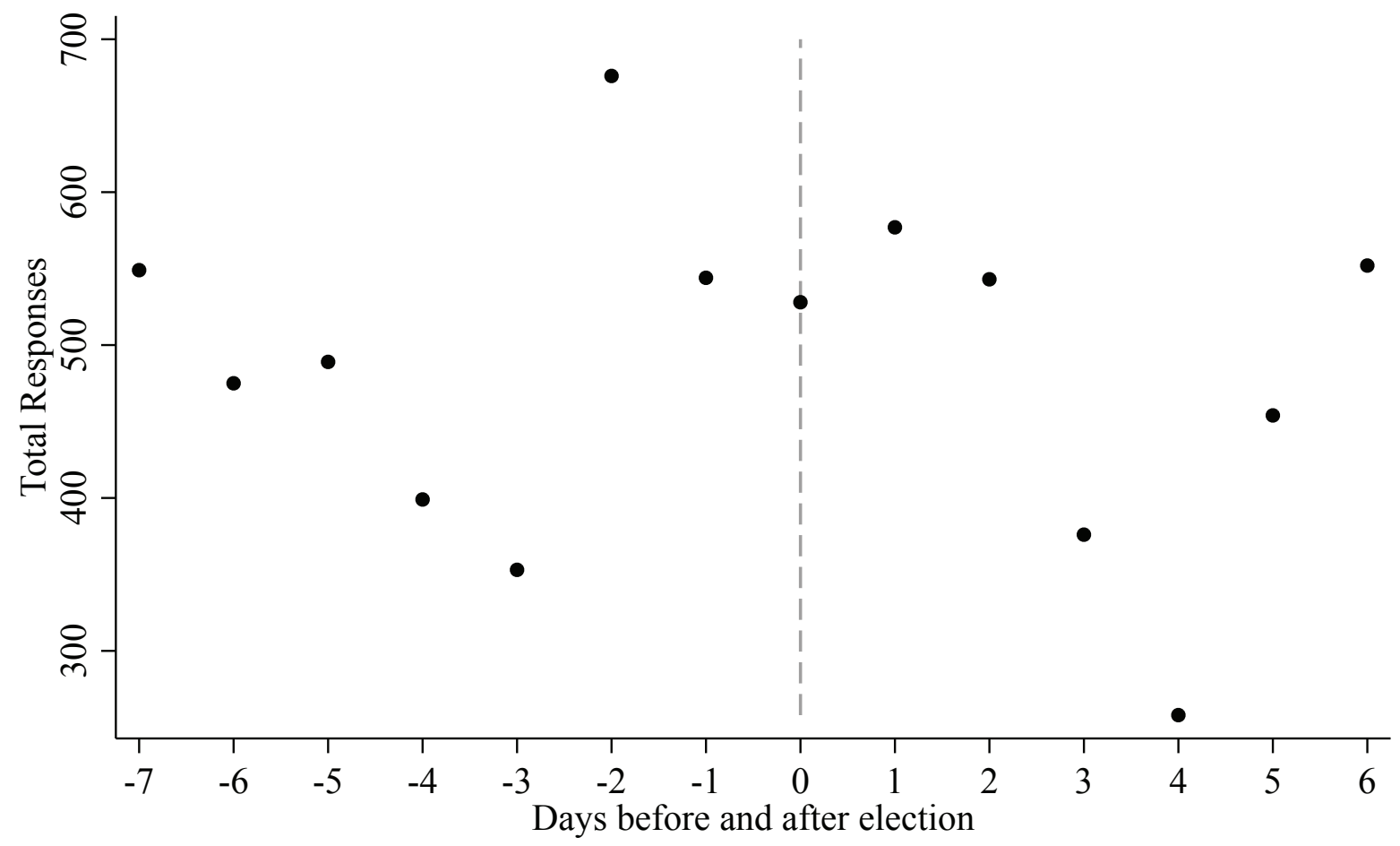

Supplemental Figure S6B: Count of the responses before and after New-

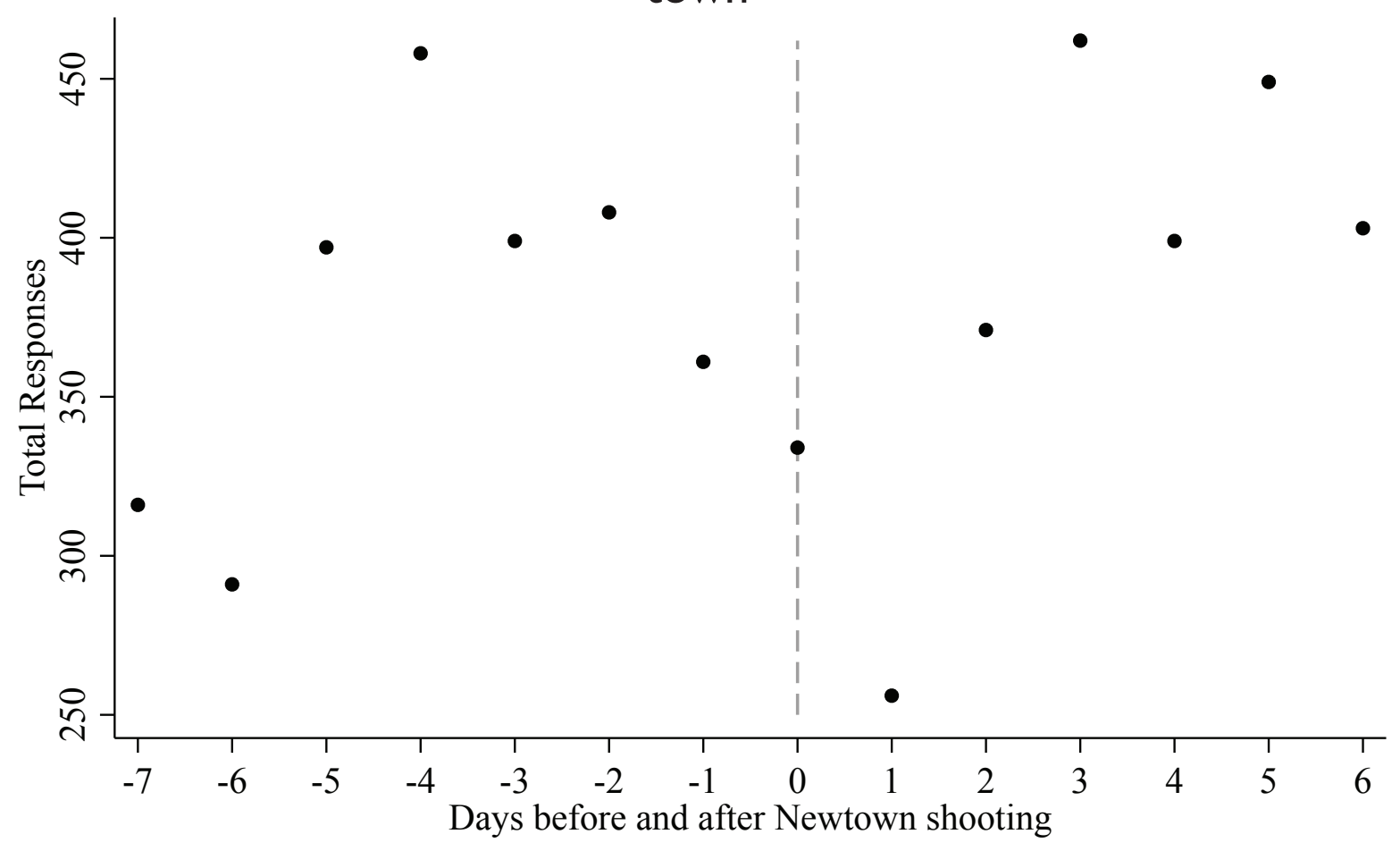


Supplemental Figure S6C: Count of responses before and after the Bos-

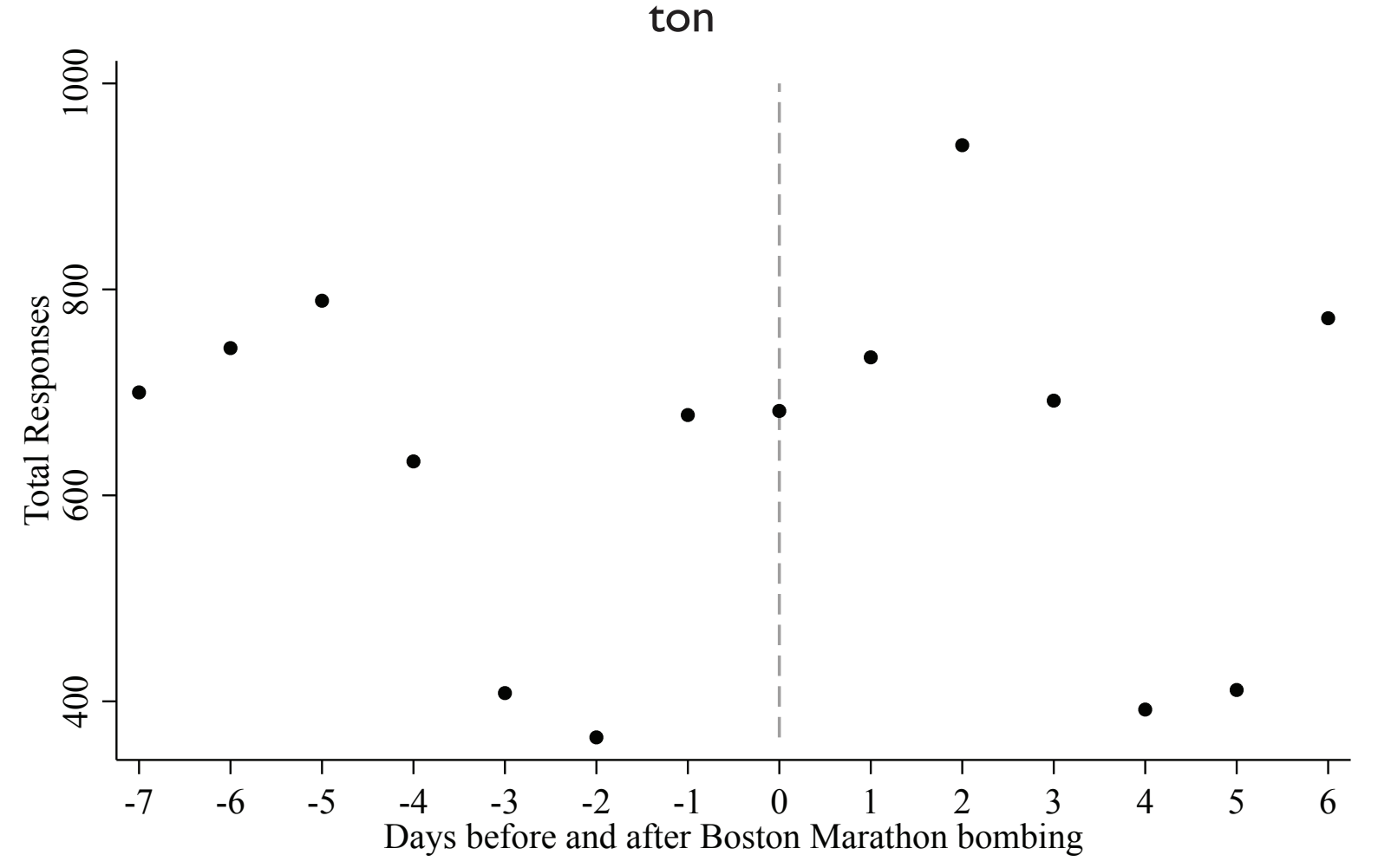




\section{Supplemental Figure S8A: Republican happiness two months before and after the election:Weekly interrupted time series}

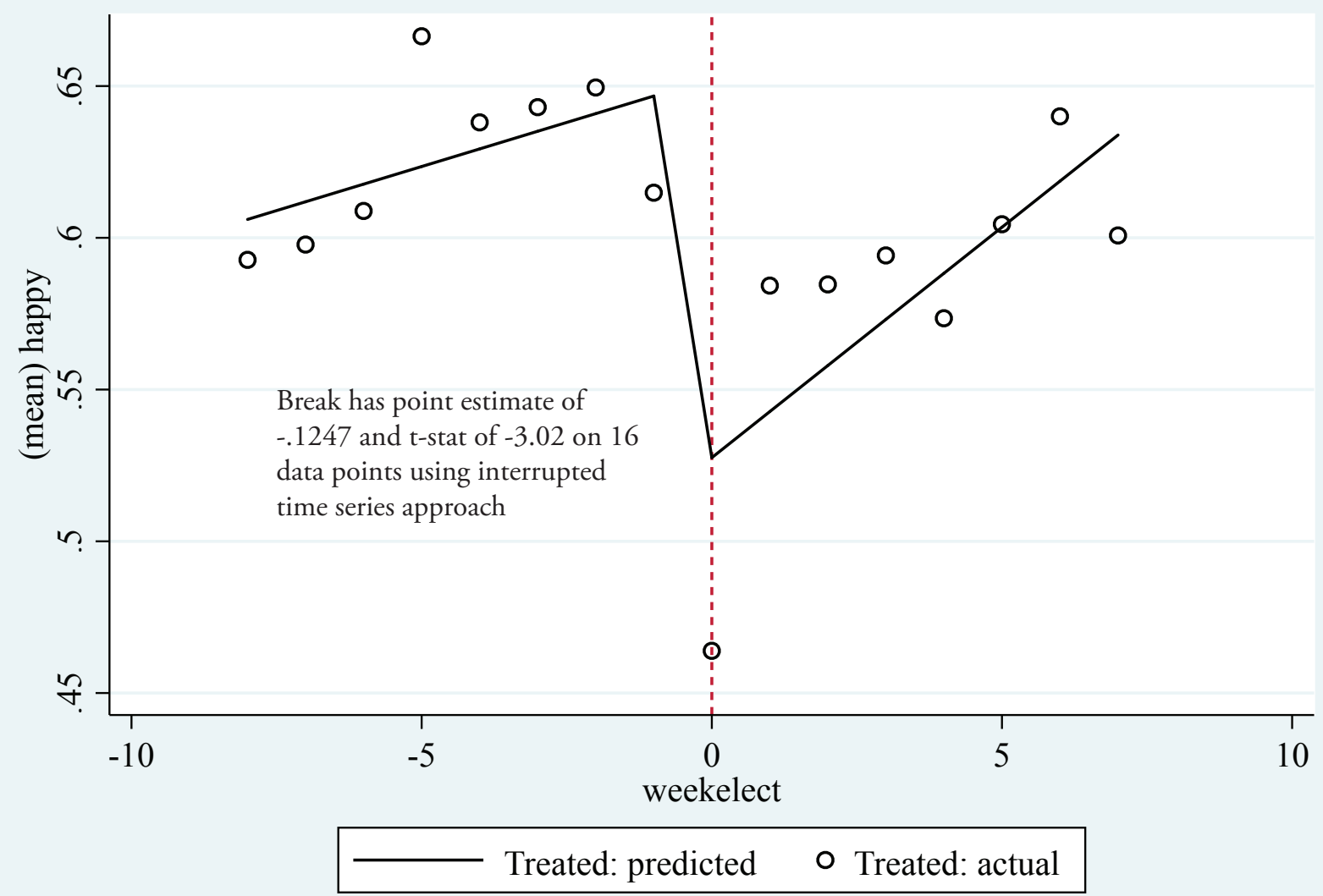

Regression with Newey-West standard errors 
Supplemental Figure S8B: Republican happiness two months before and after the election: Daily interrupted time series

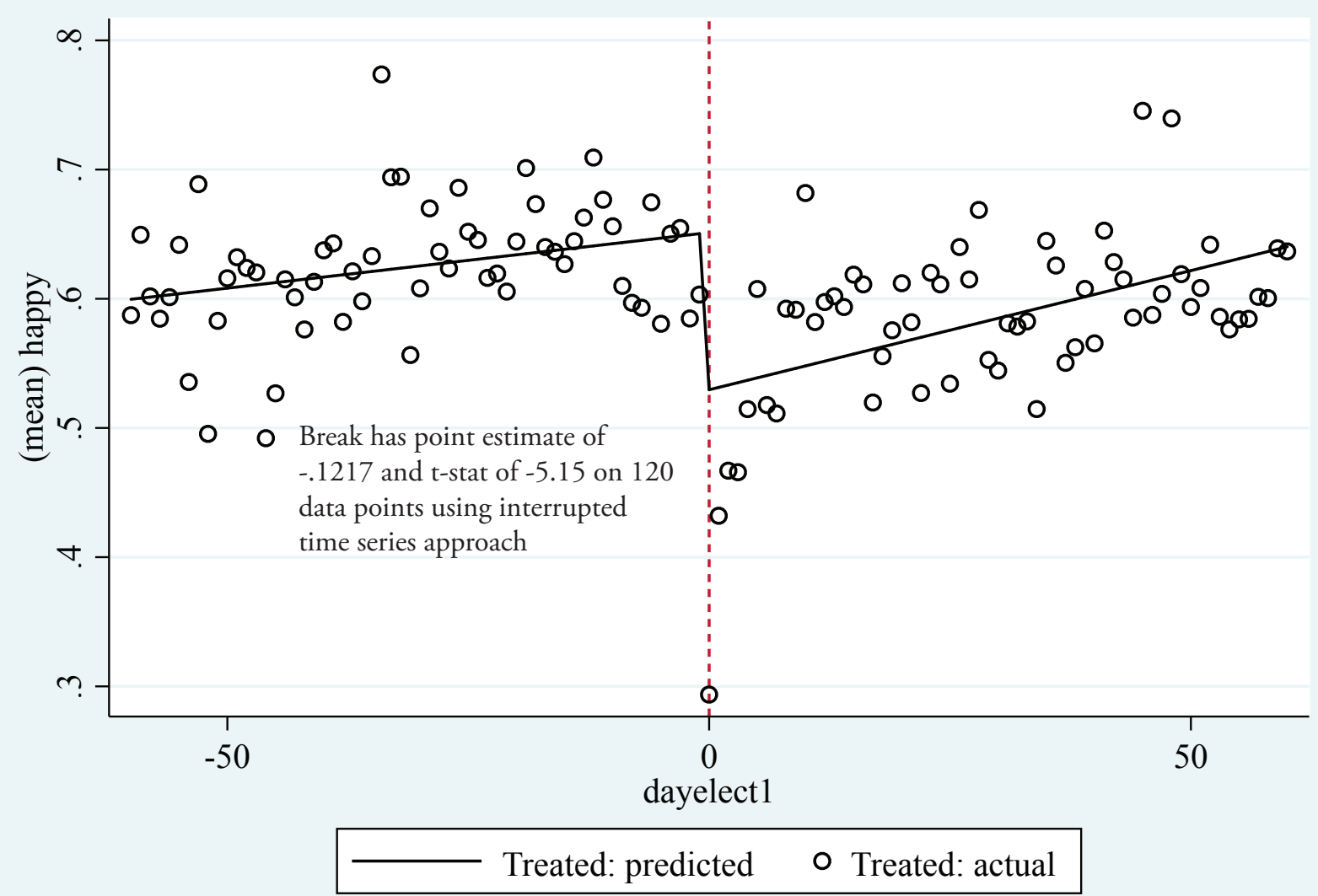

Regression with Newey-West standard errors 